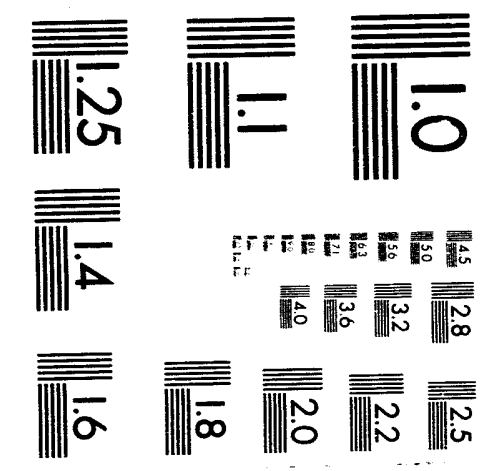



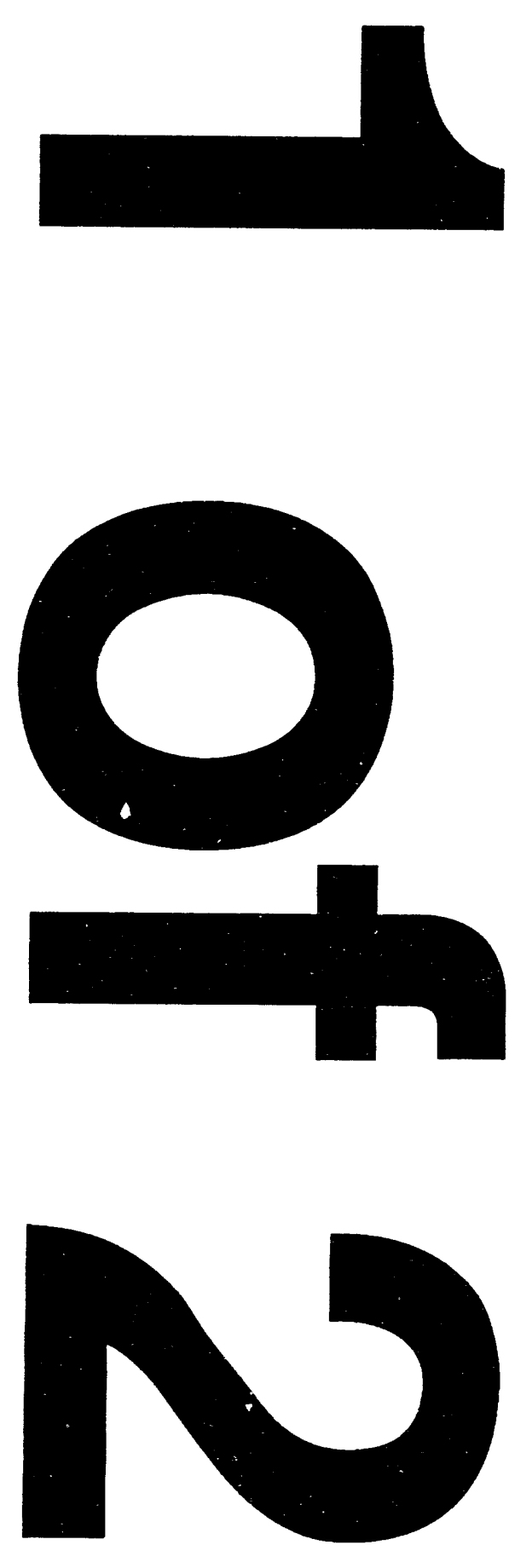


\title{
Optimization of Separation and Detection Schemes for Dna with Pulsed Field slab Gel and Capillary Electrophoresis
}

\author{
by David MoGregor
}

\author{
thesis submitted to Iowa State University \\ Ames Laboratory, U. S. DOE
}

Iowa State University

Ames, Iowa 50011

Date Transmitted: July 1993

Prepared for the U. S. Department of Energy

Under contract no. W-7405-eng-82.

The Government reserves for itself and others acting on its behalf a royalty free, nonexclusive, irrevocable, world-wide license for goverrmental purposes to publish, distribute, translate, duplicate, exhibit, and perform any such data copyrighted by the contractor.

\section{DISCLAIMER}

\begin{abstract}
This report was prepared as an account of work sponsored by an agency of the United States Government. Neither the United States Government nor any agency thereof, nor any of their employees, makes any warranty, express or implied, or assumes any legal liability or responsibility for the accuracy, completeness, or usefulness of any information, apparatus, product, or process disclosed, or represents that its use would not infringe privately owned rights. Reference herein to any specific commercial product, process, or service by trade name, trademark, manufacturer, or otherwise does not necessarily constitute or imply its endorsement, recommendation, or favoring by the United States Government or any agency thereof. The views and opinions of authors expressed herein do not necessarily state or reflect those of the United States Government or any agency thereof.
\end{abstract}


Optimization of separation and detection schemes for DNA with pulsed field slab gel and capillary electrophoresis

\title{
David Arthur McGregor
}

\author{
Under the supervision of Dr. Edward S. Yeung \\ From the Department of Chemistry \\ Iowa State University
}

The purpose of the Human Genome Project is outlined followed by a discussion of electrophoresis in both slab gels and capillaries and its application to deoxyribonucleic acid (DNA). Techniques used to modify electroosmotic flow in capillaries are also addressed. Several separation and detection schemes for DNA via gel and capillary electrophoresis are described. Emphasis is placed on the elucidation of DNA fragment size in real time as well as shortening separation times to approximate real time monitoring.

First, the migration of DNA fragment bands through a slab gel can be monitored by UV absorption at $254 \mathrm{~nm}$ and imaged by a charge coupled device (CCD) camera. Background correction and immediate viewing of band positions to interactively change the field program in pulsed-field gel electrophoresis are possible throughout the separation via this detection scheme. The use of absorption removes the need for staining or radioisotope labeling thereby simplifying sample preparation and reducing fazardous waste generation. This 
leaves the DNA in its native state and further analysis can be performed without de-staining. The optimization of several parameters considerably reduces total analysis time. DNA from $2 \mathrm{~kb}$ to $850 \mathrm{~kb}$ can be separated in 3 hours on a $7 \mathrm{~cm}$ gel with interactive control of the pulse time, which is 10 times faster than the use of a constant field program.

Finally, the separation of $\Phi$ X174RF DNA-HaeIII fragments is studied in a $0.5 \%$ methyl cellulose polymer solution as a function of temperature and applied voltage. The migration times decrease with both increasing temperature and increasing field strength, as expected. However, the relative migration rates of the fragments (selectivities) do not change with temperature but are affected by the applied field. A clear transition from the Ogston separation mechanism to the reptation separation mechanism is observed. Conditions were established for the separation of the $271 / 281$ bp fragments, even without the addition of intercalating agents. At $700 \mathrm{~V} / \mathrm{cm}$ and $20^{\circ} \mathrm{C}$, all fragments are separated in less than 4 minutes with an average plate number of 2.5 million per meter. 
Optimization of separation and detection schemes for DNA with pulsed field slab gel and capillary electrophoresis

by

David Arthur McGregor

A Dissertation Submitted to the

Graduate Faculty in Partial Fulfillment of the

Requirements for the Degree of

DOCTOR OF PHILOSOPHY

Department: Chemistry

Major: Analytical Chemistry

Approved:

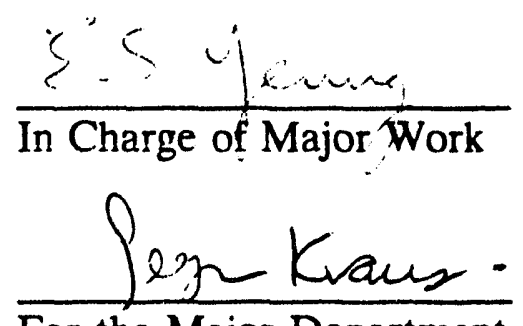

For the Major Department

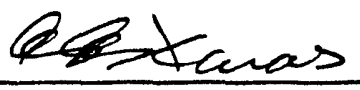

For the Graduate College

Iowa State University

Ames, Iowa 


\section{TABLE OF CONTENTS}

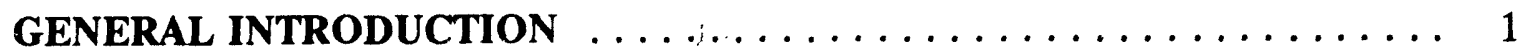

Dissertation Organization $\ldots \ldots \ldots \ldots \ldots \ldots \ldots \ldots \ldots \ldots$

Human Genome Project $\ldots \ldots \ldots \ldots \ldots \ldots \ldots \ldots \ldots \ldots$

Deoxyribonucleic Acid (DNA) $\ldots \ldots \ldots \ldots \ldots \ldots \ldots \ldots \ldots \ldots \ldots$

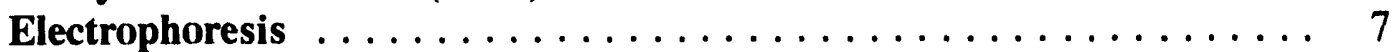

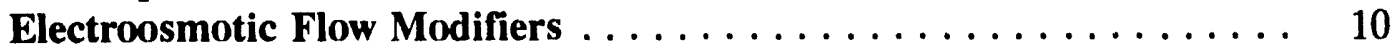

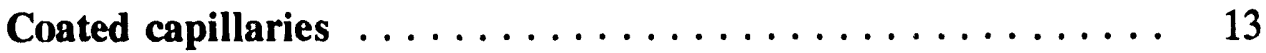

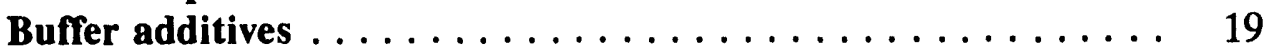

Gels and non-gel polymers $\ldots \ldots \ldots \ldots \ldots \ldots \ldots \ldots \ldots \ldots \ldots$

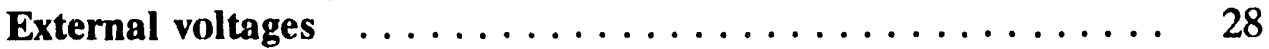

PAPER I. INTERACTIVE CONTROL OF PULSED FIELD GEL ELECTROPHORESIS VIA REAL TIME MONITORING ................. 30

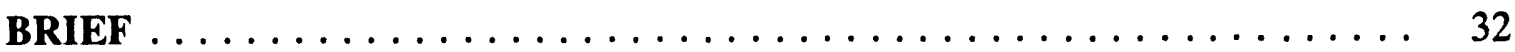

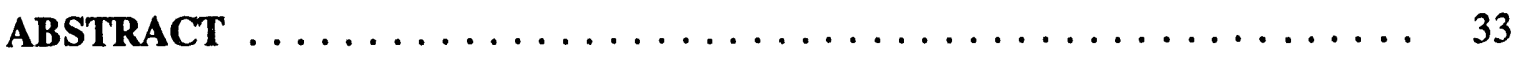

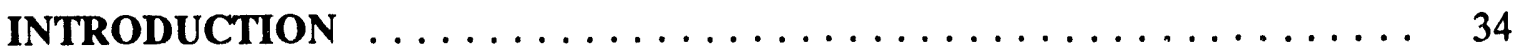

EXPERIMENTAL SECTION $\ldots \ldots \ldots \ldots \ldots \ldots \ldots \ldots \ldots \ldots \ldots \ldots$

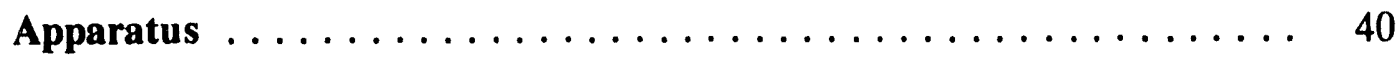

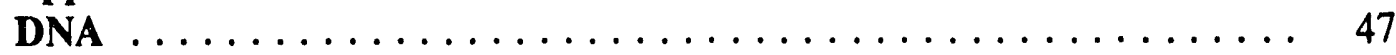

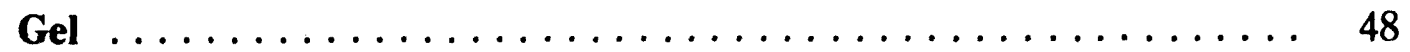

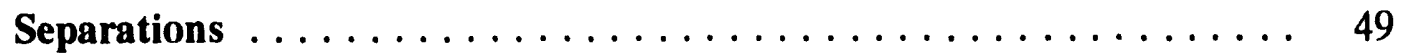

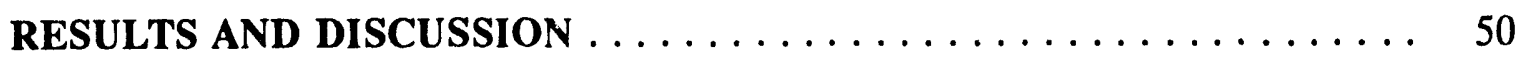

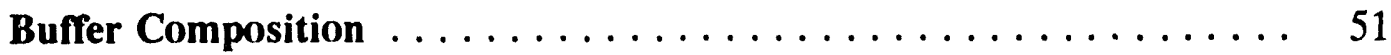

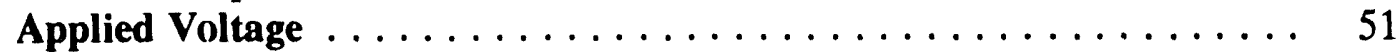

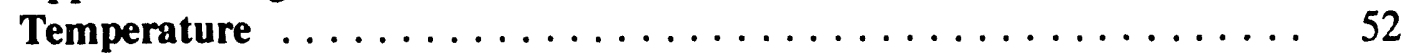

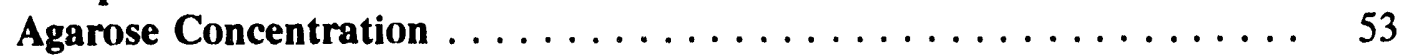

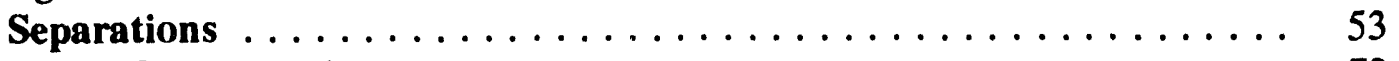

Other Considerations . . . . . . . . . . . . . . . . 72

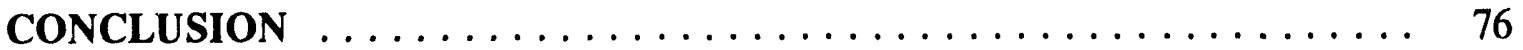




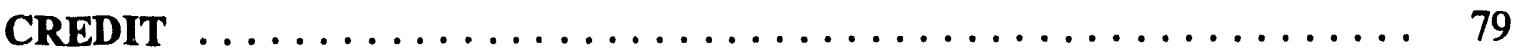

LITERATURE CITED $\ldots \ldots \ldots \ldots \ldots \ldots \ldots \ldots \ldots \ldots \ldots \ldots \ldots \ldots \ldots$

PAPER II. OPTIMIZATION OF CAPILLARY

ELECTROPHORETIC SEPARATION OF DNA

FRAGMENTS BASED ON POLYMER FILLED

CAPILLARIES

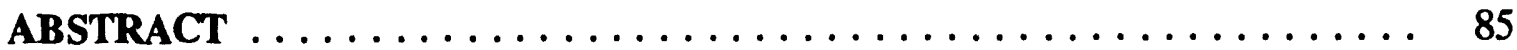

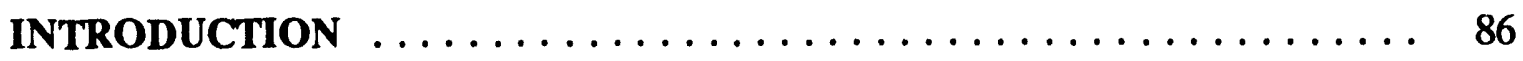

EXPERIMENTAL SECTION $\ldots \ldots \ldots \ldots \ldots \ldots \ldots \ldots \ldots \ldots$

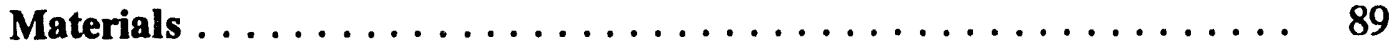

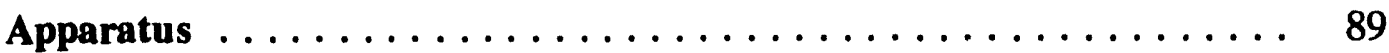

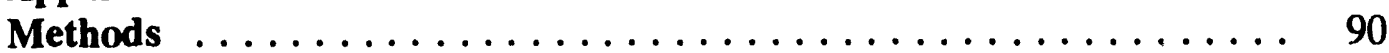

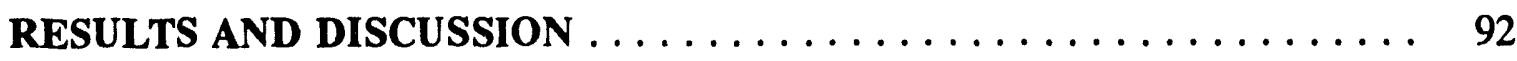

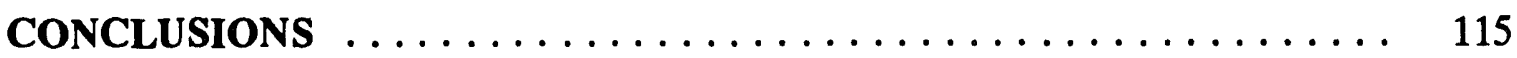

ACKNOWLEDGEMENT $\ldots \ldots \ldots \ldots \ldots \ldots \ldots \ldots \ldots \ldots \ldots \ldots$

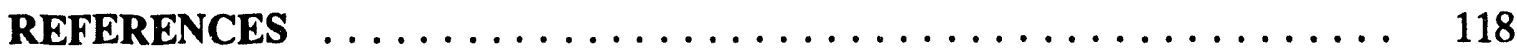

GENERAL SUMMARY $\ldots \ldots \ldots \ldots \ldots \ldots \ldots \ldots \ldots \ldots \ldots \ldots$

LITERATURE CITED . . . . . . . . . . . . . . . . . . . 123

ACKNOWLEDGEMENTS $\ldots \ldots \ldots \ldots \ldots \ldots \ldots \ldots \ldots \ldots \ldots \ldots$

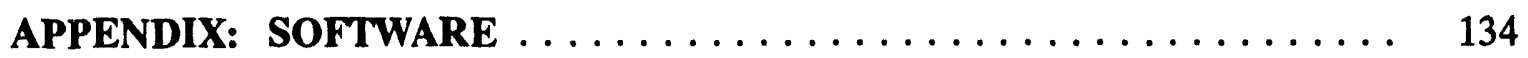




\section{GENERAL INTRODUCTION}

\section{Dissertation Organization}

This general introduction and literature review precede two research papers which have been published in major chemistry journals. These research papers are followed by a general conclusion and the references for the literature review. References for each of the research papers follow the manuscript in which they are cited.

\section{Human Genome Project}

The U.S. Human Genome Project (HGP) is a national coordinated 15-year effort to identify all the human genetic material by improving existing human genetic maps of entire chromosomes and to ultimately determine the entire sequence of deoxyribonucleic acid (DNA) arrangement in the human genome (1). The genome consists of 24 distinct chromosomes which contain more than 100,000 human genes in which there are around 3 billion base pairs. Current technology, as of 1993, has made great strides in achieving this impressive goal. If the genome is to be known absolutely in 15 years, immense strides must continue in deciphering the genome. Existing technology used to analyze the genome must constantly be reevaluated to improve speed and accuracy. This is what the research involved in this dissertation hopes to demonstrate. The Human Genome 
Project is a truly vast undertaking which is occurring around the globe. Space limitations prevent a detailed description of the undergoing task but a small overview with references will be attempted.

In 1984, the Office of Health and Environmental Research (OHER) produced a report for Congress in which the value of a reference sequence of the human genome was recognized. In 1988, a study by the National Research Council (NRC) entitled Mapping and Sequencing the Human Genome proved a boon to the initial national effort to start the HGP (2). Finally, in 1989, the National Institutes for Health (NIH) joined the effort and an office was created to be the center of the U.S. Human Genome Project.

Why is there a need to decipher the human genome? This undertaking is expected to immensely benefit medical science. It should help in understanding and eventually treating the more than 4000 genetic disorders that afflict humankind as well as a vast number of the multifactorial diseases (cancer) in which genetic predisposition plays a role. Of course, the technology that comes from this effort will also benefit other research, such as agricultural and environmental sciences. It would prove of value for areas such as the effects of radiation and other environmental hazards on human genetic material.

The five-year goals of the U.S. HGP outline are stated below (3).

1) Mapping and Sequencing the Human Genome

a) Genetic Mapping: Complete a genetic map with markers 
spaced around 2 to 5 centimorgans apart ( 1 million $b p)$. Identify each marker by sequence tagged sites (STS).

b) Physical Mapping: Assemble STS maps of all chromosomes with the goal of having markers spaced at $\sim 100,000 \mathrm{bp}$ intervals. Generate overlapping sets of cloned DNA of closely spaced unambiguously ordered markers. c) DNA Sequencing: Improve current and develop new methods for sequencing that will allow large scale capacity at cost of $\$ 0.50$ per base pair.

2) Model Organisms: Prepare a mouse genome map based on similar techniques. Sequence an aggregate of 20 megabase pairs $(\mathrm{Mbp})$ of DNA from a variety of model organisms focusing on stretches that are $1 \mathrm{Mbp}$ long and develop and validate new and improved sequencing technology.

3) Informatics - Data Collection Analysis: Develop effective new software and database designs to support the large-scale mapping and sequencing projects. Develop algorithms and analytical tools that can be used to interpret the genomic information.

4) Ethical, Legal And Social Issues: Develop programs aimed at understanding the implications of the HGP. Identify and define the major issues and develop initial policy options to address them. 
5) Research Training: Support research training of pre and postdoctoral fellows. Examine the need for other types of research training.

6) Technology Development: Support automated instrumentation and innovative and high-risk technological developments, as well as improvements in current technology.

7) Technology Transfer: Enhance closer working relations with industry. Facilitate the transfer of technologies and information to the medical community.

As one will ascertain, the work in this dissertation best fits into the continuing effort to develop new technologies and upgrade existing technology, but it is just a small part of the ongoing effort to decipher the code of the human genome. For further reading, there are a variety of reviews on the worldwide effort to decipher the human genome (4-6).

\section{Deoxyribonucleic Acid (DNA)}

The human body has about 10 trillion cells. Each type of cell has a certain function to perform. Proteins determine the function and structure of each cell. Proteins are derived from a code that is stored in the nucleus of each cell. These codes are contained in chromosomes in the nucleus. The cell uses that information to manufacture the individual proteins. A chromosome is a long chain of DNA 
that is tightly folded and packed with proteins. Most human cells have a full set of 46 chromosomes which contain about 100,000 genes. Each gene contains anywhere from 2000 to 2 million nucleotide pairs and have enough information to be a blueprint for a specific protein which the cell can then produce. Finally, the four different types of nucleotides, adenine (A), cytosine $(C)$, guanine $(G)$ and thymine (T), are the basic building blocks and are specifically paired to one another. $\mathrm{C}$ is always paired with $G$ and $A$ with $T$.

Humans have 22 pairs of autosomes (each parent contributes one member to every pair) and two sex chromosomes (the $\mathrm{X}$ and $\mathrm{Y}$ chromosomes in the male and two $\mathrm{X}$ chromosomes in the female). The diploid human genome is composed of 46 DNA molecules of 24 distinct types. Because the human genome exists in pairs and are almost identical, only 3 billion nucleotide pairs (the haploid genome) need to be sequenced. Thus, it is often sce id that the human genome contains 3 billion base pairs when most cells in the human contain 6 billion base pairs. The average size of a protein allows the inference that about 100 million nucleotide pairs need to be present in the human genome. That is only about 3 percent of the total and leads to the conclusion that much of the DNA is not used as the template for protein production (non-coding DNA). Most of the non-coding DNA plays a role in organizing the DNA into chromosomes, and other parts are possibly for regulating gene activity. The function of much of the non-coding DNA remains a mystery. 
In 1953, Watson and Crick discovered the precise structure for DNA which has helped scientists unravel the function of this molecule. DNA has three parts, a phosphate backbone by which the structure is held together, connected to a deoxyribose sugar unit, which is connected to a nitrogen containing base. Three bases together form a code for a specific amino acid. When these bases are grouped in three, such as AAT or GCA, these codes (or codons) are specific for the adding of a particular amino acid to a chain of amino acids. There are 20 chemically different amino acids in human proteins, and when attached end to end and folded they make up the complex proteins that reside within the human body. One change in the code from the DNA can change not only the structure of a particular protein but also its function.

If all the DNA in a human cell were placed together end to end it would result in a molecule that is roughly 6 feet long. The elucidation of the DNA structure has taken many shapes over the years. Many techniques are currently being used to distinguish the pattern of DNA. Scanning tunneling microscopy which can decipher between the purines ( $C$ and $T$ ) and pyrimidines $(A$ and $G)$ is used. Flow cytometry or flow karyotyping is used for the sorting and collection of chromosomes. Light microscopy with staining is employed for low resolution physical maps. Higher resolution maps can be obtained by electrophoresis for the separation of DNA that has been digested or specifically cut at certain sites along the chain with restriction enzymes. The highest resolution physical map obtainable 
is of a single base pair which is accomplished by sequencing. The next section will deal with the separation of DNA fragments by electrophoresis.

\section{Electrophoresis}

The first practical demonstration of electrophoresis was shown by Tiselius in 1937 (7). Consden et al. demonstrated zone electrophoresis with the use of silica gel as an anti-convective medium (8). The introduction of polyacrylamide, in the late 1950's, revolutionized the electrophoresis of biopolymers (9). With polyacrylamide, analytes could be separated based on a mechanism of sieving instead of strictly based on charge to mass ratio.

Polyacrylamide and agarose have been a consistent medium for separation of biopolymers, but they do have distinct disadvantages. First, the gel structure is capable of separation by size only up to a point. Beyond a certain size or weight range, all biomolecules will travel at the same speed or mobility, usually visualized as compression zones in typical separations. Another mechanism must be employed to separate the larger molecules. In the case of DNA separations, agarose gels are only capable of separations up to $\sim 30-50 \mathrm{~kb}$ and polyacrylamide gels separate even smaller fragments. The sieving mechanism fails beyond this point and another approach must be employed.

In 1985, a new technique was demonstrated by Schwartz and Cantor in which the electric field was alternated at some predetermined angle to force the 
DNA to switch course through the medium (10). The separation mechanism known as reptation would now allow separations into the millions of base pairs. Reptation, succinctly put, is the snakelike movement of the DNA through the gel. When the electric field is changed, there is some distinct time that corresponds to each DNA fragment and its ability to realign with the electric field. When the fragment has realigned, it can then travel in the direction of the electric field. If the pulse is too short, the larger fragments will not align in the field before it changes, and no effective separation will occur.

Pulsed field gel electrophoresis (PFGE) in 1993 has a variety of designs depending on speed and resolution desired (11). Because of the similar underlying design in all slab electrophoresis systems (conventional slab and PFGE), there is a common problem. These systems are usually immersed in a large buffer reservoir, and joule heating is common to all of these separations. This limits these techniques to lower resolution and longer separation times.

In 1981, Jorgenson and Lukacs demonstrated exceptional results with the use of capillary electrophoresis (CE) (12). Capillaries are employed because of the excellent heat dissipation which allows for much higher applied voltages, typically 30,000 volts applied across 30 to $70 \mathrm{~cm}$. The fact that the separation is electrically driven instead of pressure driven eliminates the parabolic flow profile and allows very sharps analyte zones (Figure 1).

Unfortunately, proteins and DNA are not well separated in free solution CE 
Figure 1. Above is a schematic diagram of electroosmotic flow in a capillary. The capillary walls are charged negatively because of the presence of silanol groups. A layer of cations are closely associated with the negative wall. These cations are mobile and hydrated, when an electric field is applied, the cations at the walls will tend toward the negative electrode (left to right) drawing with it the bulk fluids in the capillary. Below is a cross-section of the flow profile in CE and HPLC for comparative purposes. 
10
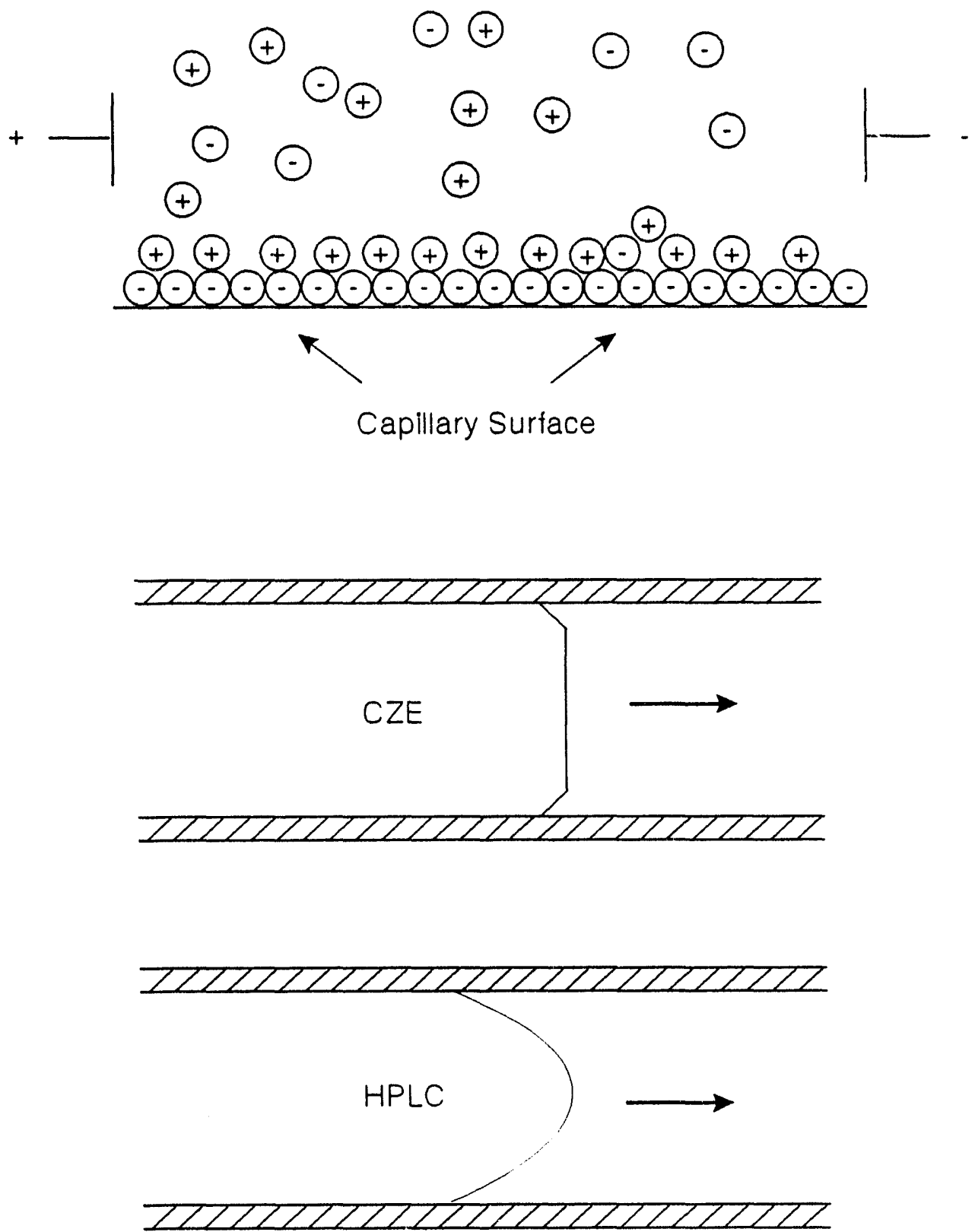

Flow Profile 
due to the similar size to charge ratios of these large biopolymers and interactions between the biomolecules and the capillary wall. Gel-filled columns were shown to be feasible in 1985 when Hjertan demonstrated isoelectric focusing (13). Since then significant progress has been made in the use of gel-filled capillaries for the size based separation of proteins and DNA (14). At this point, a closer look must be taken at the coatings, modifiers, gels, non-gels, and other additives used to achieve size-based separations currently done in CE.

\section{Electroosmotic Flow Modifiers}

CE has proven to be an efficient means to separate anions, cations, neutrals, chiral compounds, and large biopolymers. Electroosmotic flow has proven useful in the separation of both cations and anions in the same separation. The existence of electroosmotic flow presents problems when large biological molecules are separated.

The presence of osmotic flow stems from the fact that there are fixed negatively charged silanol groups on the capillary walls. When a solution is introduced, a double layer is formed at the capillary wall. Positive ions tend to gather at the wall surface to counter the negative charge. These mobile cations are hydrated and tend to move with the bulk flow toward the negative electrode when a potential is applied. Thus, the permanent charge on the wall induces osmotic flow. Negatively charged silanol groups are present at pHs above 2 and 
become more significant as $\mathrm{pH}$ increases.

Separations involving large biomolecules have exhibited respectable behavior in CE. Unfortunately, the walls of a bare fused silica capillary are highly negatively charged which can cause adsorption of the positively charged regions of the protein or other biomolecule. This phenomenon manifests itself by broad and/or tailing peaks with poor efficiencies and poor reproducibility when the biomolecule of interest elutes. Thus, efforts have been made to reduce, control or

eliminate this phenomenon. Reviews on CE separations of biomolecules are fairly numerous (15-18).

One method used to overcome the adsorption of biomolecules in $\mathrm{CE}$ is to perform the separations at $\mathrm{pH}$ extremes. At low $\mathrm{pH}$ (less than 3), ionization of silanol groups is minimal. This leads to decreased attraction of the analyte to the walls of the capillary (19). When a high $\mathrm{pH}$ is used (greater than 11 or above the pI of the proteins being analyzed), all analytes will be negatively charged, and repulsive forces will dominate the wall/analyte interactions $(20,21)$. Model protein separations involving systems in which $\mathrm{pH}>\mathrm{pI}$ or $\mathrm{pH}<\mathrm{pl}$ have been used in capillary electrophoresis-mass spectrometry (CE-MS) as well (22). These investigations have shown better separation than over mid-range $\mathrm{pHs}$, but biopolymers are not well behaved at these extreme pHs. Proteins and DNA tend to degrade or denature at extreme $\mathrm{pHs}$ and problems then exist when trying to analyze the ensuing electropherogram. 
Efforts to overcome this difficulty in performing $\mathrm{CE}$ are discussed below. Current research efforts can be categorized into two main areas, coating the silica capillary wall, and masking the capillary wall with buffer additives. Other novel modifiers and osmotic flow modifiers will be discussed.

\section{Coated capillaries}

The first method for overcoming the adsorption of analyte to the capillary walls is to cover the silica with a coating of known charge or zero charge. When the walls are covered with the coating, the silanol groups will not be accessible to the solution. Pioneering work in this area was done by using siloxane coupling chemistry which connected the silanol groups via siloxane bonds, Si-O-Si (23). The reacted silane reagent could then be further reacted to give some final external coating.

Coated capillaries have shown usefulness in many areas of the biological sciences. Gurley et al. showed that histones can be fractionated with a coated capillary in $100 \mathrm{mM}$ phosphate buffer $(\mathrm{pH} 2.5)$ (24). The elution order was different than normally observed in acid-urea polyacrylamide gels or in reversedphase high performance liquid chromatography (HPLC), but this gives an extra dimension to the analysis of histones.

One application has been approached by coating capillaries to reduce osmotic flow thereby allowing superior albeit longer separation of trace 
components in bulk materials. The use of a non-polar phase (usually a methyl or methyl-phenyl capped) coated to the walls is presented by Nielen for the separation of phenylenediamine isomeric impurities in samples (25).

Towns and Reigner have examined the adsorption of poly-cationic ions (analytes) on capillary walls (25). The investigation showed that recovery of the proteins varied inversely with the isoelectric point of the protein. Adsorption occurred primarily at the capillary inlet which then produced a nonuniform distribution of zeta potential in the capillary which tended to influence osmotic flow. The predominant effect of the fouling was turbulent mixing at the capillary inlet which reduced efficiency and reproducibility.

Gilges et al. devised an inert atmosphere apparatus for derivatizing capillary walls that removes oxygen and water from the derivatizing environment (27). The coating procedure was applied to the separation of basic proteins in low $\mathrm{pH}$ buffers. Comparisons with other coating procedures and additives to the buffer were also studied.

Tsuji and Little demonstrated the use of an amphipathic polymer coating to characterize recombinant, basic, and chimeric glycoproteins (28). This polymer has hydrophilic/hydrophobic characteristics that allow for attraction to the wall surface and shield the walls from the analyte. Modifications of buffer composition, ionic strength, and $\mathrm{pH}$ are examined.

Castagnola et al. examined tryptic digests in capillaries coated with a 
monolayer of acrylamide (29). Separation of 8 pmol tryptic digest was achieved in less than 30 minutes and was reproducible. The use of $\mathrm{CE}$ for separation of tryptic digests can offer another dimension in mapping these digestions of proteins.

Coating proccdures including the use of polyethers have been demonstrated. Bruin et al. have suggested three coated capillaries $(30,31)$. First, $\gamma$ glycidoxypropyltrimethoxysilane is reacted with the capillary wall then polyethylene glycol 600 is reacted to the siloxane reagent to obtain protein separations in the $\mathrm{pH}$ range 3-5 but adsorption still occurs. A rapid decrease in efficiency and polymer stability occurs as $\mathrm{pH}$ is increased. An epoxy diol coating was described where the epoxide was opened by addition of $\mathrm{HCl}$ to the capillary. This column showed similar behavior to that of the previous coating. Third, by using 3 aminopropyltriethoxysilane as the derivatizing agent reacted with maltose and sodium cyanoborohydride will yield a maltose coated capillary. This coating is stable to $\mathrm{pH} 7$, but is prone to microbial attack. The lack of stability at high $\mathrm{pH}$ is a common problem in many of these attempts to coat capillaries.

Surface-bound hydroxylated polyether functionalities have been developed by Nashabeh and Rassi for work with proteins. In one approach, the hydrophilic coatings consisted of two layers: a glycopropylpolysiloxane sublayer covalently attached to the wall and coated with a polyether top layer (32). In another approach, a single layer of polysiloxane polyether chain of which both ends were attached to the capillary wall was attempted. Both of these coatings produced 
differing electroosmotic flows. Both procedures produced acceptable separations of proteins at $\mathrm{pHs}$ from 4-7.5. Similar capillaries were used to separate fluorescent tagged oligosaccharides as well as tryptic digests in the presence of tertbutylammonium bromide $(33,34)$.

Furthermore, a procedure to restore capillaries that have degraded after prolonged use was presented. Smith and Rassi have used quaternary ammonium functions electrostatically bound to the silanol groups and a top layer of long polyether chains (35). Because the coating is not covalently attached to the surface, osmotic flow is still present and can be adjusted by varying the $\mathrm{pH}$. This in effect leads to the switching of the osmotic flow if desired. The long polyether chain effectively shields the analyte from the capillary wall, and as a consequence, good separation efficiencies are achieved. Separations of proteins, nucleotides, and acidic oligosaccharide separations have been demonstrated.

An aryl pentafluoro-modified capillary was described by Swedberg (36). The bulky aryl pentafluoro group protected the analyte from the silanols and gave predictable elution orders. The capillary still had significant osmotic flow which suggested that not all of the silanol groups were reacted. Lower than expected plate efficiencies indicated that some adsorption was still present.

Other silylated columns include an aminopropyl silylated column first proposed by Lukacs (37). Separation of bioactive peptides and subsequent analysis by fast atom bombardment-mass spectrometry (FAB-MS) utilize this silation to 
separate acidic proteins, but again a basic $\mathrm{pH}$ produces serious tailing for some proteins (38). Capillary electrophoresis lends itself nicely to mass spectrometric techniques because of the small quantities eluted and the low flow rates introduced into the vacuum chamber. Capillary electrophoresis-tandem mass spectrometry (CE/MS/MS) can elucidate structure of biomolecules. Other tandem techniques involving $\mathrm{CE}$ include inductively coupled plasma (ICP) ionization and MS detection. $\mathrm{CE}$ is ideal for plasma ionization in that it will not overload (quench) the flame and can be introduced by direct injection nebulization (39).

Coated capillaries have been used to separate recombinant DNA-derived proteins (40). This may prove useful in the analysis of charged variations in the rDNA products. Separation of charged variants of the protein rCD4 shows improvement over bare fused silica from $\mathrm{pH} 2.5$ to 5.5. Other novel uses of coated capillaries have been the separation of proteins in the lung fluid of rats that have been exposed to perfluoroisobutylene (41). A coated capillary was used to separate ribonucleoside and deoxyribonucleoside triphosphates in free solution (42).

A procedure for roughening the inner wall and attaching octadecyl functions was used to preconcentrate triazine herbicides prior to injection to CZE (43). This tandem capillary procedure increased solute concentration by least an order of magnitude. This preconcentration procedure is performed by first running the analyte through the first column (precolumn concentrator) with sodium phosphate 
then washing the analyte onto the next column with a small amount of acetonitrile in the running buffer.

A study was done by Wang and Hartwick on the effects of applied voltage, buffer conditions, and capillary surface modification (44). This work was performed by indirect absorbance and several correlations between noise and various contributing factors are discussed. Two independent noise sources were distinguished, the detector and the indirect buffer.

McCormick reported the use of polyvinylpyrrolidine (PVP)-coated capillary in conjunction with low pH buffers (19). 3-methacryloxypropyltrimethoxysilane is used as the coupling reagent followed by the addition of 1-vinyl-2-pyrrolidone, ammonium persulfate, and N,N,N',N'-tetramethylethylenediamine (TEMED). The reaction of 1-vinyl-2-pyrrolidone leads to a linear coating. Unfortunately, two proteins show up as split peaks which the author attributes to denaturation of the analyte. This is a perfect example of how extreme pHs can effect biomolecule separation.

Unfortunately, many of the above described procedures still use siloxane linkage chemistry which prohibits use of alkaline conditions where many proteins are well separated. More recently, two procedures have been suggested that will allow separations in a basic environment. Towns and Reigner developed and characterized a polyethyleneimine-coated capillary for protein separation (45). Polyethyleneimine is adsorbed to the wall and cross-linked with ethylene glycol and 
triethylamine. This maintains a constant positive charge over a $\mathrm{pH}$ range of 2-12. Recently, Cobb, Dolnik and Novotny describe a polyacrylamide-coating (46). This process is similar to Hjertan's, but instead of the Si-O-Si bond, a carbon silicon bond is used. This results in greater hydrolytic stability in $\mathrm{pH}$ extremes $(\mathrm{pH} 2$ 10.5). These techniques allow for separations at high or low $\mathrm{pH}$ where all proteins will travel in the same direction. Relative standard deviation of retention times is improved from $2 \%$ to $0.2 \%$ for the coated capillaries versus the uncoated.

Towns et al. use a diol-epoxy coating to deactivate capillary walls (47). This covalently bonded polymer eliminates most of the silanol charges on the wall, and the coating limits the interaction of biopolymers with the remaining wall charges. The polymer coating restricts adsorption of protein to the wall but still allows electroosmotic pumping to occur. These coated capillaries are reported to be stable for more than 120 hours of use and work in the $\mathrm{pH}$ range 5-10.

Coatings have been invaluable in the technique of capillary isoelectric focusing (CIEF). For the ampholytic buffer to remain stationary and develop a constant $\mathrm{pH}$ gradient across the capillary, no osmotic flow should be present. A study by Bolger et al. shows results from coated and uncoated capillaries that suggest a coating is necessary for separation of proteins at a basic $\mathrm{pH}(48)$.

\section{Buffer additives}

Buffer additives or dynamic coatings can simulate the effects of covalently 
bonding a coating to the wall surface. By including buffer additives, some of the modifier will preferentially attach to the wall by electrostatic attraction modifying the wall charge.

The first use of this dynamic coating was demonstrated by Jorgenson using high concentrations of zwitterionic salts (glycine to triglycine) for protein separations in CZE $(49,50)$. Using high concentration zw:tterionic salts has the advantage of not increasing the current used to separate the proteins. Unfortunately, basic proteins such as lysozyme would still tend to adsorb to the walls.

A study by Belder and Schomberg showed that the addition of low concentrations $(<0.05 \%)$ of polyvinyl alcohol (PVA) or hydroxyethyl ce!lulose (HEC) in conjunction with a chiral selector such as $\gamma$-cyclodextrin increased resolution and efficiency (51). Further studies with buffer concentration and applied voltage, both regular and radial, were performed. Work in Novotny's lab used soluble alkylhydroxyakylcellulose derivatives for separation of chiral compounds (52). Both studies showed the need for further additives above the cyclodextrins for increased resolution and efficiency. Polyvinyl alcohols (PVAs) have been used in several other laboratories with success $(27,51)$. With the addition of PVA to the buffer, the walls became coated with this polymer and were deactivated or at least covered the reactive negative charge of the capillary wall. The use of fluorinated cationic buffer additives helped to achieve the 
separation of proteins at neutral $\mathrm{pH}(53)$. The use of this additive did diminish the adsorption of analytes onto the walls of an otherwise untreated capillary. Other laboratories have utilized the fluorinated surfactant as a means to surface charge reversal (54). With this positive charge on the walls, the proteins are repelled from the walls and good peak shapes result. The fact that these surfactants have a hydrophobic tail is believed to be a reason for the increased performance. Cationic surfactants have the ability to reverse the osmotic flow. With proper adjustment, osmotic flow can be minimized, but these surfactants can also form micelles which will also affect the separation. Other cationic surfactant additives are demonstrated in the following references $(55,56)$.

One novel additive was not added to the running buffer but was added to the sample (57). By adding ethylene glycol to the sample, the wall adsorption was reduced and peak shapes and efficiencies were improved. This technique has benefits over conventional slab gel technology for protein separations. From this work, it is shown that the ethylene glycol is probably wusorbing to the walls preferentially over the proteins. This helped to reduce the fouling that occurred at the injection end of the capillary. When the modifier was added to the running buffer it did not significantly enhance the separation over what was previously stated. It did reduce the limits of detection because of the strong UV absorption of the ethylene glycol.

Additives are not exclusively limited to surfactants, salts, and alcohols. 
Polymers, gels, and linear polymers are another form of additive. These additives will be discussed in the following subsection.

\section{Gels and non-gel polymers}

The use of agarose in capillaries has been investigated along with variations such as liquified agarose and agarose/polyacrylamide mixtures. Unfortunately, when liquid agarose is introduced into a capillary, the solution will contract upon cooling leading to voids in the matrix. This can be overcome with careful preparation of the gel. Bocek and coworkers have investigated the use of agarose and liquified agarose as a means to separate DNA (58-60). Liquified agarose offers a little more durability to the gel and increases the effective pore size which will allow separation of larger DNA fragments. The problem remains that the agarose is not as durable under very high voltage applications. This tends to preclude the use of this matrix in HPCE.

The use of polyacrylamide gels in electrophoresis is a standard in the molecular biology field. More recently, the use of polyacrylamide in capillaries has been a viable tool for separation of biomolecules. Typical slab gel separations use a variety of percentage composition acrylamide (\%T) and then add a known amount of cross-linking bis-acrylamide (\% $)$ to form the rigid gel. These gels are fixed in place when polymerization occurs. Acrylamide must be polymerized by using ammonium persulfate (APS) the initiator, $N, N, N^{\prime}, N^{\prime}-$ 
tetramethylethylenediamine (TEMED) the catalyst, and acrylamide/bis-acrylamide. Polymerization of acrylamide is dependent on several factors such as oxygen content which will terminate the radical ion driven reaction. The reaction mechanism for the polymerization of acrylamide is the following (61).

$$
\begin{gathered}
M+I \rightarrow R \cdot \\
R \cdot+M \rightarrow R M . \\
R M \cdot+n M \rightarrow R M_{\underline{n}+1}^{\cdot} \\
R M_{\underline{n}+1}^{\cdot}+R M \cdot \rightarrow P \\
R \cdot \rightarrow S
\end{gathered}
$$

Reaction (A) is the formation of the free radical from the monomer by the initiator. Reactions (B) and (C) are the chain polymerization stages. Reaction (D) is the chain termination by disproportionation to give products while reaction (E) is the removal of the free radicals by a process leading to products. In the case of the vinyl polymerization of acrylamide, reaction (E) often involves atmospheric oxygen. Thus the amount of oxygen in solution is critical to the knowledge of the amount of polymerization. The acrylamide reaction is exothermic $(\Delta H=-84 \mathrm{~kJ})$. 
Therefore, it is essential to regulate the heat removal of the polymerization, or heating in the capillary could lead to bubble formation.

The polyacrylamide-filled column can be pre-run to eliminate the initiator and catalyst, but this will decrease the duty cycle of the polymer in the capillary and does not always guarantee the removal of all excess persulfate. The addition of ammonium persulfate to initiate the acrylamide polymerization adds significantly to the current and forces the use of lesser voltages and increased separation times.

The amount of APS and TEMED in ratio to the acrylamide is crucial in determining the amount of polymerization as well as the amount of change in current. Another factor in polymerization include oxygen concentration in the initial buffer. The oxygen will terminate the free radical driven polymerization and distribute the average pore size differently every time depending on oxygen concentration. Temperature of the solution will affect the rate at which the polymerization occurs. Advantages to polymerization include no osmotic flow and a well characterized pore size based on existing data from slab gel work. Regardless of the critical nature of the acrylamide, good results have been achieved by several laboratories.

Guttman et al. have shown good separations of oligonucleotides by using a fixed polyacrylamide gel in capillary with theoretical plates to 30 million/meter (62). These impressive results were performed on a $6 \% \mathrm{~T} 5 \% \mathrm{C}$ gel capillary. Unfortunately, the separation times were quite lengthy, albeit shorter than standard 
slab gel sequencing. They also showed the feasibility of micro preparative fraction collection. Zhang et al. have used cross-linked polyacrylamide in conjunction with fluorescence detection for the separation and detection of DNA sequencing in capillaries (63). The fluorescence tagging of the DNA fragments allows detection down to a few hundred analyte molecules.

Other DNA work has included temperature and voltage studies by Guttman and Cooke $(64,65)$. They showed the effects of temperature and voltage on the separation efficiency of the separation of polymerase chain reaction (PCR) size DNA. Temperature does play a role in the effective viscosity and activation energy of the polymer. Voltage gradients have effect on the resolution and the separation time. Work by Yeung et al. has shown that voltage gradients play a significant role in the separation mechanism involved, and temperature does not significantly affect the separation except for the total time needed for a complete separation (66).

Other work from Guttman and Cooke showed an acrylamide gel separation with the addition of ethidium bromide as a modifier to the separation process (67). Guttman and Cooke showed an increased absorbance from the intercalation of ethidium bromide into DNA. But band inversion can occur when intercalators are used prior to separation (11). Others have shown that the addition of ethidium bromide will enhance the separation most likely due to the intercalation of the dye molecule into the DNA helix (68). Others have shown good results for sequencing of DNA in capillaries (68-74). 
Sodium dodecylsulfate-polyacrylamide gel separations normally used on conventional slab gel have been demonstrated by several people. Absorption detection with a $5 \% \mathrm{~T}$ and $3 \% \mathrm{C}$ polyacrylamide gave good resolution for proteins in the molecular weight range $10,000-200,000$ Daltons $(\mathrm{Da})(75)$.

Several studies by Righetti $e t$ al. use differing acrylamide monomers and c:oss-linking monomers to investigate new gels having high hydrophilicity, high resistance to hydrolysis, and larger pore sizes than conventional polyacrylamide gels $(76,77)$. Unfortunately, the most promising acrylamide monomers exhibit instability in basic pHs. Other investigations in Giorgio's laboratory involve novel polymerization techniques performed in capillaries $(78,79)$ and the use of these novel acrylamide systems for isoelectric focusing $(80,81)$.

As was mentioned above, these gels are not rugged enough to allow the high voltages that should be utilized in CZE. This leads to finding a polymer or gel that is replaceable. Hence, the reduction of the cross-linking agent in polyacrylamide gels leads to a polymer that is not fixed and can be replaced. When these gels are formed in a capillary, the need for a cross-linking factor is no longer a complete necessity. Since the gels are supported by the capillary, the gel can then be as close to a liquid as desired for the separation. Many separations with acrylamide are now being performed with no cross-linking agent. This allows the flushing of the old polymer with new polymer and the capillary can be reused. Linear polyacrylamide $(0 \% \mathrm{C})$ has been studied extensively over the past few 
years with good results. A protein separation was performed with SDS $0.5 \%$, and $10 \%$ linear polyacrylamide at $\mathrm{pH} 5.5$ for a set of test proteins from 18,000 to $77,000 \mathrm{Da}(82)$.

Work has been done with linear polyacrylamide and DNA separations. The separation of restriction fragments up to $12 \mathrm{~kb}$ has been shown with zero crosslinked polyacrylamide using continuous and pulsed electric fields (83). Ferguson plots of $\log$ mobility versus $\% \mathrm{~T}$ were used to asses the size selectivity of these gels. Holmes and Stellwagen have put forth an extensive paper on the effects of different cross-linker concentrations, added agarose, and linear polyacrylamide (84).

Work has recently moved into the use of non-acrylamide separations. Polymers include celluloses, polyvinyl alcohols, polyethylene glycols, and dextrans. These polymers offer advantages over polyacrylamides in that they are not toxic, the relative size of the polymer can be easily changed, and these polymers exhibit less absorption in the UV region where biopolymers have high molar absorbtivity. Bonn and coworkers have been using hydroxyethyl cellulose (HEC) and ethidium bromide to separate oligonucleotides and DNA (85). They point out that these polymers are more resilient to injection voltages and higher current than acrylamide systems.

Protein separations involving $0.03 \%$ hydroxypropylmethyl cellulose (HPMC) at $\mathrm{pH} 2.0$ showed separation of the phosphorylated and non-phosphorylated as 
well as the acetylated and non-acetyl variants of Histone $\mathrm{H} 1(86,87)$. Other protein separations included applications to near real time evaluation of enzymelabelled monoclonal antibody conjugates (88). Hydroxyethyl cellulose (HEC) was the model for rigorous study by Grossman and Soane (89). They discussed the sieving ability and the anti-convective state of the medium. HEC was also studied by Bonn et al. for DNA separations involving the addition of ethidium bromide (90). Methyl cellulose (MC) has been used to separate DNA fragments up to 23 $\mathrm{kb}$ when run at low voltages with good success $(91,92,66)$. Lower voltages may be required when larger fragments are separated due to trapping of the DNA fragments in the polymer network (11). Applications have now started to appear using these polymers as a separation medium. One article has demonstrated the use of polymer filled capillaries for detection of the HIV virus in blood (93).

These non-gel polymers are not restricted to the cellulose homologs. Capillaries with polyethylene glycol additives for protein separations are currently available from several commercial vendors $(94,95)$.

\section{External voltages}

Another approach to controlling the osmotic flow in CZE is to apply some external voltage to the capillary to alter the internal charge on the wall. Several examples are listed below.

Hayes and Ewing coated a capillary with a conductive polymer sheath to 
provide the necessary radial voltage and investigate the application of the polymer to the capillary (96). Experimental results follow theory adequately. Lee et al. have applied an external field to reduce adsorption of biomolecules to the capillary wall $(97,98)$. This application may also have a benefit in that it can speed up separations as a gradient system in LC would have.

Another promising variation on coating or modifying capillaries is the immobilization of trypsin to the capillary surface to act as a digestion region for proteins $(99,100)$. The protein is injected into the end of the capillary or into a region that has trypsin covalently bound to the capillary surface. The protein is allowed to digest and then the fragments are mapped. This concept could be expanded to digestion of DNA or other forms of degradation of biomolecules. 
PAPER I. INTERACTIVE CONTROL OF PULSED FIELD GEL ELECTROPHORESIS VIA REAL TIME MONITORING 
INTERACTIVE CONTROL OF PULSED FIELD GEL ELECTROPHORESIS VIA REAL TIME MONITORING

\author{
David A. McGregor and Edward S. Yeung \\ Ames Laboratory-USDOE and Department of Chemistry, \\ Iowa State University, Ames IA 50011
}

Reprinted with permission from Analytical Chemistry, 1992, 64, pages 1-6.

Copyright 1992 American Chemical Society. 


\section{BRIEF}

By monitoring the progress of the separation in pulsed-field gel

electrophoresis, interactive control of pulse times can be implemented to drastically reduce run times. 


\begin{abstract}
The migration of DNA fragment bands through a slab gel can be monitored by UV absorption at $254 \mathrm{~nm}$ and imaged by a charge coupled device (CCD) camera. Background correction and immediate viewing of band positions to interactively change the field program in pulsed-field gel electrophoresis is possible throughout the run via this detection scheme. The use of absorption removes the need for staining or radioisotope labeling thereby simplifying sample preparation and reducing hazardous waste generation. This leaves the DNA in its native state and further analysis can be performed without de-staining. The optimization of buffer concentration, electric field strength, temperature, agarose concentration, as well as pulse duration, can considerably reduce total run time. As an example, DNA from $2 \mathrm{~kb}$ to $850 \mathrm{~kb}$ can be separated in 3 hours on a $7 \mathrm{~cm}$ gel with interactive control of the pulse time, which is 10 times faster than if a constant field program is used.
\end{abstract}




\section{INTRODUCTION}

Major advances have been made in the human genome project, as can be witnessed by the current achievement of complete sequencing of one chromosome of the yeast, Saccharomyces cerevisiae, of about 300 kilobase pairs (kb) (1). Still, to map and sequence the entire human genome, which is 24 distinct chromosomes with $3 \times 10^{9}$ base pairs (bp), this current achievement is 4 orders of magnitude short. To ultimately achieve this goal, critical reevaluation of the current techniques used to map the genome must be done. The methods currently used are (2): 1) family studies, genetic maps which are large databases of family histories and trends; 2) ordered libraries, physical maps, of large DNA fragments (100's kb) from chromosomes to allow mapping of the individual genes, usually separated by pulsed field gel electrophoresis (PFGE); 3) digestion of the larger fragments into smaller fragments and separation, usually done by direct current (DC) field gel electrophoresis; and 4) sequencing of the smaller fragments into the

constituent A (adenine), $\mathrm{T}$ (thymine), $\mathrm{C}$ (cytosine), and $\mathrm{G}$ (guanine) bases, which is done by slab gel or more recently by capillary electrophoresis (3). This article will center around the separation of large fragments of DNA.

DC field gel electrophoresis can separate fragments up to $\sim 30 \mathrm{~kb}$ based directly on the size to mobility ratio. Above this size the separation mechanism breaks down and the fragments will not separate because they can no longer 
effectively 'sieve' through the gel. To alleviate this problem, another mechanism is introduced by pulsing the electric field. PFGE relies on reptation, or the snake like motion of the fragments through the separation media. Simply, the larger the fragment, the longer time it takes for it to align in the new applied field. Shorter fragments can quickly align with the field at shorter pulse times and then travel down the gel. Longer fragments require longer pulse times to align. DNA must realign with the electric field before it can move through the medium. If the pulse is too short larger DNA cannot fully align and will not travel at a unique mobility. Hence all other DNA larger than the fragment that just does not fully align will travel as one band or compression zone. When the electric field is applied in two directions alternately, the fragments reptate, or snake through the gel and separations into the megabase pairs $(\mathrm{Mb})$ can be performed. PFGE was first demonstrated in 1984 (4). As opposed to DC electrophoresis, PFGE alternates the electric field at a predetermined angle (Figure 1). There are many configurations currently being utilized $(5,6)$. One such reliable configuration is the contour-clamped homogeneous field (CHEF) device (7). In the CHEF apparatus the electric fields are applied at $120^{\circ}$ angles and the apparatus is horizontal. By switching the electric field for some predetermined time, the fragments will zig-zag down the length of the gel. The CHEF apparatus separates fragments with reasonably straight lanes and offers an open design.

The separation mechanism of PFGE is not well understood and several 
Figure 1. Schematic diagram of a conventional Contour-Clamped Homogeneous Electric Field (CHEF) device. The electric field alternates from the $\mathrm{A}$ electrodes to the $\mathrm{B}$ electrodes at some predetermined pulse sequence. 


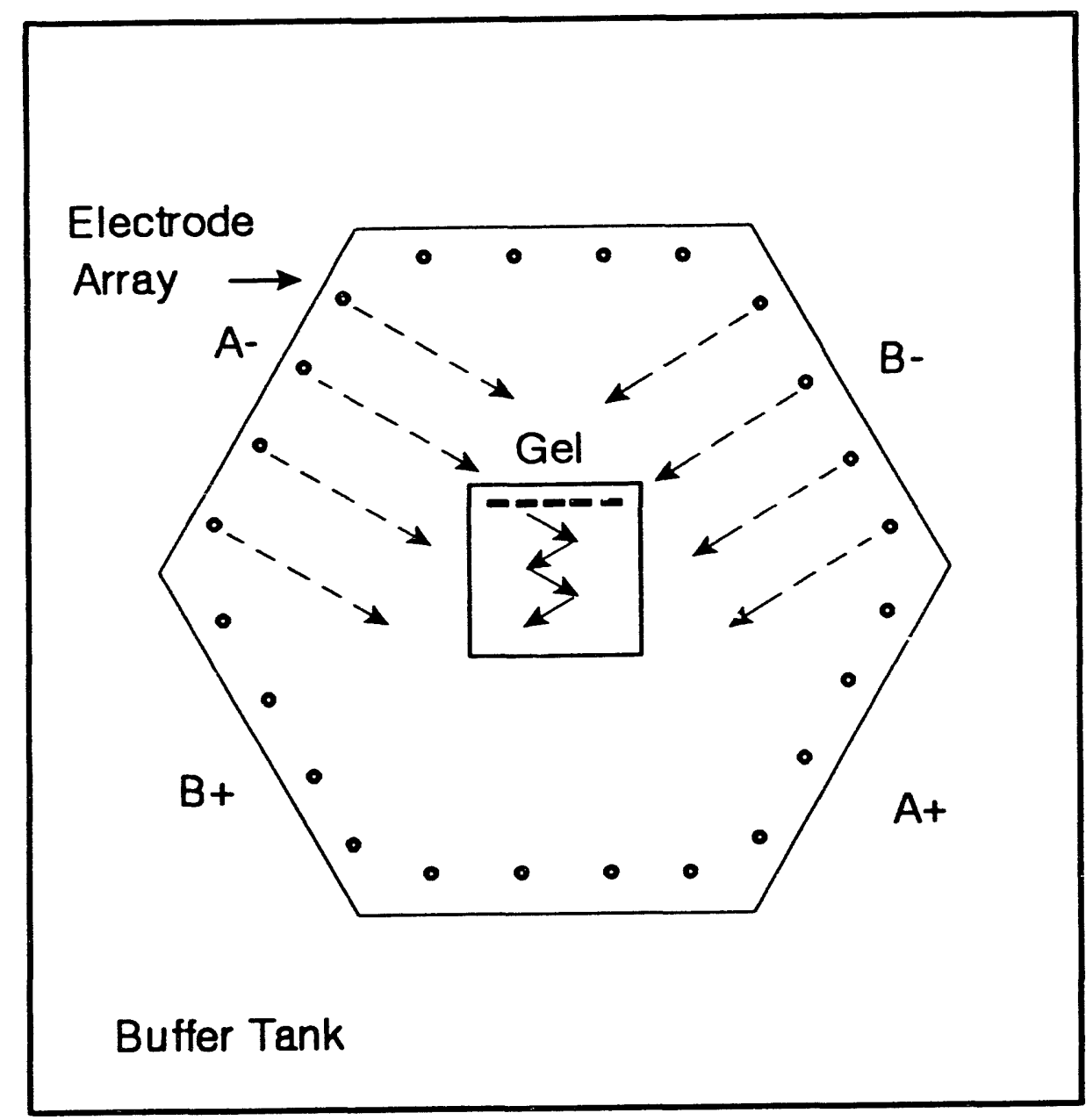


theories have been proposed (8-12). PFGE has the capability of separating DNA fragments from less than $1 \mathrm{~kb}$ to over $13 \mathrm{Mb}$. When restriction digests are performed on unmapped chromosomal DNA, the resultant fragments are of unknown size and quantity. The digestion of whole chromosomes by restriction enzymes yields fragments that will add up to the original size of the chromosome. Restriction enzymes use a recognition sequence of certain bases (i.e., 5'-AAGCT-3' as in the HindIII restriction enzyme) along the DNA strand. When the enzyme finds that sequence in the strand, it will cleave the helix in that spot. Obviously the larger the recognition sequence, the more infrequent the cleavages. When the DNA strand is very long, a small recognition site would yield hundreds of fragments. Therefore it is desirable to use rare site cutting restriction enzymes. These enzymes have recognition sequences of 8 to 12 base pairs. Even so, the number of fragments can still be quite large if a chromosome is rich in one set of bases or another (i.e., A\&T or G\&C). The choice of pulse length is critical to optimal separation of these fragments.

Current procedures for PFGE require a prior loading of the sample into wells, then separation at predetermined running conditions. These conditions vary and when the restriction fragments are of unknown size and number, the correct pulse conditions are also unknown. For optimum separation of an unknown fragmentation pattern, some 'educated guess' as to the pulse conditions must be chosen. The electrophoresis is performed and the results must then be visualized 
by staining with ethidium bromide or by labeling with a radioisotope and exposing film. The results are then viewed and the separation can be analyzed. If the pulse or pulse sequence were not optimal for electrophoresis, the separation must be done again with new switching times. When a PFGE separation can take from 9 hours to 100 hours to complete a lot of time is spent waiting for results. However, if DNA migration through the agarose is monitored in real time the pulse length can be adjusted to optimize the separation as the fragment sizes become apparent. This reduces the number of experiments required for optimal separation of chromosomal DNA fragments. Monitoring of fragments as they migrate allows for separation and identification over a wide range of sizes in a single run.

In this work, we demonstrate the advantages of interactive control in PFGE. Real time monitoring of the separation is possible using $\mathrm{UV}$ absorption and $\mathrm{CCD}$ (charge-coupled device) imaging (13). The optimal separation condition can be arrived at in a systematic fashion. The final result is a substantial reduction in the separation time compared to constant field programming approaches. 


\title{
EXPERIMENTAL SECTION
}

\begin{abstract}
Apparatus
The apparatus shown in Figure 1 consists of the CHEF design made inhouse from blueprints supplied by Chu et al. (14). The power supply and pulse controller were purchased from Bio-Rad Laboratories. For cooling, a pump (ColeParmer model 7520-00) recirculates the running buffer through Tygon tubing contained in a constant temperature bath.

The agarose gel is illuminated only during imaging by a $30 \mathrm{~W}$ UV lamp (Cole-Parmer) operating at $254 \mathrm{~nm}$ which is mounted $60 \mathrm{~cm}$ above the gel. The imaging system consists of a scientific grade CCD (Thomson TH7882 576 x 384 pixel) thermoelectrically cooled to $-40^{\circ} \mathrm{C}$ (Photometrix Ltd.). The focusing lens is a $90 \mathrm{~mm} \mathrm{f} / 2.5$ tele-macro (Tamron Co.) which has flat-field focusing properties at low aperture. The flat-field lens allows full focusing across the entire imaged area. A $600 \mathrm{~nm}, 80 \mathrm{~nm}$ band pass filter is used to reject the direct illumination from the lamp and any stray light from the room. The CCD is $75 \mathrm{~cm}$ from the agarose. The entire experimental apparatus is shown in Figure 2. An enlargement of the absorption scheme is shown in Figure 3.

Images shown were $3.0 \mathrm{~s}$ each for 16 individual exposures. An exposure filled the individual pixels to roughly $90 \%$ capacity. The 16 frames were averaged together to further reduce the shot-noise limitations of the CCD. Total
\end{abstract}


Figure 2. Schematic diagram of experimental setup. UV light illuminates the gel. As the UV passes through the gel the DNA fragments will absorb some of the radiation. The remaining light strikes the lexan plate and is re-emitted as fluorescence to be imaged by the CCD. To achieve true absorbance, a background image is taken before the voltage is applied and all subsequent images are divided by this blank image. UV, $254 \mathrm{~nm}$ UV lamp; $600 \mathrm{~nm}$ filter, $600 \mathrm{~nm} 80 \mathrm{~nm}$ band pass filter; Lens, focuses images onto $C C D$; $C C D$, charge coupled device; $C C 200$, dedicated data array for image storage; 80386, PC for electronic storage of images; Monitor, for hard copy and visual analysis of separation. 


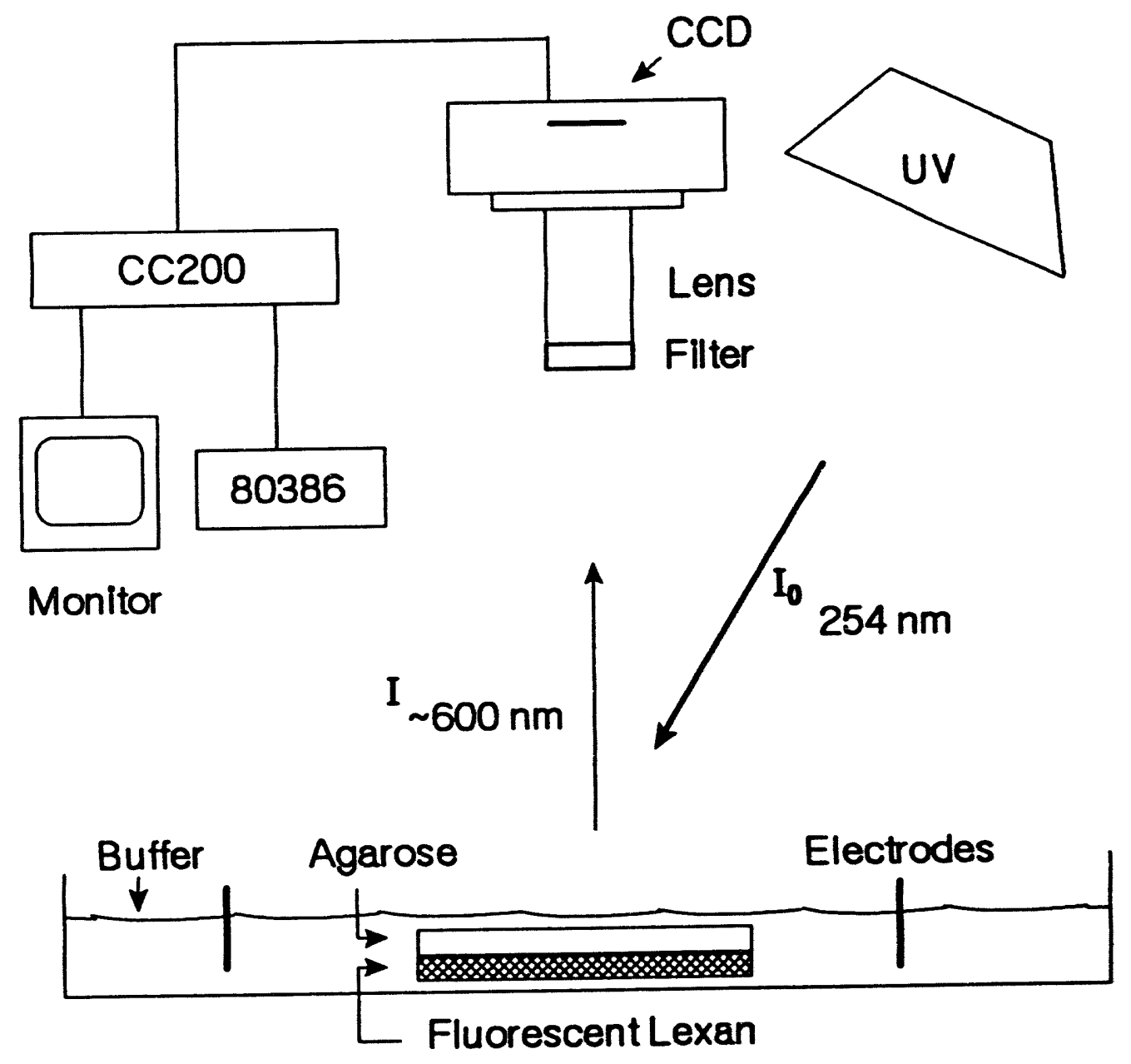


Figure 3. Schematic diagram of the absorbance scheme for the detection of DNA via ultraviolet shadowing. Incoming UV light strikes the DNA where some of the light is absorbed, then continues through to the fluorescent plate and is then reradiated as fluorescence at around $600 \mathrm{~nm}$. The UV that does not strike the DNA is reradiated at the same intensity and is essentially seen as a white background. Where UV light is absorbed, the pattern shows as a shadow. 


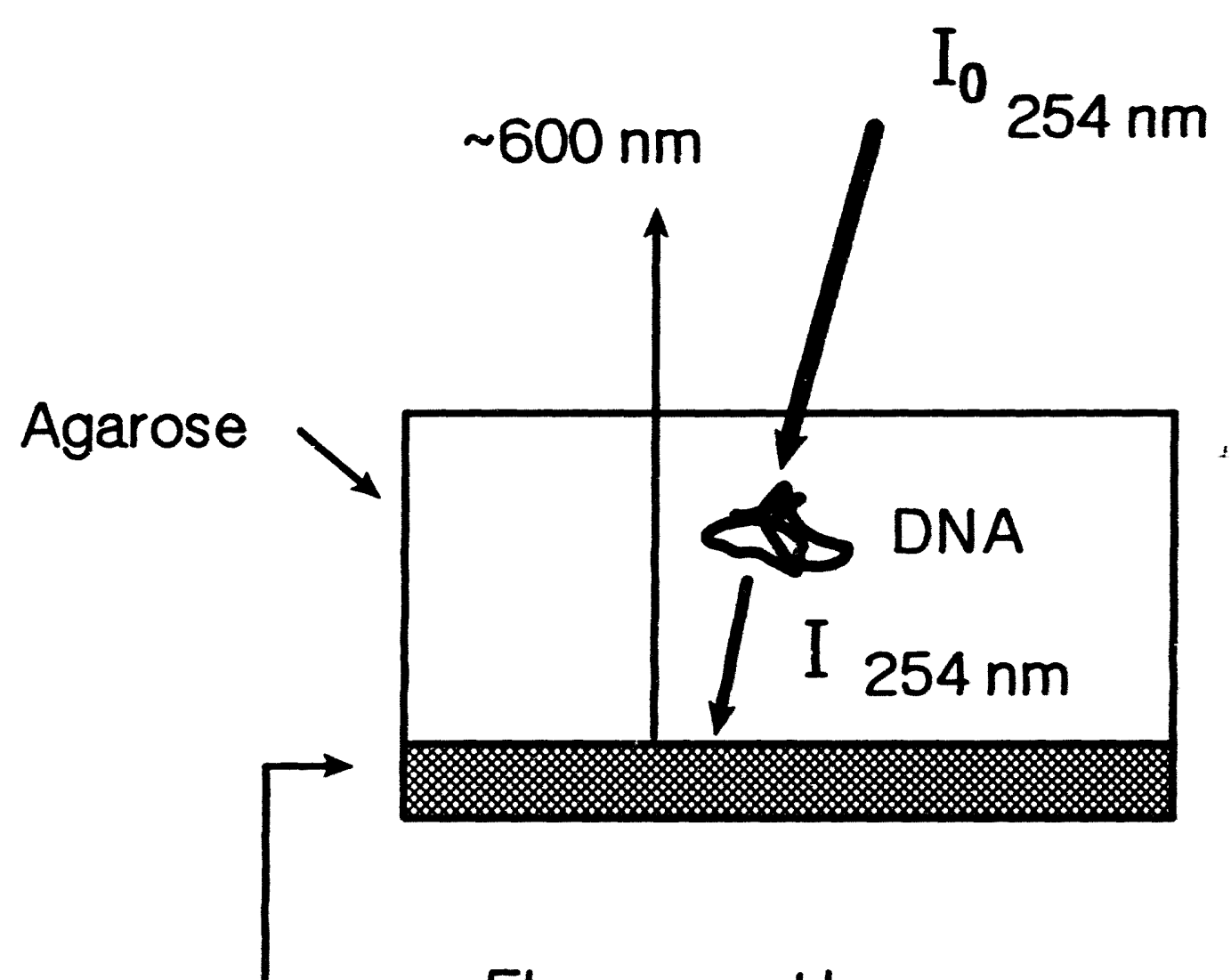

Fluorescent Lexan 
illumination time per image (every $1 / 2$ hour) for the gel and DNA was around 3 minutes. This UV exposure time was not sufficient to damage (nick) the DNA for this experiment since no smearing of the bands was evident. When the gel is imaged the running buffer is static and the applied voltage is off. All two dimensional data taken from the gels are analyzed by taking the average of 35 pixel rows across each lane, as shown in Figure 4.

Since the absorption bands of the DNA absorb around 5\% of the UV light or less the inhomogeneities in the gel and the fluorescent background must be reduced to allow proper visualization. This is accomplished by taking an image prior to applying the electric field and storing it in the CCD memory buffer (CC200). All subsequent images are normalized relative to this blank image, thereby reducing much of the systematic noise. This type of imaging is called flat-fielding. The subsequent images can be sent to a monitor for immediate analysis or to a PC for electronic storage for later data workup. Photo documentation of the gels were taken off the monitor by a $35 \mathrm{~mm}$ camera.

\section{DNA}

The DNA used in this research consists of lambda DNA digested with HindIII (lot 9PD114) from Bethesda Research Laboratories (BRL) as a marker from $560 \mathrm{bp}$ to $23.1 \mathrm{~kb}$. A medium size distribution of DNA fragments which was used is the High Molecular Weight Marker (HMW) from BRL (lot AEH703), a 
Figure 4. Separation of High Molecular Weight Markers. Note the negative peaks indicating UV absorbance. 35 pixels have been averaged across one lane. Conditions; $6 \mathrm{~V} / \mathrm{cm}, 0.9 \mathrm{~s}$ pulse, $10 \mathrm{mM}$ TPE buffer,

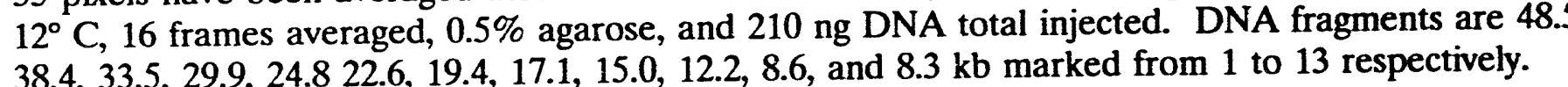




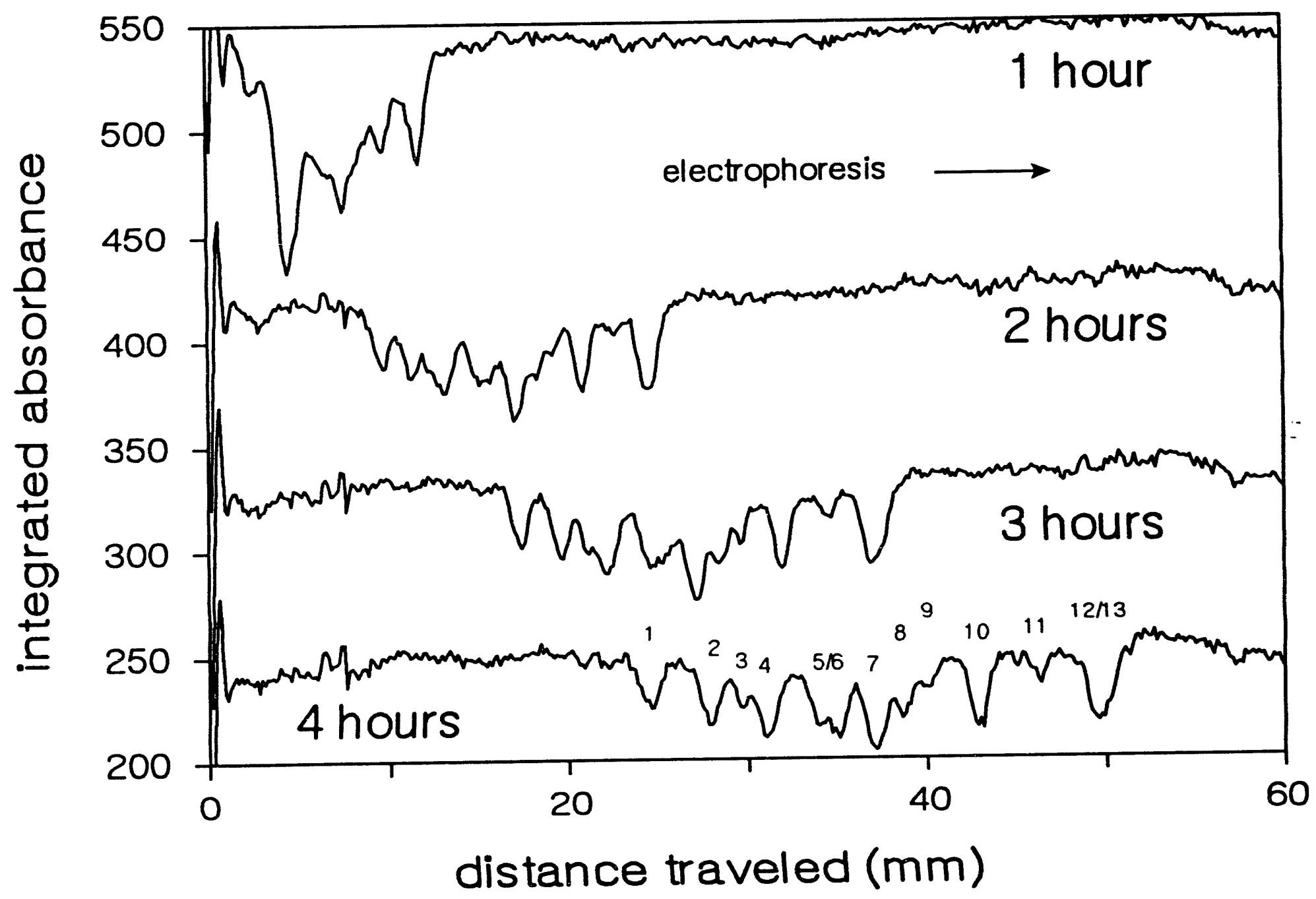


marker from 8.3 to $48.5 \mathrm{~kb}$. All chromosomal DNA was purchased from Promega. The chromosome of Moraxella bovis (lot L31) (3.1 Mb) was digested with both NotI (lot 02302) (8 base recognition site) and CspI (lot 01740) (7 base recognition site). The chromosome of Staphylococcus aureus (3.1 Mb) (lot L21) was digested with CspI. The chromosomal digestions were performed as per the protocol from Promega, then allowed to equilibrate in the running electrophoresis buffer for 45 minutes prior to separation.

The chromosomal DNA is supplied in $1.6 \mathrm{~mm}$ diameter strings of agarose which are cut to $5 \mathrm{~mm}$ lengths. Digest of the $M$. bovis with Not I is first equilibrated with the restriction enzyme buffer for 30 minutes on ice. Then the enzyme [5:1 enzyme(u):DNA $(\mu \mathrm{g})]$ and bovine serum albumin (BSA) is added and allowed to equilibrate for 30 minutes on ice to allow the enzyme to completely pervade the agarose plug. The digest is performed at $37^{\circ} \mathrm{C}$ for 3 hours and the reaction quenched by adding EDTA to $50 \mathrm{mM}$. Digestion of $M$. bovis and $S$. aureus with CspI is equilibrated as before then the enzyme (8:1) is added with BSA and equilibrated. The digestion is performed at $30^{\circ} \mathrm{C}$ for 5 hours.

\section{Gel}

The $0.5 \%(w / w)$ agarose (FMC Fast Lane lot 11509) was melted and poured between the fluorescent lexan base and a quartz plate with $4 \mathrm{~mm}$ spacers and allowed to set for 30 minutes at room temperature. The wells were formed 
with a teflon comb of $5 \mathrm{~mm}$ wide by $1.5 \mathrm{~mm}$ thick and $4 \mathrm{~mm}$ deep.

The $10 \mathrm{mM}$ TPE (THAM, phosphoric acid, EDTA) running buffer for electrophoresis consisted of $7.86 \mathrm{mM}$ THAM (Tris[hydroxymethyl]aminomethane), $2.07 \mathrm{mM}$ phosphoric acid and $0.07 \mathrm{mM}$ EDTA (ethylenediaminetetraacetic acid) at $\mathrm{pH}$ 7.75. The $\mathrm{pH}$ of the buffer did not significantly change after 3 to 6 hours of electrophoresis. The running buffer was poured to a depth approximately $4 \mathrm{~mm}$ over the top of the agarose slab for enhanced cooling.

The quartz plate was then removed and the HMW and $\lambda /$ HindIII was injected with a $5 \mu \mathrm{L}$ pipet. The chromosomal DNA was cut into $5 \mathrm{~mm}$ lengths prior to digestion and was inserted as a plug of agarose into the slab gel. The agarose plug allows handling of the large DNA fragments without shearing or demaging of the DNA.

\section{Separations}

The optimized separation took 3 hours with a dynamically adjusted pulse sequence. At $12 \mathrm{~V} / \mathrm{cm}$ or $333 \mathrm{~V}$, the current was $250 \mathrm{~mA}$ and $70 \mathrm{~W}$ of power was dissipated. Pulse sequence was $0.6 \mathrm{~s}$ for 1 hour, then $3.0 \mathrm{~s}$ for 1 hour, then $6.0 \mathrm{~s}$ for 1 hour. Other separations shown are for static pulses for up to 6 hours to show the lack of complete separation in the system. 


\section{RESULTS AND DISCUSSION}

The purpose of this work is to achieve the fastest separation of DNA fragments over a wide range of sizes in an unknown sample. The size range being considered is from $560 \mathrm{bp}$ to $850 \mathrm{~kb}$. This range is important in the mapping of the human genome (15), and has proven utility in forensic applications involving DNA fingerprinting (16). The critical point is that fragments resulting from cutting a given DNA with restriction enzymes do not have predictable sizes. Even though statistical considerations can provide an estimate of the number and rough sizes of the set of fragments, there is always the possibility that important information will be missed if a generic recipe is used for electrophoresis. Some of the parameters for electrophoresis are relatively easy to select, such as buffer composition, applied voltage, temperature, and agarose concentration. These will first be optimized for the test system. One is then left with the control of the pulse forms in CHEF. These will be interactively adjusted during the separation to achieve adequate resolution at the maximum speed for a given sample. To demonstrate this concept, we have used different DNA digests to cover the $1000 \mathrm{X}$ size range in different lanes on one slab gel. This is necessitated by the lack of available standards that will form a good test case and to avoid cross-interactions between the DNA fragments which will affect the integrity of the size standards. 


\section{Buffer Composition}

Buffer type and concentration affect the separation time. Many PFGE buffers have concentrations on the order of $100 \mathrm{mM}$. This research constitutes a reduction of buffer concentration by 10 to 20 fold (17), and produces a marked increase in mobility. In this case, the reduction of running buffer concentration does not adversely affect the DNA or separation. Further reduction in the buffer concentration may have adverse effects on the separation because of denaturation of the DNA or activation of enzymes or other contaminants that may lyse the DNA strands much as the restriction enzymes do. There is no evidence for this occurring in these separations because of the sharp bands, which would otherwise be smeared if the aforementioned problems were present. Other buffer compositions could increase the mobility, thus decreasing separation time, but were not investigated in this work.

\section{Applied Voltage}

Another parameter involved in decreasing the separation time is the potential gradient. Standard potential gradients for PFGE on chromosomal DNA fragments range from $3 \mathrm{~V} / \mathrm{cm}$ to $10 \mathrm{~V} / \mathrm{cm}$. In principle, higher voltages will increase the migration velocities. However, voltages higher than this can present other problems in separation. Joule heating can become important even with circulation, leading to band distortions (18). The higher voltages will also lead to 
trapping of the DNA in the gel. Trapping at higher voltages has been demonstrated previously $(19,20)$. Trapping is the phenomenon where larger fragments cannot travel through the agarose because the pore size is too small or may become hung up on the pores because Brownian motion cannot overcome or unhook the DNA strands when the force of the electric field is too strong. It appears that an $850 \mathrm{~kb}$ fragment is severely attenuated in one lane of some of our gels, most probably due to the intermittent removal of the electric field during visualization. When the field is reapplied some DNA remains behind where the compression zone was last imaged. Lower voltages or decreased agarose concentration can partially correct this problem. In these separations the electric field is $12 \mathrm{~V} / \mathrm{cm}$.

\section{Temperature}

Most separations of this nature are run at 4 to $10^{\circ} \mathrm{C}$. This low temperature is required due in part to the length of the separation and the severe ohmic heating by the higher buffer concentrations normally used. The separations here are performed at $30^{\circ} \mathrm{C}$. The problem often encountered at higher temperatures is denaturation of the DNA above their critical temperature $\left(\mathrm{T}_{m}\right)$. Once again this is not a problem here as the $\mathrm{T}_{m}$ for these chromosomal DNAs are around $43^{\circ} \mathrm{C}$. The $\mathrm{pH}(7.75)$ change is not significant between $24^{\circ}$, where the buffer is made, and $30^{\circ} \mathrm{C}$, where the separation is run. The increase in mobility from $15^{\circ}$ to $30^{\circ} \mathrm{C}$ is 
found to be almost a factor of two.

\section{Agarose Concentration}

The agarose concentration for these experiments is $0.5 \%(w / w)$. This is not extraordinary for PFGE separations, but normal concentrations are around 0.75 to 1.5\%. Lower concentrations would speed the separation in general. Lower gel concentrations would make the agarose very hard to manipulate, but in this setup the gel remains stationary throughout. Lower agarose concentrations can also help to reduce trapping of the DNA by the pores because of the larger pore sizes. Ultimately, the requirement for adequate gel strength would limit the decrease in gel concentration.

\section{Separations}

The separation, as it occurs, is monitored by illumination of the gel with UV light. Typically, at the $1 / 2$ hour mark, the smaller fragments have moved away from the darker band which is closer to the wells. This darker band has all the remaining fragments and is called the compression zone (CZ). This zone has a wide range of DNA fragments that are all moving through the gel with the same mobility. The constant pulse separations almost all have compression zones whether they are behind the main separation area or in front or both. This demonstrates the need for different pulse times to optimally separate the full range 
of fragments.

Figure 5 shows the mobilities of the fragments in three different runs where the pulse times are kept constant. Note the plateau regions where the mobilities are relatively wide ranging for the DNA sizes involved. This shows good separation for this range of fragments at this particular pulse time. The three individual plots in Figure 5 converge at lower fragment sizes. This shows the independence of the mobilities on pulse time for smaller fragments, demonstrating contribution primarily from a sieving mechanism for these smaller fragments. At this particular set of conditions, the convergence limit is around $20 \mathrm{~kb}$. The upward trend of the plots at lower mobilities shows the start of the $\mathrm{CZ}$, where the pulse length is not sufficient to separate the fragments.

Figure 6 shows results of constant-pulse separations, showing the lack of separation at those particular pulse times. Even at 6 hours the separations are not complete. This demonstrates the need for modification of pulse times during the separation. Ideally, one would continuously alter the pulse times during separation so that the plateaus in Figure 5 keep moving up to maximize resolution. We note that the three pulse times displayed in Figure 5 provide well spaced plateaus already, and a finer dynamic modification is not necessary.

The protocol is as follows. A given pulse time is selected and the separation is monitored at regular intervals. As soon as the lower molecular weight fragments begin to move away from the compression zone, even though the 
Figure 5. Graph of mobility vs. DNA size. The three curves represent mobilities of DNA (cm $\left.{ }^{2} / \mathrm{Vs}\right)$ as a function of pulse width. Note the independence of pulse time on the mobilities at DNA sizes below $20 \mathrm{~kb}$. The plateaus show the wide range of mobilities for relatively small regions of DNA sizes. At higher fragment sizes there is no change in mobilities for the 0.6 and $3.0 \mathrm{~s}$ pulses indicating the compression zone. Data is from three static separations using $0.6 \mathrm{~s}(0), 3.0 \mathrm{~s}(+)$, and $6.0 \mathrm{~s}(\Delta)$ pulses. Other conditions: $12 \mathrm{~V} / \mathrm{cm}, 30^{\circ} \mathrm{C}, 0.5 \%$ agarose, $10 \mathrm{mM}$ TPE buffer, 16 frames averaged. 


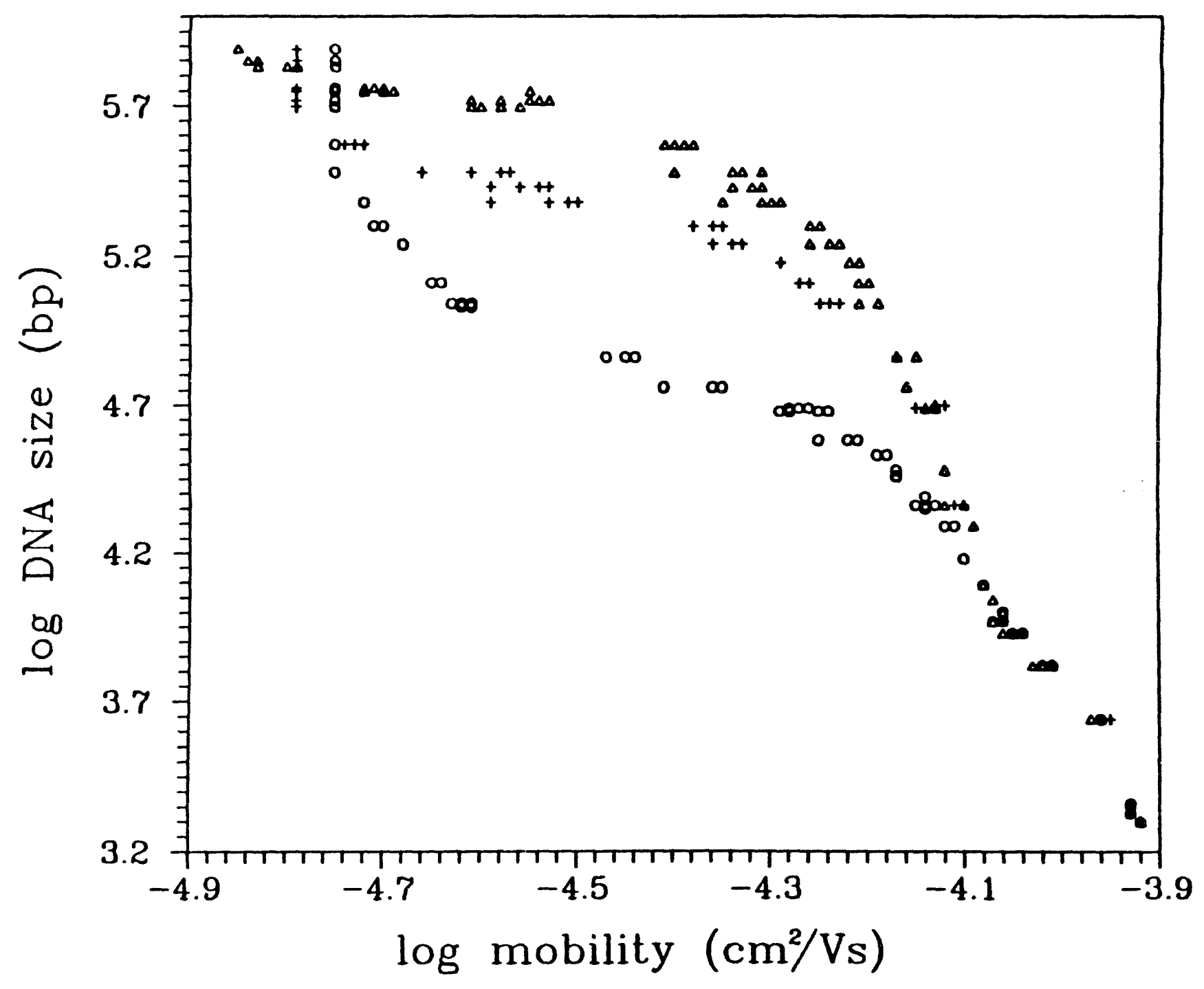


Figure 6. The three separations using static pulses; $0.6 \mathrm{~s}$ pulse for 3 and 6 hours, $3.0 \mathrm{~s}$ pulse for 3 and 6 hours and $6.0 \mathrm{~s}$ pulse for 2 and 4 hours. DNA digestions from left to right: Lanes 1 and $2, M$. bovis/CspI; 3, M. bovis/NotI; 4 and 5, S. aureus/CspI; 6, High Molecular Weight Markers (270 ng); 7, $\lambda /$ HindIII (180 ng). Amount of chromosomal DNA loaded into the gels is 1 to $2 \mu \mathrm{g}$. Other conditions: $12 \mathrm{~V} / \mathrm{cm}, 30^{\circ} \mathrm{C}, 0.5 \%$ agarose, $10 \mathrm{mM}$ TPE buffer, 16 frames averaged. Note that resolution is not achieved above $200 \mathrm{~kb}$ for the $0.6 \mathrm{~s}$ pulse even after 6 hours. Resolution is not adequate in the 3.0 $\mathrm{s}$ static pulse above $370 \mathrm{~kb}$ and some resolution is lost at the lower sizes as well. For the $6.0 \mathrm{~s}$ pulse the middle range $(240 \& 320 \mathrm{~kb})$ are not resolved and marked loss in resolution at lower DNA sizes is noted although the largest fragments are well separated within 4 hours. 


\section{0 hours}

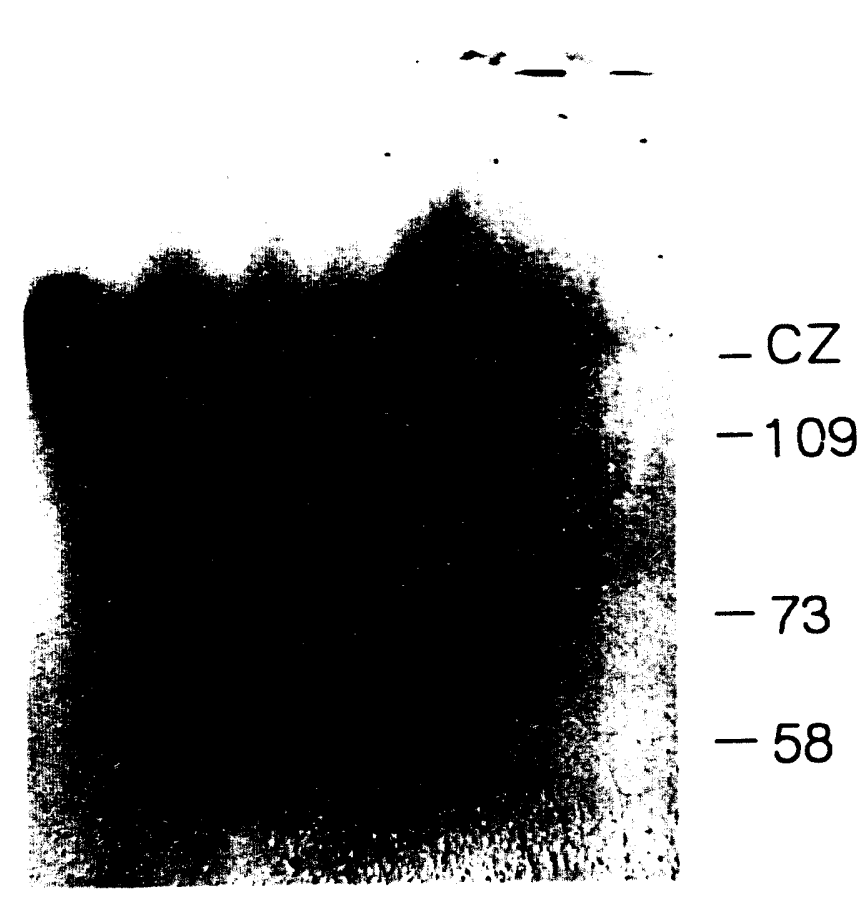

6.0 hours

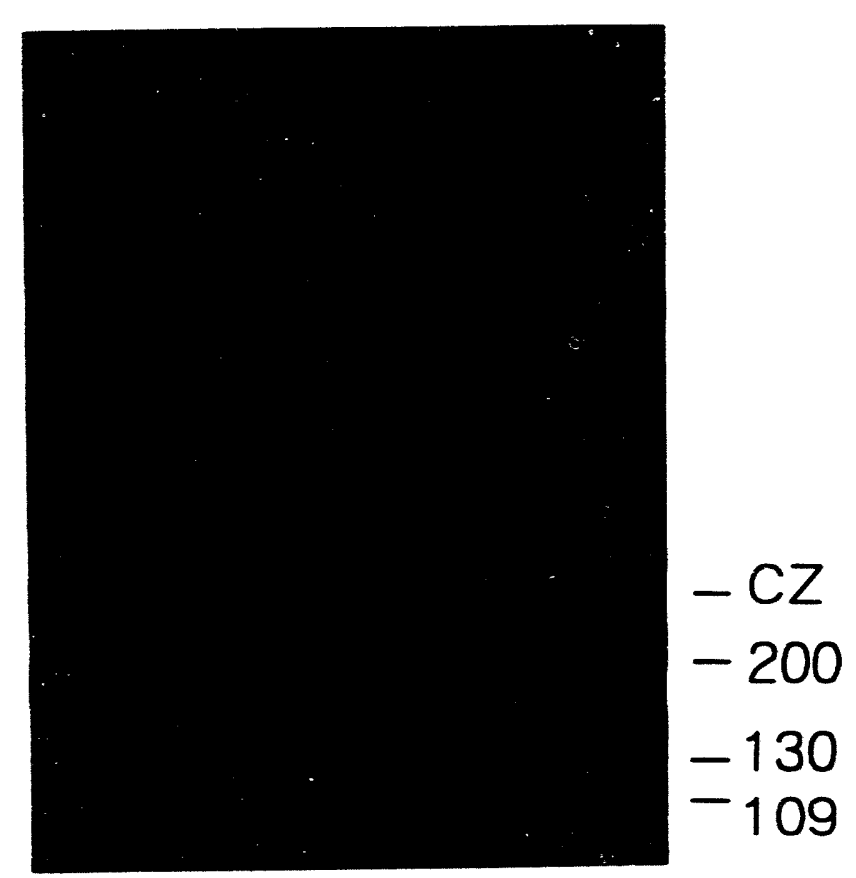


Figure 6. (Continued) 


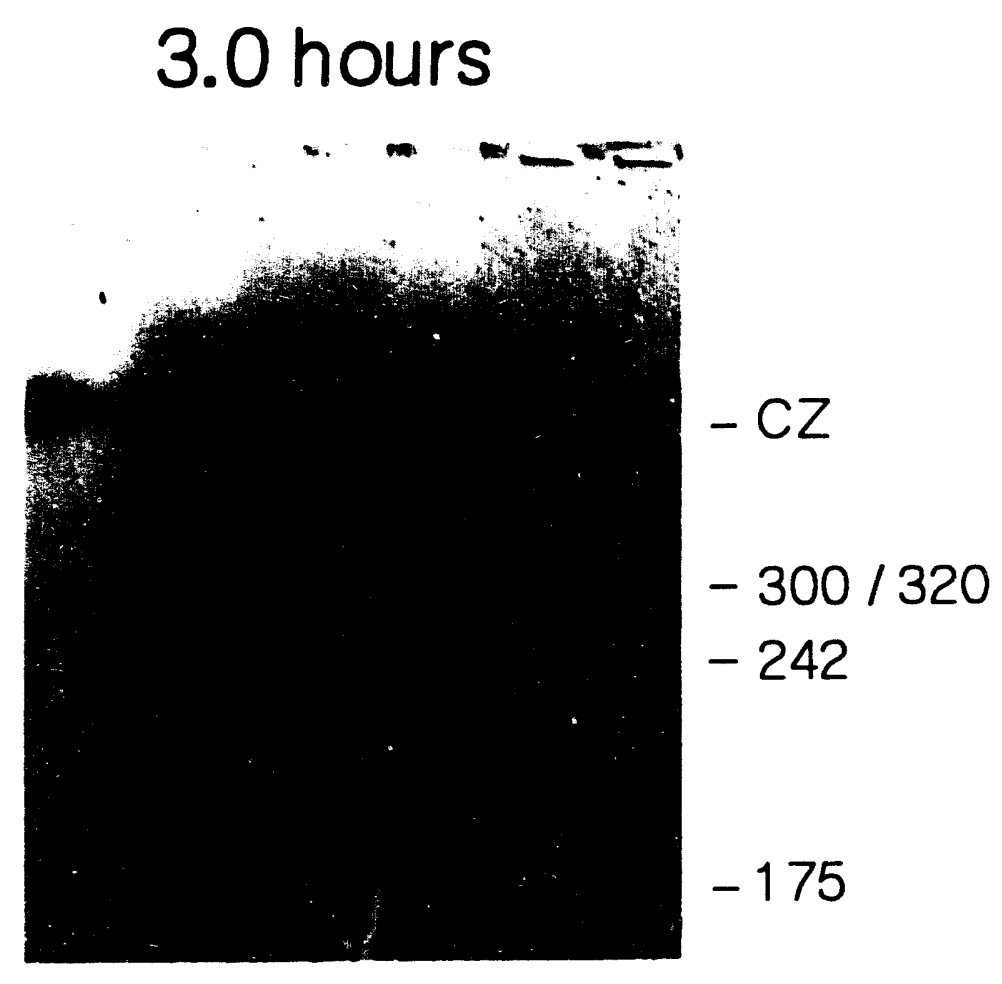

\section{0 hours}

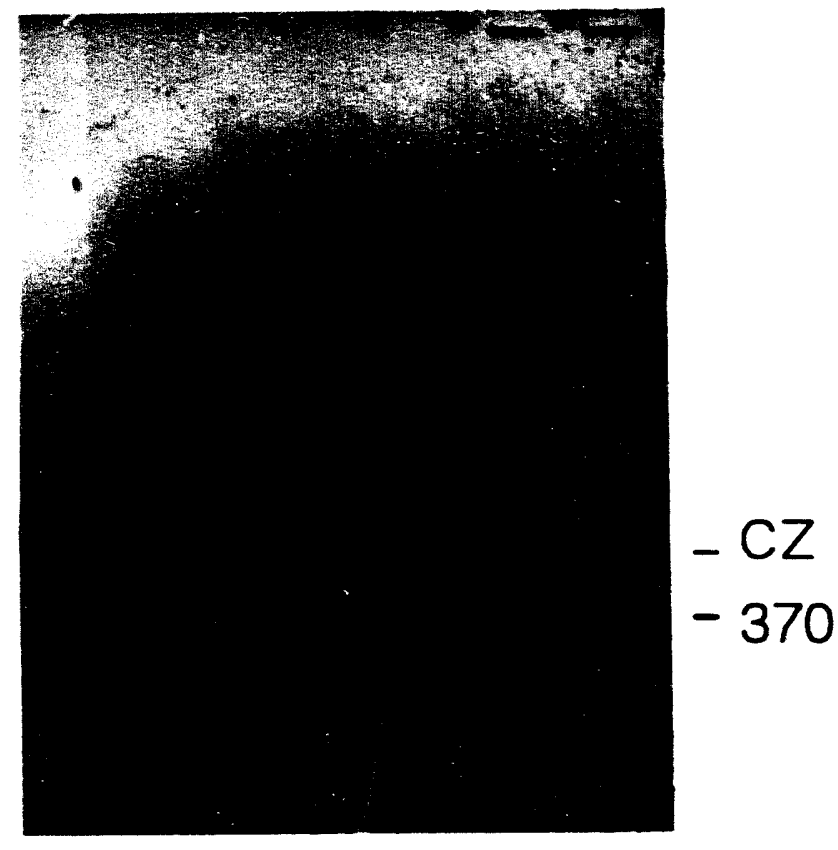


Figure 6. (Continued)

$\sigma$

- 


\section{0 hours}

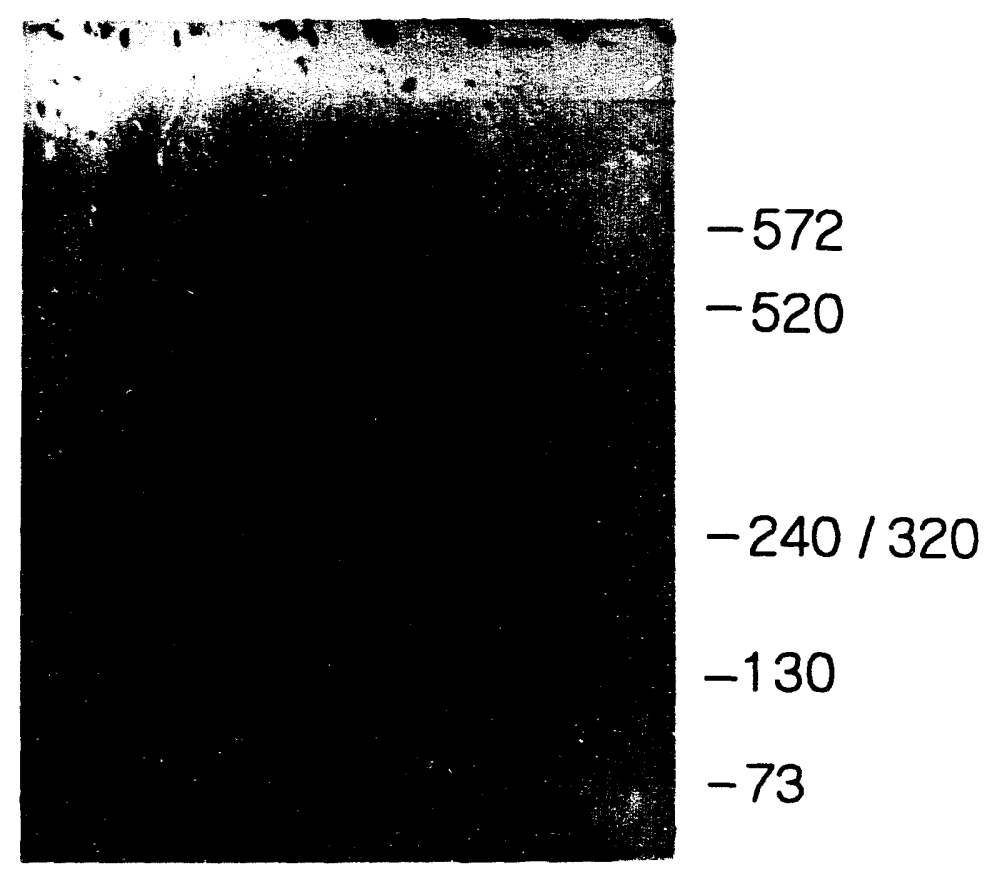

\section{0 hours}

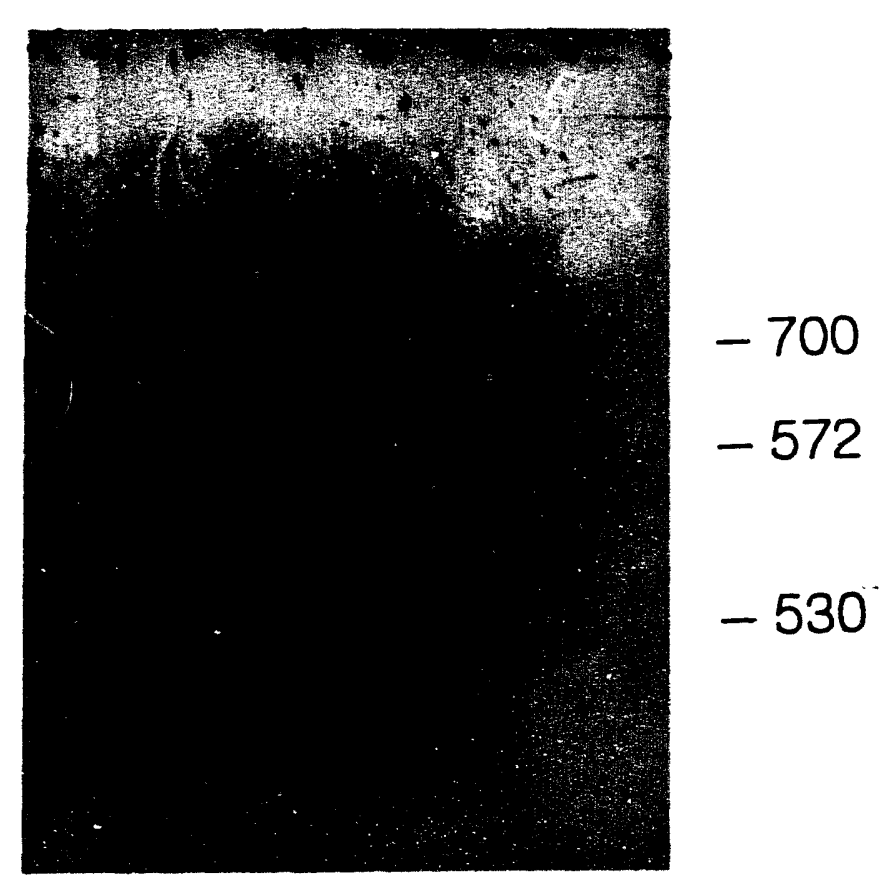


complete separation of all fragments in that range is not achieved, the next pulse time is selected. This is because one can anticipate further separation of the lower molecular weight bands when the next longer pulse time is in effect. When the intermediate sizes of fragments begin to separate from each other, the final pulse time can be selected. The electrophoresis will continue under this pulse time until final separation is observed in the image. Exactly when the pulse times are changed depends on the size range of the fragments in the particular sample and on the proximity of the bands in each size range. This must be done interactively. In this work, the operator decides on the parameters by following the separation in real time. There is no reason why this decision process cannot be converted into an "expert system" to achieve full automation. For example, the CCD image can be analyzed as in Figure 4 and standard chromatographic "resolution" indicators can be used to judge the separation performance at every stage.

Figure 7 shows the results of a separation of DNA fragments with interactive contiol of the pulse times via real-time monitoring. After the selection of the buffer composition, temperature, voltage and agarose concentration, the optimal dynamic pulse times were arrived at during the very first trial. In preliminary runs the temperature was much lower and the total optimized separation time was 6 hours. This shows the clear advantage of interactive control.

The bands of DNA for the chromosomal DNA used here have been previously determined $(21,22)$. The higher resolution of this separation has 
Figure 7. Images are from the three-hour separation utilizing the real time capabilities of the system to interactively control pulse sequence. Pulse sequence is $0.6 \mathrm{~s}$ for 1 hour, $3.0 \mathrm{~s}$ for 1 hour, and $6.0 \mathrm{~s}$ for 1 hour. Electrophoresis is from top to bottom in all images. Wells are at the top of the images. Note the HMW is not completely separated when the $3.0 \mathrm{~s}$ pulse is applied at 1 hour but that sieving will further separate the fragments even when the pulse is not optimized to separate that fragment range. All the fragments in the two right lanes have moved off the gel by 2.5 hours. Other conditions: $12 \mathrm{~V} / \mathrm{cm}, 30^{\circ} \mathrm{C}, 0.5 \%$ agarose, $10 \mathrm{mM}$ TPE buffer, 16 frames averaged. 
0.5 hour

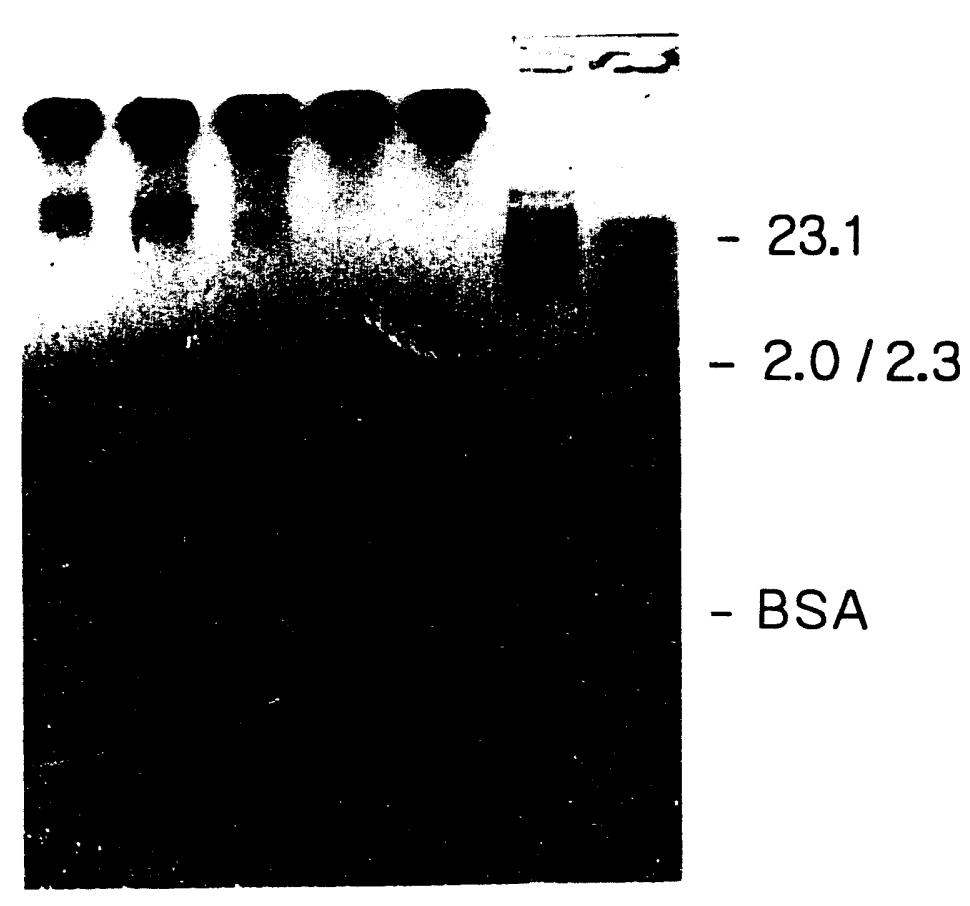

1.0 hour

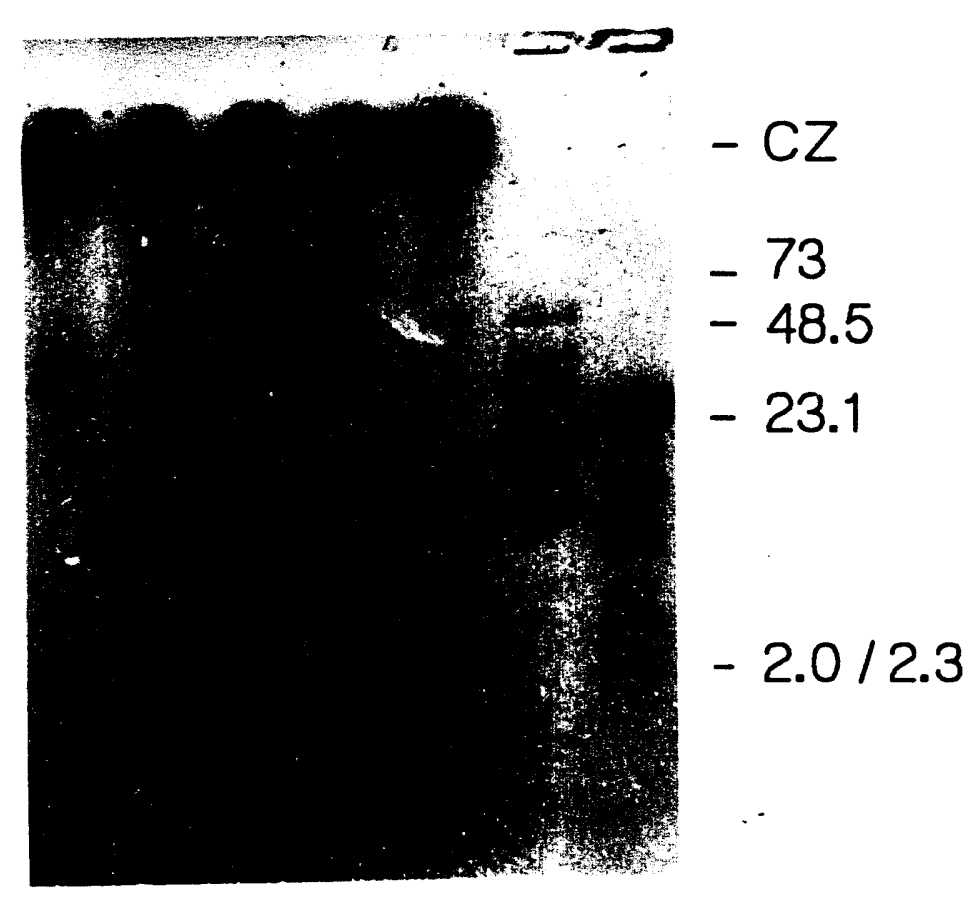


Figure 7. (Continued) 
1.5 hours

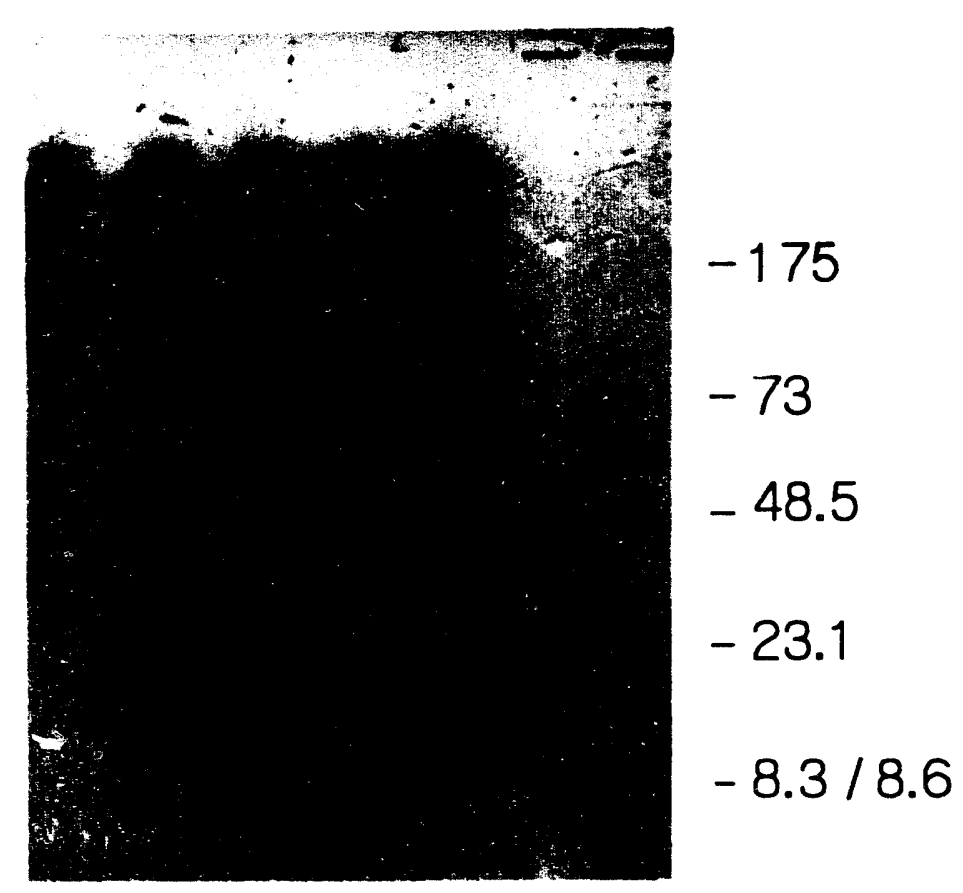

2.0 hours

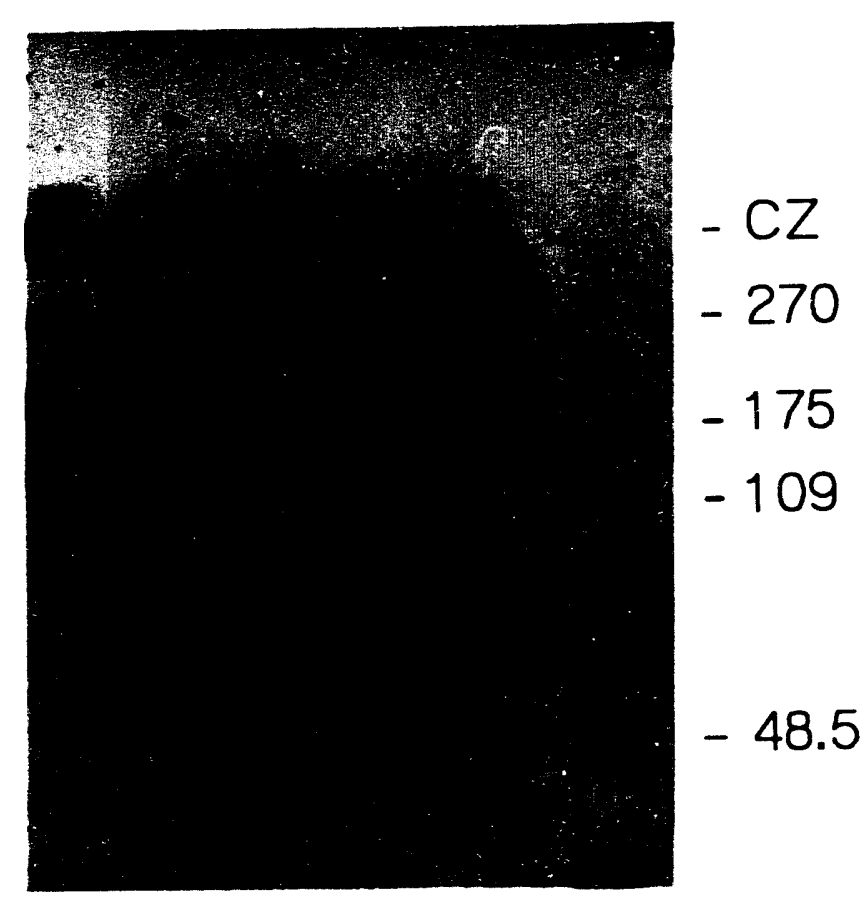




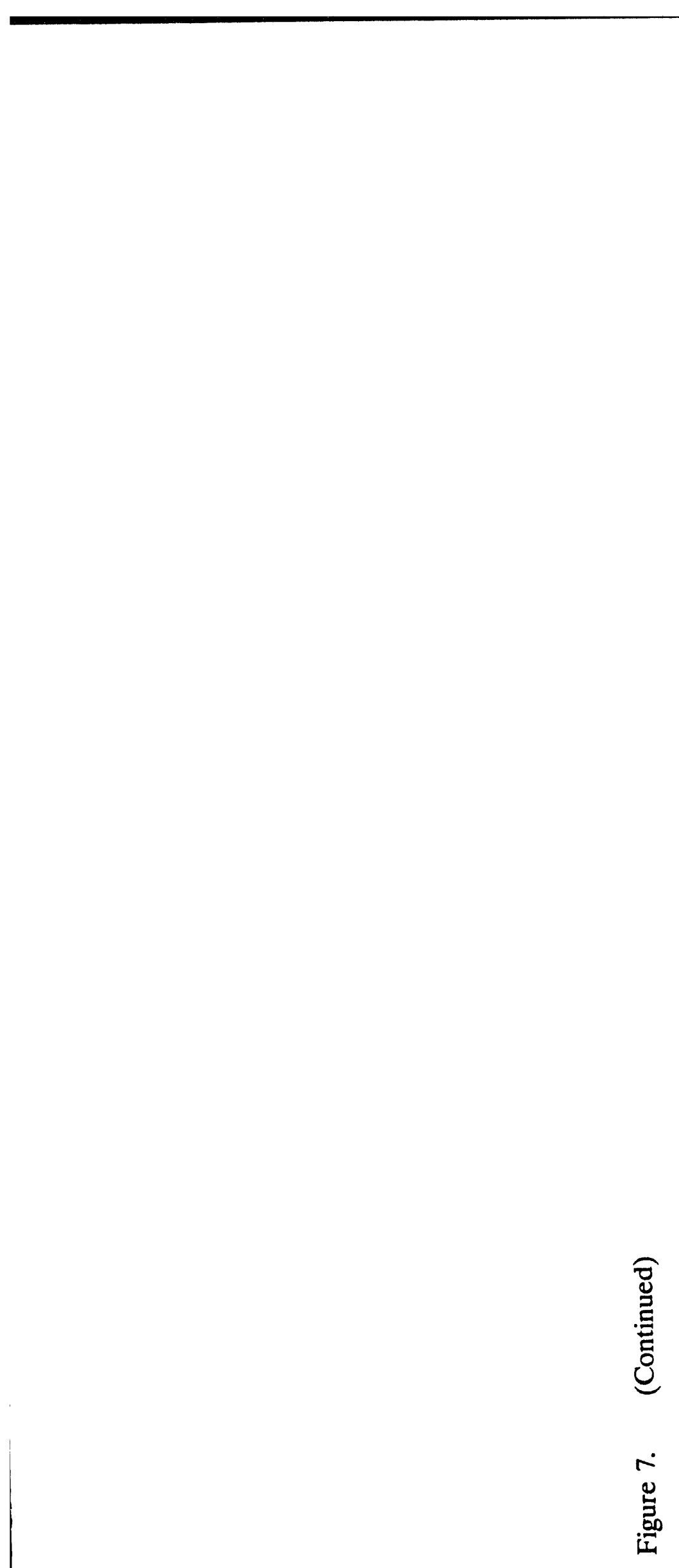


2.5 hours

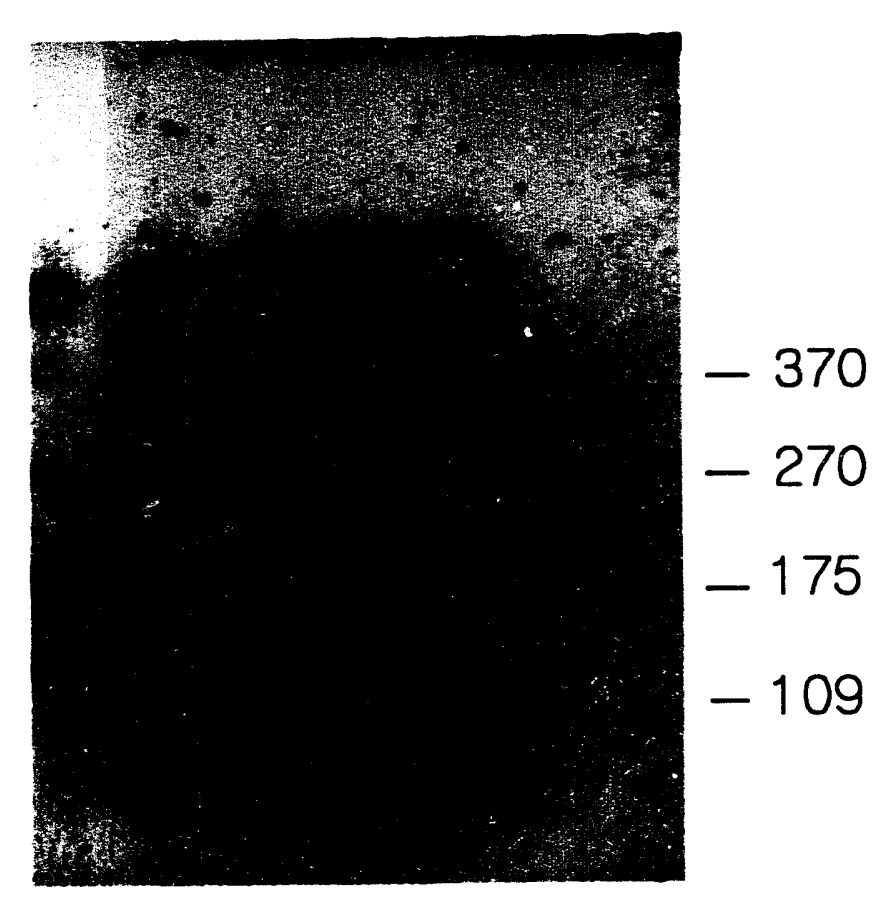

3.0 hours

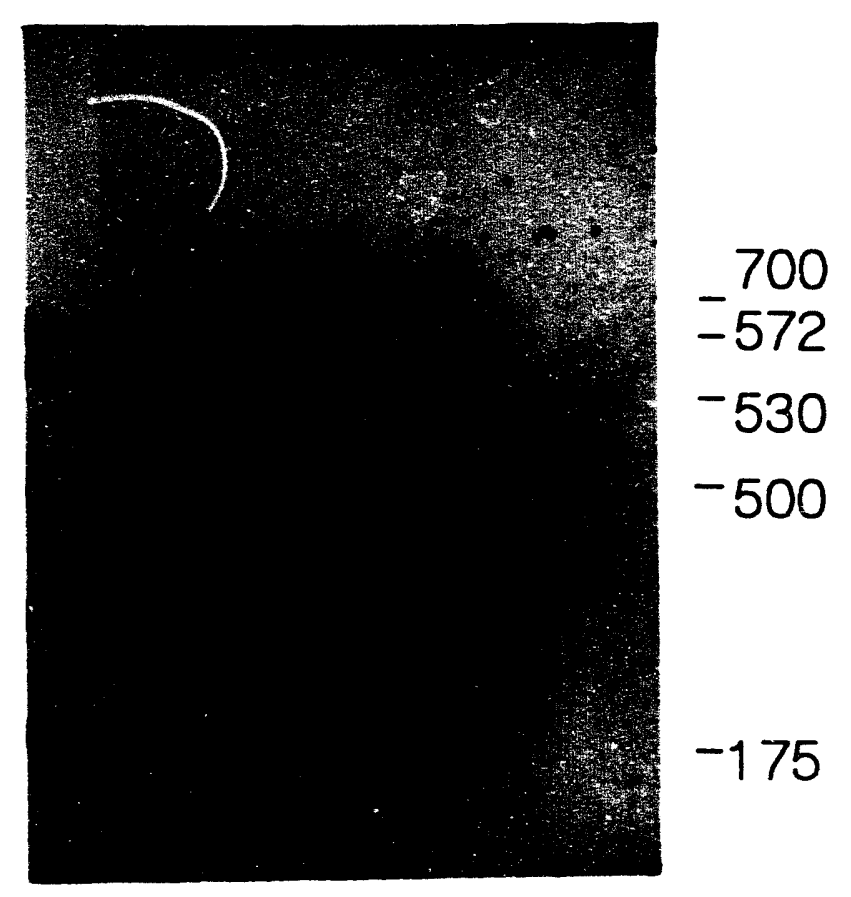


resulted in several doublets from 48 to $175 \mathrm{~kb}$ in the $S$. aureus/CspI digest. This is at least three more sets of doublets than previously noted by Promega (22) and six more than by Pattee. Currently, there is no explanation for these doublets. A size calibration was performed for this set of fragments based on the published values, as shown in Figure 8. The important feature is the size separation within the sets of doublets rather than their absolute sizes or the percentage separation. This separation is not constant. So, size calibration indicates that they are not ligation of several bands due to the presence of small fragments. The extra bands would indicate an increase in the original chromosomal DNA size calculation from 3.1 $\mathrm{Mb}$ to $3.5 \mathrm{Mb}$. These extra bands including a band at $500 \mathrm{bp}$ were discovered due to the increased resolution in our separation. This shows the need for higher resolution for resolving bands throughout the separation. The separation performed here shows separation from $2.3 \mathrm{~kb}$ to $750 \mathrm{~kb}$. A similar separation of the $S$. aureus was performed with two constant pulse times, each of which took 15 hours each to complete (23). This still only separates the region from $48 \mathrm{~kb}$ to 750 $\mathrm{kb}$. The $6 \mathrm{~s}$ pulse only separated the lower size ( 48 to $242 \mathrm{~kb}$ ) and the $20 \mathrm{~s}$ pulse only separated the higher series (242 to $700 \mathrm{~kb}$ ). This research constitutes a decrease in separation time of at least one order of magnitude, even including the separation of fragments below $48 \mathrm{~kb}$. Actually, the $560 \mathrm{bp}$ fragment from HindIII is also completely separated from the others. The absorption signal there is much lower and the contrast was insufficient for visualization. 
Figure 8. Graph of $\log$ DNA sizes vs. $\log$ mobility of the doublets encountered in the separation of $S$. aureus/CspI. Note the differences ranging from $16 \mathrm{~kb}$ to $3.6 \mathrm{~kb}$ indicating that ligation of fragments is not likely. Fragments at 255 and $136 \mathrm{~kb}$ are from another digest in the separation and are used strictly to extend the calibration. Other conditions: $12 \mathrm{~V} / \mathrm{cm}, 30^{\circ} \mathrm{C}, 0.5 \%$ agarose, $10 \mathrm{mM}$ TPE buffer, 16 frames averaged. 


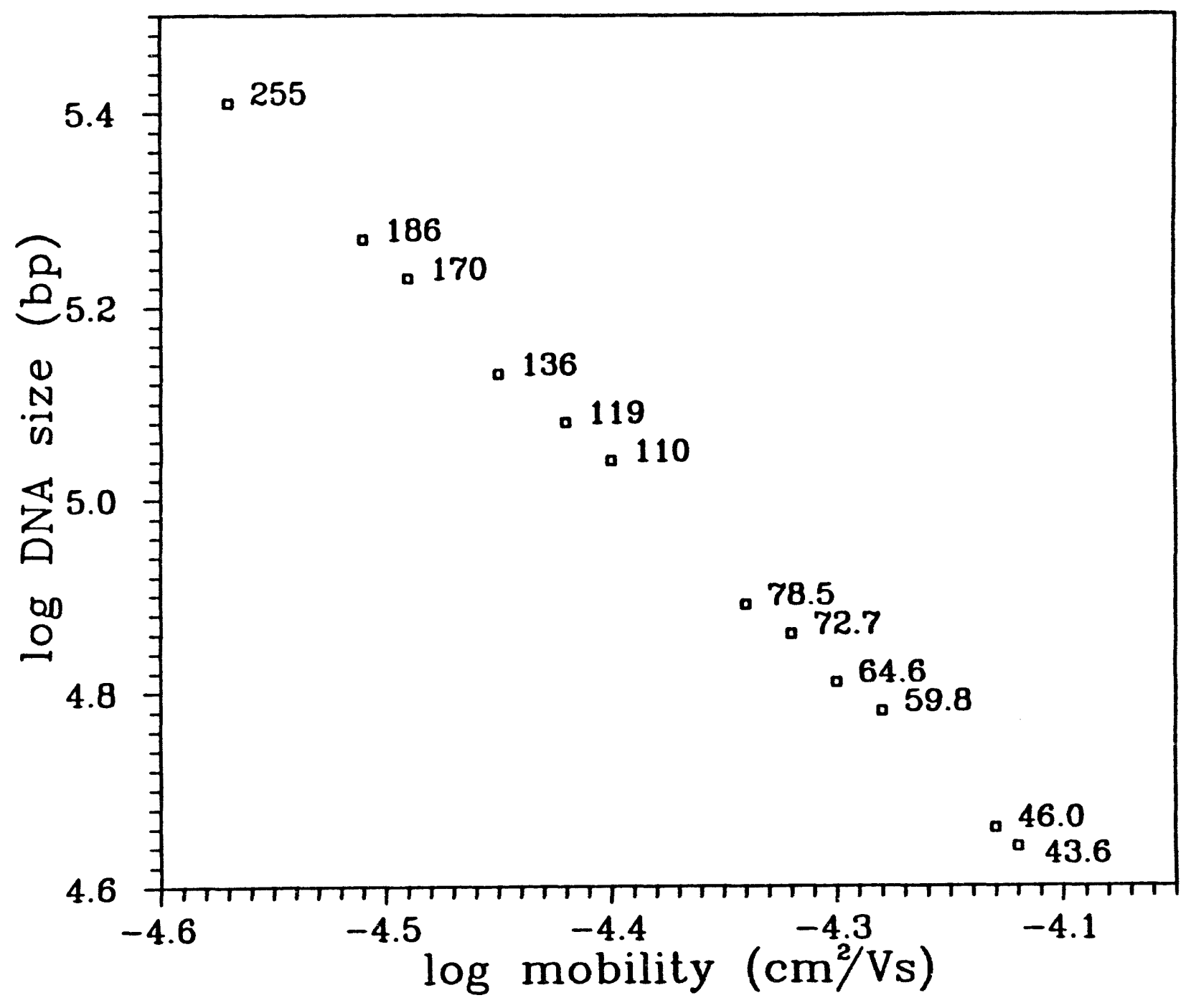




\section{Other Considerations}

The DNA fragment is left in its native state after separation which means that specific site tagging and hybridization can proceed without further manipulation. The fact that no ethidium bromide, an intercalating dye which is mutagenic, or radioisotope labeling, which is a radiation hazard, is used to visualize the fragments has benefits because health risks are reduced. The DNA here can be isolated and further amplified by cloning or further fragmented (digested) or sequenced for higher resolution of its structure. Also, since tagging is not required, the migration rates are more reliable for estimating fragments sizes.

The three-hour separation was achieved by monitoring every half hour and deciding on the next pulse time. Obviously if higher resolution were desired the monitoring and decision intervals could be decreased. The 3-minute data acquisition time is dictated by the lamp intensity and the present lamp and camera placement. A higher illumination intensity will shorten the exposure time without causing damage to the DNA. A closer placement of the camera will be even better, since the collection efficiency will increase.

These separations were performed on a $7-\mathrm{cm}$ gel. This is considerably shorter than most PFGE separation gels. Obviously the gel could hold many more fragments if the gel were twice as long. However, the size information is already contained in the early images for the smaller fragments. There was no need to retain those fragments on the gel. Short gels are advantageous because of the ease 
of casting, lower voltages required, and less dissipated power for the cooling system to handle. Extraction of the DNA from the gel could be accomplished by collecting at the edge of the gel in real time without affecting the separation in progress.

Quantitation of this detection scheme has been demonstrated previously by Chan et al. (13). Due to photon counting and two dimensional ability of the CCD, it is possible to add up the entire absorbance of the band of DNA in question. It is then possible to accurately quantify the fragments in question. By this same capability, it would be possible to determine whether there is more than one band unresolved in the separation. When a certain amount of DNA is fragmented, smaller fragments will have a smaller mass, and will have a linear dependence of integrated absorbance versus fragment size. Quantitation has not been pursued in this paper due to the non-quantitative nature of the slipplied chromosomal samples. The current limit of detection for this system is around 2 ng DNA which is typical of PFGE studies. Detection limits for conventional forms of detection can be substantially lower, 10 to 100 's of pg for ethidium bromide staining and $\mathrm{fg}$ to low pg for radioisotope labeling. These detection limits are dependent on exposure times for their limits, which are $30 \mathrm{~s}$ to 30 minutes for ethidium bromide staining and hours to days exposure for radioisotope labeling. Exposure of photographic film also makes it difficult to quantitate over a large weight range. The quantity of DNA loaded on the gels in this experiment are typical amounts 
that are used in electrophoresis. DNA amounts should not be a problem because the ability to clone eliminates the need for working with very small amounts of DNA (24). 


\section{CONCLUSION}

The separations demonstrated here show a large decrease ir c separation time. This can be advantageous to separations in this tec uiy... Tiere separations can take on the order of 100 hours to complete. Even if all the modifications are not desired (i.e., temperature, buffer, voltage, agarose), the fundamental idea of real time monitoring of the separation can eliminate the first run trial where the fragment sizes are unknown.

The discovery of more bands demonstrates the higher resolution of this system as well as the reduced time waiting for results. The use of this design will not be limited to the human genome project. It has been stated that if we are to better understand the human genon ust have an extensive database of DNA sequence from other species (25) (i.e., ....use, bacteria, yeast, etc.).

The DNA is left in its native state after separation and specific site tagging and hybridization can occur even without staining. If staining is still required it is still possible after the separation is achieved. The fact that no ethidium bromide, an intercalating dye which is mutagenic, or radioisotope labeling, which is a radiation hazard, is used to visualize the fragments has benefits because hazardous waste generation is reduced. The DNA can then be isolated and further amplified by cloning for further study or for fragmentation for higher resolution of the structure. 
The three hour separation was achieved with one analysis and was monitored every half hour. Obviously if more resolution were desired at a particular size range the pulse length could be more finely tuned or could be left at a desired pulse time for a longer time. These separations were performed on a 7 $\mathrm{cm}$ gel. This size gel is considerably smaller than those that are used in most PFGE separations. Obviously the gel could hold many more fragments if the gel were twice as long. Extraction of the DNA from the gel could be accomplished by monitoring its progress in the gel then cutting a portion of the gel away as it reaches the end of the slab, thereby extracting the isolated DNA fragment and still allowing the separation to continue.

Since the CHEF apparatus has an open horizontal configuration and the gel is unobstructed the ability to image the gel is good. This system, in conjunction with new algorithms that can straighten lanes and identify peaks, has the possibility of being automated (26).

Quantitation of this detection scheme has been demonstrated previously by Chan, et al. (13). Due to the photon counting and two dimensional ability of the CCD it is possible to add the entire absorbance of the band of DNA in question. It is then possible to accurately quantitate the fragments in question. By this same capability, it would be possible to determine whether there are more than one band unresolved in the separation. When certain amount of DNA is fragmented, smaller fragments will have a smaller mass, and will have a linear calibration of 
absorbance versus fragment size. Quantitation has not been pursued in this paper due to the non-quantitative nature of the supplied chromosomal samples although the current limit of detection for this system is around 2 ng DNA. DNA amounts should not be a problem because the ability to clone eliminates the need for analyzing very small amounts of DNA.

Rapid automated sequencing is becoming a reality. The ability to sequence in excess of $23,000 \mathrm{bp} / \mathrm{hr}$ is feasible. However, further evaluation and automation are still needed in labor intensive steps prior to sequencing. Our work shows that optimization and application of PFGE separations or zero integrated field electrophoresis (ZIFE) separations (27) can be speeded up substantially. Naturally, there is still much time spent preparing and isolating the chromosomal DNA. This remains a major bottleneck on the way to mapping the entire human genome. 


\section{CREDIT}

The Ames Laboratory is operated Iowa State University for the U. S.

Department of Energy under contract W-7405-Eng-82. This work was supported by the Director of Energy Research, Office of Health and Environmental Research. 


\section{LITERATURE CITED}

1. Andrew, L.; Olson, M. V. Genetics 1991, 127 681-698.

2. Jordan, E. Anal. Chem. 1991, 637, 420A-423A.

3. Drossman, H.; Luckey, J. A.; Kostichka, A. J.; D’Cunha, J.; Smith, L. M. Anal. Chem. 1990, 62, 900-903.

4. Schwartz, D. C.; Cantor, C. R. Cell, 1984, 37, 67-75.

5. Schwartz, D. C. In New Directions in Electrophoretic Methods; Jorgenson, J. W.; Phillips, M., Eds.; ACS Symposium Series 335; American Chemical Society; Washington DC, 1987; pp 167-181.

6. Lai, E.; Birren, B. W.; Clark, S. M.; Simon, M. I.; Hood, L. BioTechniques $19897(1), 34-42$.

7. Chu, G.; Vollrath, D.; Davis, R. W. Science 1986, 234, 1582-1585.

8. Lalande, M.; Noolandi, J.; Turmel, C.; Rousseau, J.; Slater, G. W. Proc. Natl. Acad. Sci. U.S.A 1987, 84, 8011-8015.

9. Viovy, J. L. Biopolymers 1987, 26, 1929-1940.

10. Deutsch, J. M. Science 1988 240, 922-924.

11. Olson, M. V.J. Chromatogr. 1989, 470, 377-383.

12. de la Cruz, M. O.; Gersappe, D.; Schaffer, E. O. Phys. Rev. Lett. 1990, 64, 2324-2327. 
13. Chan, K. C.; Koutny, L. B.; Yeung, E. S. Anal. Chem. 1991, 63, 746-750.

14. Chu, G.; Vollrath, D.; Davis, R., Stanford University Medical Center, personal communication.

15. Dawkins, H. J. S. J. Chromatogr. 1989, 492, 615-639.

16. Lewis, E. M.; Kouri, R. E.; Latorra, D.; Berka, K. M. Lee, H. C.;

Gaensslen, R. E. J. Forensic Sciences 1990, 35, 1186-1190.

17. Fritsch, E. F.; Maniatis, T. Molecular Cloning: A Laboratory Manual, 2nd Ed., Cold Spring Harbor Laboratory Press, New York NY, 1989, page B.23.

18. Woolley, P. Electrophoresis 1987, 8, 339-345.

19. Noolandi, J.; Rousseau, J.; Slater, G. W.; Turmel, C.; Lalande, M. Phys. Rev. Lett. 1987, 58, 2428-2431.

20. Ulanovsky, L.; Drouin, G.; Gilbert, W. Nature 1990, 343, 190-192.

21. Pattee, P. A. Genetic Maps 1990, 5, 2.22-2.27.

22. Hung, L. C., Bandziulis, R. Promega Notes 1990, 24, 1-3.

23. Pattee, P. A. In The Bacterial Chromosome; Drilica, K.; Riley, M., Eds., John Wiley and Sons; New York NY, 1990; pp. 163-169.

24. Burke, D. T. Genet. Anal. Techn. Appl. 1990, 7(5), 94-99.

25. U.S. Department of Health and Human Services and U.S. Department of Energy, "Understanding Our Genetic Inheritance; The U. S. Human Genome Project: The First Five Years FY 1991-1995”, DOE/ER-0452P, April 1990. 
26. Koutny, L. B., Yeung, E. S., Anal. Chem., 1993, 65, 148-152.

27. Noolandi, J. Makromol. Chem., Rapid Commun. 1991, 12, 31-35. 
PAPER II. OPTIMIZATION OF CAPILLARY ELECTROPHORETIC SEPARATION OF DNA FRAGMENTS BASED ON POLYMER FILLED CAPILLARIES 


\section{OPTIMIZATION OF CAPILLARY ELECTROPHORETIC SEPARATION OF DNA FRAGMENTS BASED ON POLYMER FILLED CAPILLARIES}

David A. McGregor and Edward S. Yeung Ames Laboratory-USDOE and Department of Chemistry Iowa State University, Ames, IA 50011

Reprinted with permission from Journal of Chromatography, in press. Unpublished work copyright 1993 Elsevier Publishing. 


\begin{abstract}
The separation of $\Phi \mathrm{X} 174 \mathrm{RF}$ DNA-HaeIII fragments is studied in a $0.5 \%$ methyl cellulose polymer solution as a function of temperature and applied voltage. The migration times decreased with both increasing temperature and increasing field strength, as expected. However, the relative migration rates of the fragments (selectivity) did not change with temperature but are affected by the applied field. A clear transition from the Ogston mechanism to the reptation mechanism is observed. Conditions were established for the separation of the $271 / 281 \mathrm{bp}$ fragments, even without the addition of intercalating agents. At $700 \mathrm{~V} / \mathrm{cm}$ and $20^{\circ} \mathrm{C}$, complete separation of all fragments is achieved in less than 4 minutes with an average plate number of 2.5 million per meter.
\end{abstract}




\section{INTRODUCTION}

The identification and codification of the human genome is a continuing worldwide scientific goal. A committee for The Human Genome Initiative has proposed a 15 year time table for the completion of the human genome project (1). To ultimately achieve this goal, critical reevaluation of current separation techniques must be done to substantially increase the speed, reliability, and sensitivity in gene mapping and in DNA sequencing applications. For example, to identify the $3 \times 10^{9}$ base pairs (bp) of the human genome would require sequencing individual bases, even at a rate of $23,000 \mathrm{bp} / \mathrm{hr}$, for the next 15 years. However, completion of this task will aid us in better understanding and possibly treating the more than 4000 genetic disorders that afflict humankind (2). Although this daunting task appears impossible, great strides have been made recently.

Slab gel separation of deoxyribonucleic acid (DNA) has been the standard technology for many years, but tends to be very time consuming $(3,4)$. More recently, the union of DNA separations and high performance capillary electrophoresis (HPCE) have been achieved for separations of DNA fragments under $\sim 12$ kilobase pairs (kb) (5). The principal advantages of HPCE in DNA separation have been increased efficiencies, shortened separation times, and reduced amounts of sample needed. Separation of DNA in HPCE has been ongoing for several years. In many cases, existing slab-gel methodology was adapted to the relatively 
new technique of HPCE. Examples include filling capillaries with a proven separation medium such as agarose $(6,7)$ or cross-linked polyacrylamide $(5,8,9)$. A leading advantage of HPCE is the decrease in joule heating of the separation medium, which allows for increased voltages and consequently decreasing separation times. This combination also offers improved results over slab gels such as separation efficiency.

Problems exist in filling the capillary with the traditional separation media. When an immobilized separation medium such as agarose or cross-linked polyacrylamide is introduced into the capillary, care must be exercised to maintain the integrity of the gel. Formation of polyacrylamide inside a capillary is very difficult and careful polymerization must be achieved. Otherwise voids in the gel will occur anci the capillary will be useless. Instead of using an immobilized matrix in capillaries, polymer networks can be used. These include liquified agarose $(6,7$, 10), non-cross-linked (linear) polyacrylamide (5, 11-13), and viscous polymers (1418). These polymers can emulate the sieving effect of the fixed matrix and similar separations can be achieved. The ability to replenish the medium with fresh polymer or to vary the concentration of the polymer is a definite advantage over immobilized gels.

We will describe here optimization of electrophoretic separations in methyl cellulose solutions as an alternative to immobilized gels. With this simple polymer matrix in solution, less current is drawn and higher velocities can be achieved along 
with the capability of achieving extremely high resolution in a relatively short column. This results in drastically reduced separation times. Viscous polymers such as hydroxypropylmethyl cellulose $(14,17,18)$, hydroxyethyl cellulose (16), polyethylene glycol (14) and methyl cellulose (15) have been applied to DNA separations before. In this work, the influence of temperature and field strength on the separation of DNA fragments from 72 to 1353 bp derived from $\Phi$ X174RF DNA-HaeIII based on methyl cellulose solutions is examined. Comparisons with the behavior in linear polyacrylamide solutions $(12,13)$ will be made. 


\section{EXPERIMENTAL SECTION}

\section{Materials}

$\Phi$ X174RF DNA-HaeIII digest from United States Biochemica' (Cleveland, $\mathrm{OH}, \mathrm{USA}$ ) was diluted to $250 \mathrm{ng} / \mu \mathrm{L}$. The buffer consisted of tris[hydroxymethyl]aminomethane (THAM), boric acid, and ethylenediaminetetraacetic acid (EDTA), all from Sigma Chemical (St. Louis, MO, USA). The polymer was methyl cellulose 4000 (Sigma Chemical) which has a viscosity rating of 4000 centipoise for a $2 \%$ solution at $25^{\circ} \mathrm{C}$.

\section{Apparatus}

$50 \mu \mathrm{m}$ i.d., $360 \mu \mathrm{m}$ o.d. DB-1 coated GC Capillary (J \& W Scientific, Folsom, CA, USA) with $0.2 \mu \mathrm{m}$ coating thickness was used without any Surther modification. The capillary length was $43 \mathrm{~cm}$ total, $35 \mathrm{~cm}$ effective length. A SpectraPHORESIS 1000 system (Spectra Physics, Fremont, CA, USA) was used for all separations in the constant voltage mode. Temperature control to $\pm 0.1^{\circ} \mathrm{C}$ was achieved by the peltier cooling system of the SpectraPHORESIS-1000. Electrokinetic injection was used throughout at $1 \mathrm{~s}$ at $200 \mathrm{~V} / \mathrm{cm}$. The nucleic acids were detected at $260 \mathrm{~nm}$. Because of the small width of the peaks, the time constant was set to zero on the CE instrument to prevent any biasing of peak shapes. 


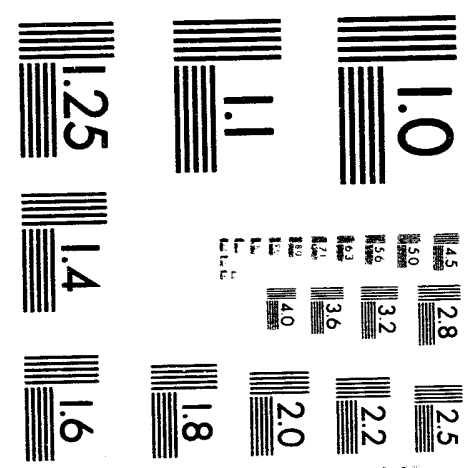



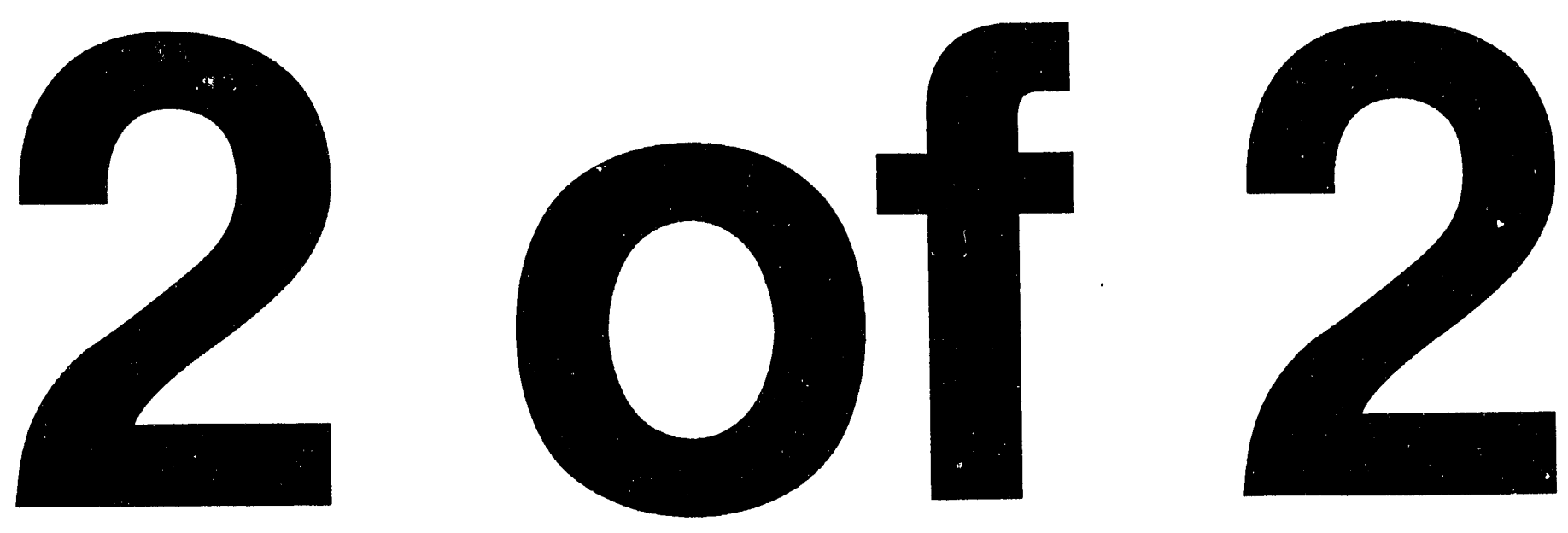


\section{Methods}

The buffer solution contained equimolar amounts (100 mM each) of THAM and boric acid, both as the free base and acid respectively, with EDTA added as a chelating agent for divalent cations that could activate DNAases. The $\mathrm{pH}$ of the solution at the $202 \mathrm{mM}$ TBE (THAM, boric acid, EDTA) was 8.2 and was not further adjusted. $19.90 \mathrm{mLs}$ of buffer was mixed with $0.5 \% \mathrm{w} / \mathrm{w}$ of methyl cellulose $(0.10 \mathrm{~g})$ and sonicated for 15 minutes. When the methyl cellulose appeared thoroughly wetted, the solution was stirred until it appeared homogeneous. To further clarify the solution, the stirring was continued on ice for at least 15 minutes. This caused the solution to appear transparent, leaving only small methyl cellulose needles in solution. Filtration was performed by passing the cooled solution through a $0.8 \mu \mathrm{m}$ cellulose acetate filter (Alltech, Deerfield, IL, USA) and the solution was stored at $4^{\circ} \mathrm{C}$ until used.

Once the capillary was pressure filled, it was allowed to equilibrate at running voltages for 5 minutes. The polymer did not degrade significantly over 30 to 40 runs and could be easily refilled once separation times started to change significantly. The current of the buffer was measured with and without the methyl cellulose additive and there was roughly a $3 \%$ decrease in current with the addition of the matrix throughout the temperature range. The TBE buffer is the cause for most of the current drawn through the capillary. The addition of the polymer to 
the buffer solution apparently did not significantly increase or decrease the current. Column lifetimes were in excess of 100 injections. The detection limit for the SpectraPHORESIS 1000 instrument used in this experiment was 17 pg at $260 \mathrm{~nm}$ UV absorption. 


\section{RESULTS AND DISCUSSION}

In Figures 1 through 3, we show the separation of DNA fragments at various temperatures and at various electric field strengths. It is clear that there are differences in migration times, efficiencies, and resolution between pairs of fragments. Several important observations can be made.

First, it appears that the triplet of fragments from 271 to 310 base pairs are moving in a certain pattern, more specifically that the $281 \mathrm{bp}$ fragment is moving from near the $271 \mathrm{bp}$ fragment to the $310 \mathrm{bp}$ fragment. This is not actually the case. What is occurring is the larger series of fragments from 310 to $1353 \mathrm{bp}$ is encroaching on the smaller fragments. This can be demonstrated by graphing the resolution of neighboring fragments (Figure 4). Note that the resolution does not change significantly at the $271 / 281$ resolution, but does change at the next neighbors.

Second, the migration times dtcrease with increasing temperature in each

case. This is consistent with published results in linear polyacrylamide gel systems (12), where the viscosity of the gel-buffer system decreases with temperature. In that study, the migration times decreased roughly by a factor of 2 over a $20^{\circ}$ temperature range. Here, we observe a factor of 1.3 decrease over the same temperature range. In effect, the activation energy for viscous flow is smaller in methyl cellulose by a factor of 0.65 (12). Figure 5 shows the temperature 
Figure 1. Separation of $\Phi$ X174RF DNA-HaeIII fragments at various field strengths. Conditions: $202 \mathrm{mM}$ TBE buffer, $0.5 \%$ methyl cellulose $4000,45 \mathrm{~cm} \mathrm{~L}, 35 \mathrm{~cm} \mathrm{l,} 50 \mu \mathrm{m}$ i.d. DB-1 coated capillary, all electropherograms are at $10^{\circ} \mathrm{C}$. 


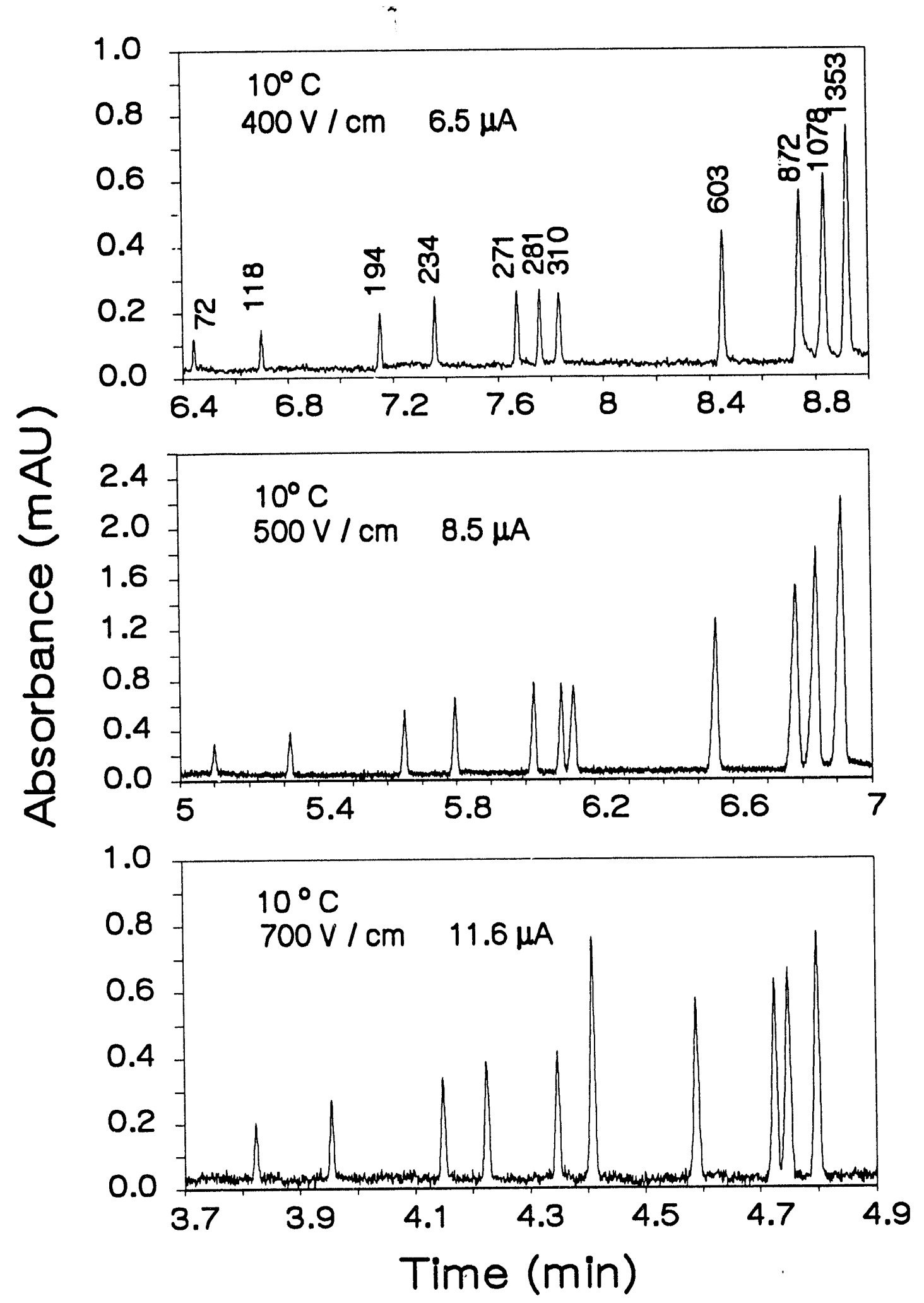


9.5

Figure 2. Separation of $\Phi$ X174RF DNA-HaeIII fragments at various field strengths. Conditions as in Figure 1 except all electropherograms are at $20^{\circ} \mathrm{C}$. 

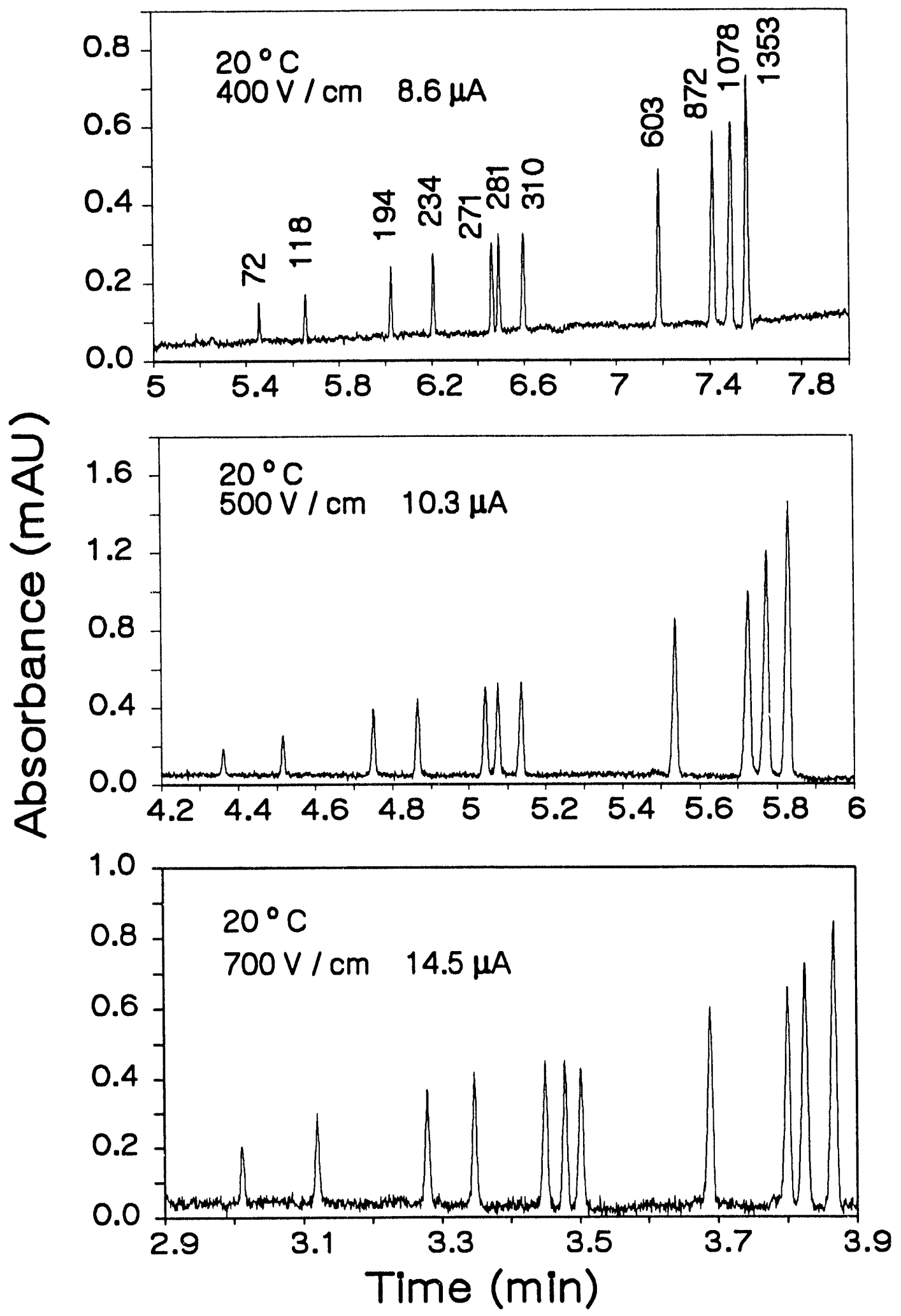
Figure 3. Separation of $\Phi$ X174RF DNA-HaeIII fragments at various field strengths. Conditions as in Figure 1 except all electropherograms are at $40^{\circ} \mathrm{C}$. 

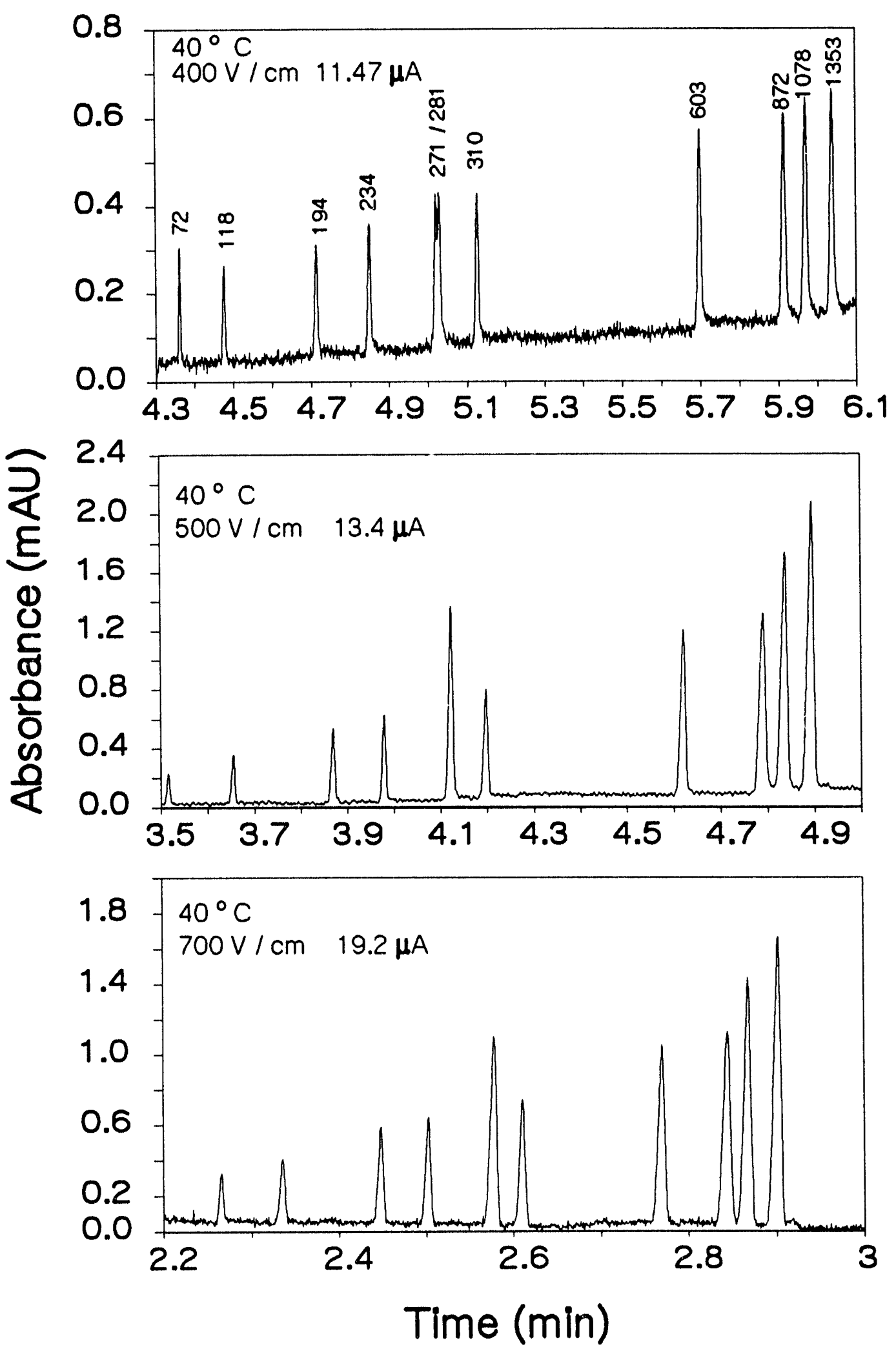
99

Figure 4. Resolution of DNA fragments at a) $10^{\circ} \mathrm{C}$, b) $20^{\circ} \mathrm{C}$, c) $40^{\circ} \mathrm{C}$. 400 $\mathrm{V} / \mathrm{cm}(17.2 \mathrm{kV})(\Delta), 500 \mathrm{~V} / \mathrm{cm}(21.5 \mathrm{kV})(0), 700 \mathrm{~V} / \mathrm{cm}(30.0 \mathrm{kV})$ (ㅁ). 

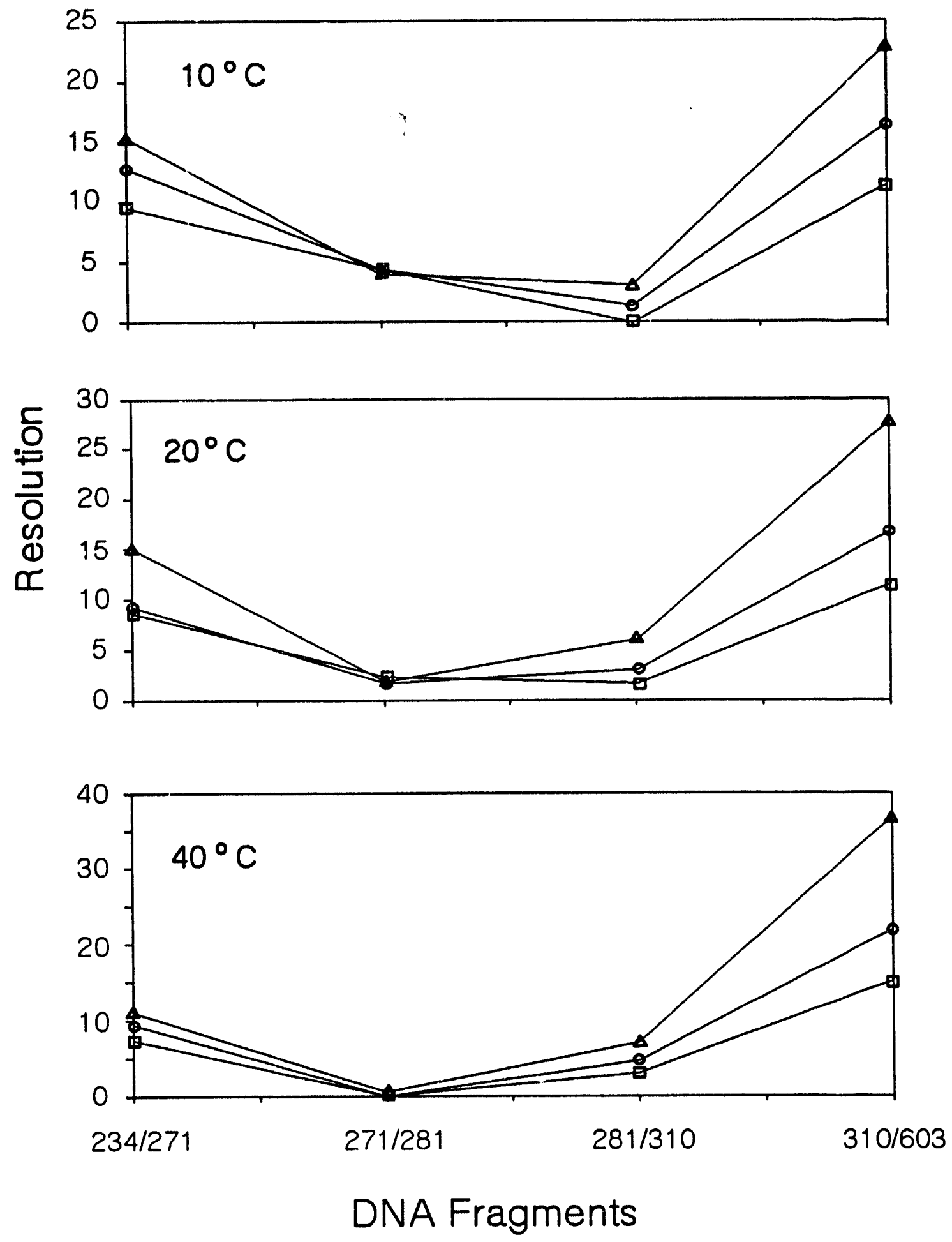
101

Figure 5. Mobilities versus DNA fragment size at various temperatures. a) 400 $\mathrm{V} / \mathrm{cm}, \mathrm{b}) 500 \mathrm{~V} / \mathrm{cm}, \mathrm{c}) 700 \mathrm{~V} / \mathrm{cm} .10^{\circ} \mathrm{C}(\Delta), 20^{\circ} \mathrm{C}(\bullet), 40^{\circ} \mathrm{C}(\boldsymbol{\square})$. 
(sı!ed əseq) $\forall N O$

00t। $0021 \quad 0001 \quad 008 \quad 009 \quad 00 t \quad 002 \quad 0$

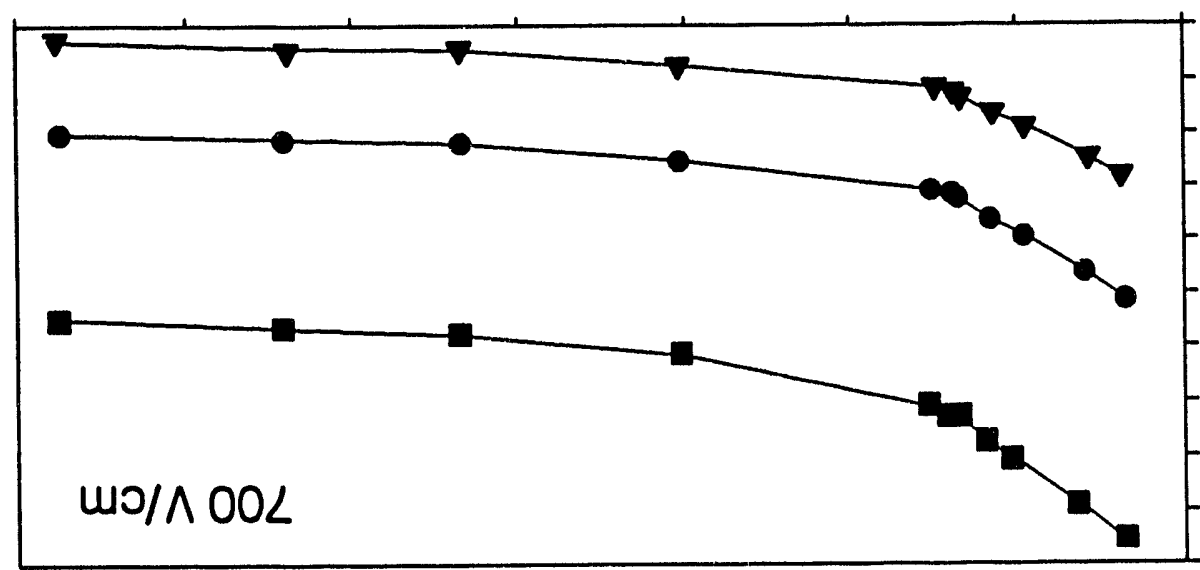

8. 1

$2 \cdot 2$

$9 \cdot 2$

$0^{\circ} \varepsilon$

เ $\varepsilon$

$8^{\circ} \varepsilon$

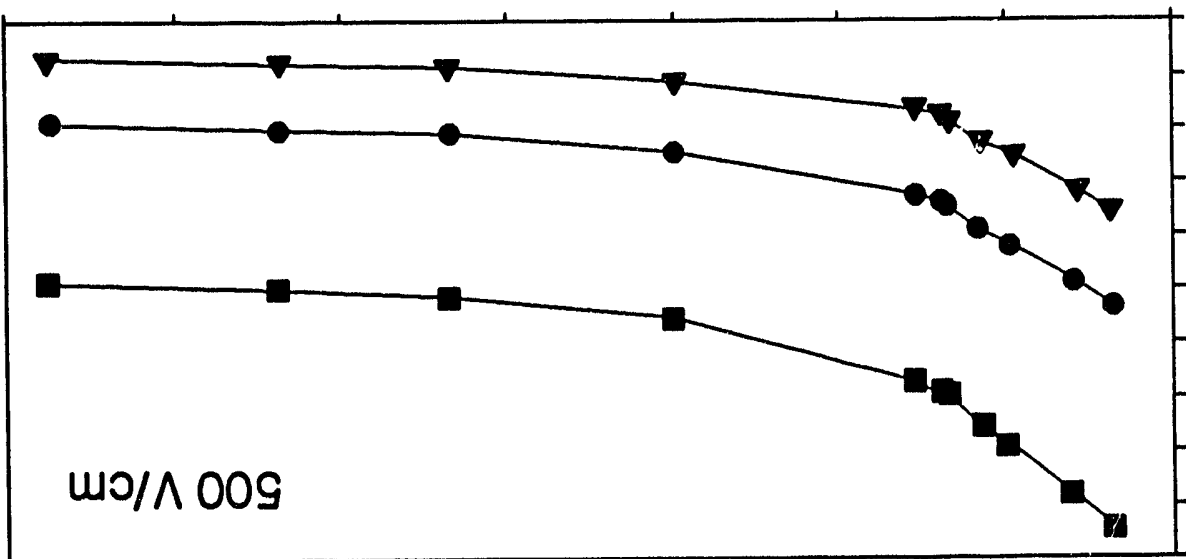

$9^{\circ} 1$

$0.2 F$

$x$

$\overrightarrow{0}$

8.2

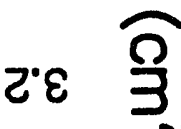

$\theta^{\circ} \sum \stackrel{N}{<}$

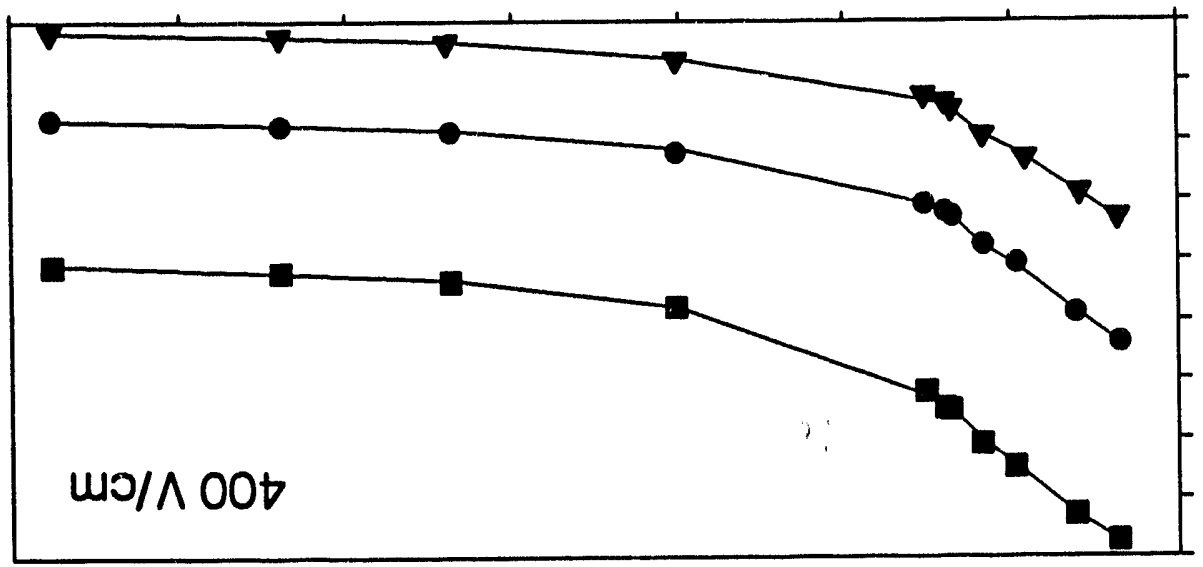

co 
dependence of mobilities of the DNA fragments at fixed field strengths. At first thought, as temperature is varied, the viscosity changes and the average pore size would change as well. As the average pore size is increased, the larger fragments would pass through the matrix more easily and the separation would change dramatically. This is not the case as can be demonstrated by the temperature studies. For comparisons, the mobilities are normalized to that of the smallest (72 bp) fragment (Figure 6). Overall, the relative mobilities show little temperature dependence, indicating that there is negligible change in the effective pore size of the polymer matrix (19) and that the DNA conformation did not change over this temperature range.

Third, the separation efficiencies generally decrease with increasing fragment size, increasing temperature, and increasing electric field strength, as shown in Table I. The peak widths should have negligible contributions from the injection process, since both the injection times and the injection voltages are lower than the separation parameters. At higher temperatures and at higher applied fields, the half-width of the bands actually decreased for a given DNA fragment, but the shorter migration times in each case led to lower numbers of theoretical plates. The concept of theoretical plates strictly should be modified since the migration times past the detector are not constant. A closer examination reveals that the physical lengths of the zones on column are insensitive to the temperature or the electric field strength. This means that one can in general shorten the 
104

Figure 6. Normalized mobilities versus DNA size for (a) $400 \mathrm{~V} / \mathrm{cm}$, (b) 500 $\mathrm{V} / \mathrm{cm},(\mathrm{c}) 700 \mathrm{~V} / \mathrm{cm}$ at various temperatures. $10^{\circ} \mathrm{C}(\Delta), 20^{\circ} \mathrm{C}(\bullet)$, and $40^{\circ} \mathrm{C}(\square)$. 

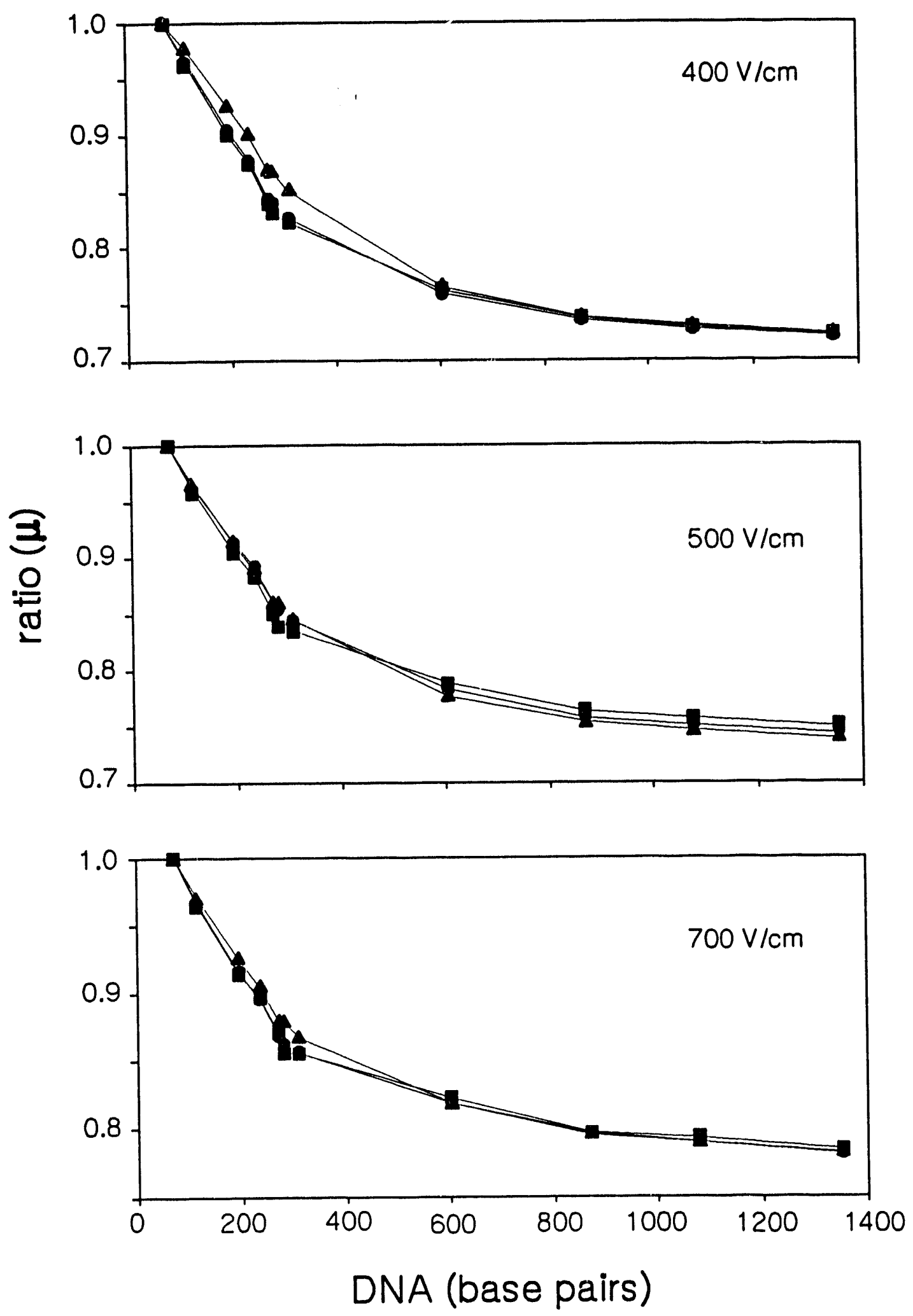
Table I. Separation Efficiencies (millions of theoretical plates) of DNA fragments under various conditions.

\begin{tabular}{l|lllllllll} 
& \multicolumn{3}{|c}{$10^{\circ} \mathrm{C}$} & & $20^{\circ} \mathrm{C}$ & \multicolumn{3}{c}{$40^{\circ} \mathrm{C}$} \\
\hline Size (bp) & $400 \mathrm{~V} / \mathrm{cm}$ & $500 \mathrm{~V} / \mathrm{cm}$ & $700 \mathrm{~V} / \mathrm{cm}$ & $400 \mathrm{~V} / \mathrm{cm}$ & $500 \mathrm{~V} / \mathrm{cm}$ & $700 \mathrm{~V} / \mathrm{cm}$ & $400 \mathrm{~V} / \mathrm{cm}$ & $500 \mathrm{~V} / \mathrm{cm}$ & $700 \mathrm{~V} / \mathrm{cm}$ \\
\hline 72 & 2.9 & 1.3 & 1.8 & 3.0 & 1.3 & 1.2 & 5.1 & 1.1 & 1.0 \\
118 & 2.6 & 2.3 & 1.5 & 2.0 & 1.2 & 1.4 & 2.1 & 1.1 & 1.0 \\
194 & 2.2 & 1.8 & 1.3 & 1.9 & 1.1 & 1.4 & 1.7 & 1.2 & 0.9 \\
234 & 2.3 & 1.9 & 1.5 & 2.3 & 1.1 & 1.4 & 1.8 & 1.2 & 1.3 \\
271 & 2.0 & 1.8 & 1.4 & 2.1 & 1.0 & 1.1 & 1.5 & 1.2 & 0.8 \\
281 & 2.2 & 1.7 & 1.2 & 2.7 & 1.1 & 1.2 & 2.3 & 1.2 & 0.8 \\
310 & 1.3 & 1.2 & 1.2 & 1.9 & 0.9 & 1.0 & 1.9 & 1.2 & 1.0 \\
603 & 1.6 & 1.4 & 1.4 & 1.8 & 0.7 & 1.0 & 1.9 & 1.0 & 1.0 \\
872 & 1.3 & 1.1 & 1.1 & 1.6 & 0.5 & 1.0 & 1.7 & 0.8 & 0.9 \\
1078 & 1.2 & 1.0 & 1.2 & 1.3 & 0.6 & 0.9 & 1.8 & 0.8 & 1.1 \\
1353 & 1.2 & 1.0 & 1.3 & 1.3 & 0.5 & 0.9 & 1.8 & 0.8 & 1.1 \\
\hline
\end{tabular}


running time by increasing the temperature or the field strength without introducing band broadening. Diffusional broadening of the DNA fragment bands should be minor based on the short residence times and the large molecular weights (sizes) involved. We can conclude that the primary contributor to the observed peak widths is a mismatch in the mobilities of the fragments compared to that of the buffer ions (20), leading to skewed, triangular peaks. This is consistent with the fact that the widths of the peaks for the larger fragments, even after correction for migration times, are larger than those for the smaller fragments. In these studies, we cannot decrease the injected amounts further because of the lack of detector sensitivity. Also, the buffer ionic strength cannot be increased if joule heating is to be avoided at these high field strengths.

Fourth, the migration times decrease as the applied field strength is increased. Mobilities are just a voltage gradient adjusted velocity value and should not change with applied voltage. But examining Figure 7 shows the equation is not entirely accurate when using DNA as the analyte. This phenomenon goes beyond the normal linear dependence of migration velocity on field strength, as is depicted in Figure 8. There, the mobilities of each series of fragments have been normalized to that of the $72 \mathrm{bp}$ fragment. The smaller fragments ( $<250 \mathrm{bp}$ ) show little dependence on field strength, a result that is similar to typical small-molecule separations in CE. The larger fragments clearly show a higher relative mobility with increased field strength. The explanation of this effect could be attributed to 


$$
108
$$

Figure 7. Mobilities versus DNA fragment size at various temperatures. a) $10^{\circ}$ C, b) $20^{\circ} \mathrm{C}$, c) $40^{\circ} \mathrm{C}$. (4) $400 \mathrm{~V} / \mathrm{cm},(\bullet) 500 \mathrm{~V} / \mathrm{cm},(匹) 700 \mathrm{~V} / \mathrm{cm}$. 

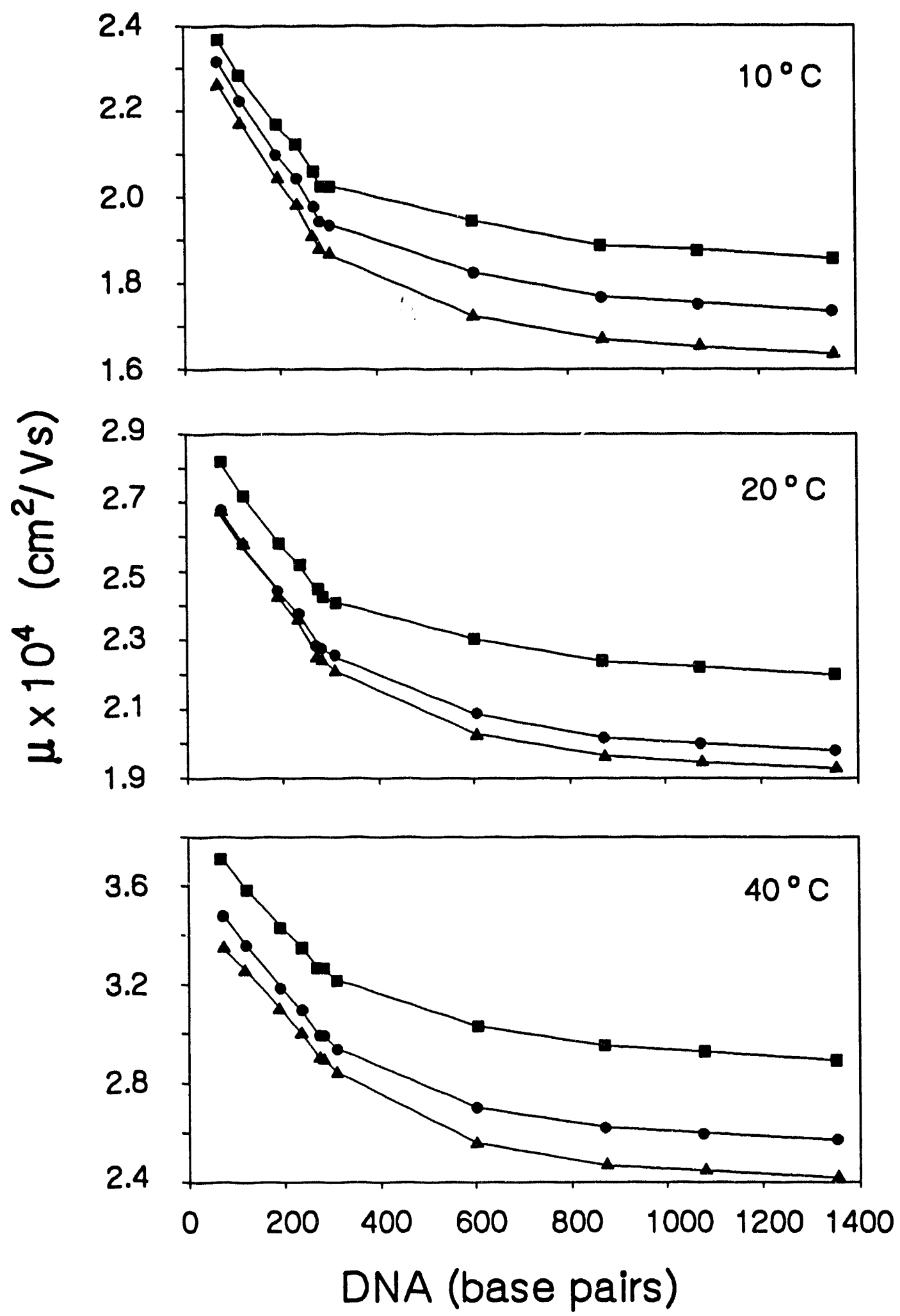
110

Figure 8. Normalized mobilities versus DNA size for (a) $10^{\circ} \mathrm{C}$, (b) $20^{\circ} \mathrm{C}$, and (c) $40^{\circ} \mathrm{C}$ at various field strengths. $400 \mathrm{~V} / \mathrm{cm}(\triangle), 500 \mathrm{~V} / \mathrm{cm},(\bullet)$ and $700 \mathrm{~V} / \mathrm{cm}(\mathbf{\square})$. 


\section{(sı!ed әseq) $\forall N O$}

00t1 $0021 \quad 0001 \quad 008 \quad 009 \quad 00 t \quad 002 \quad 0$
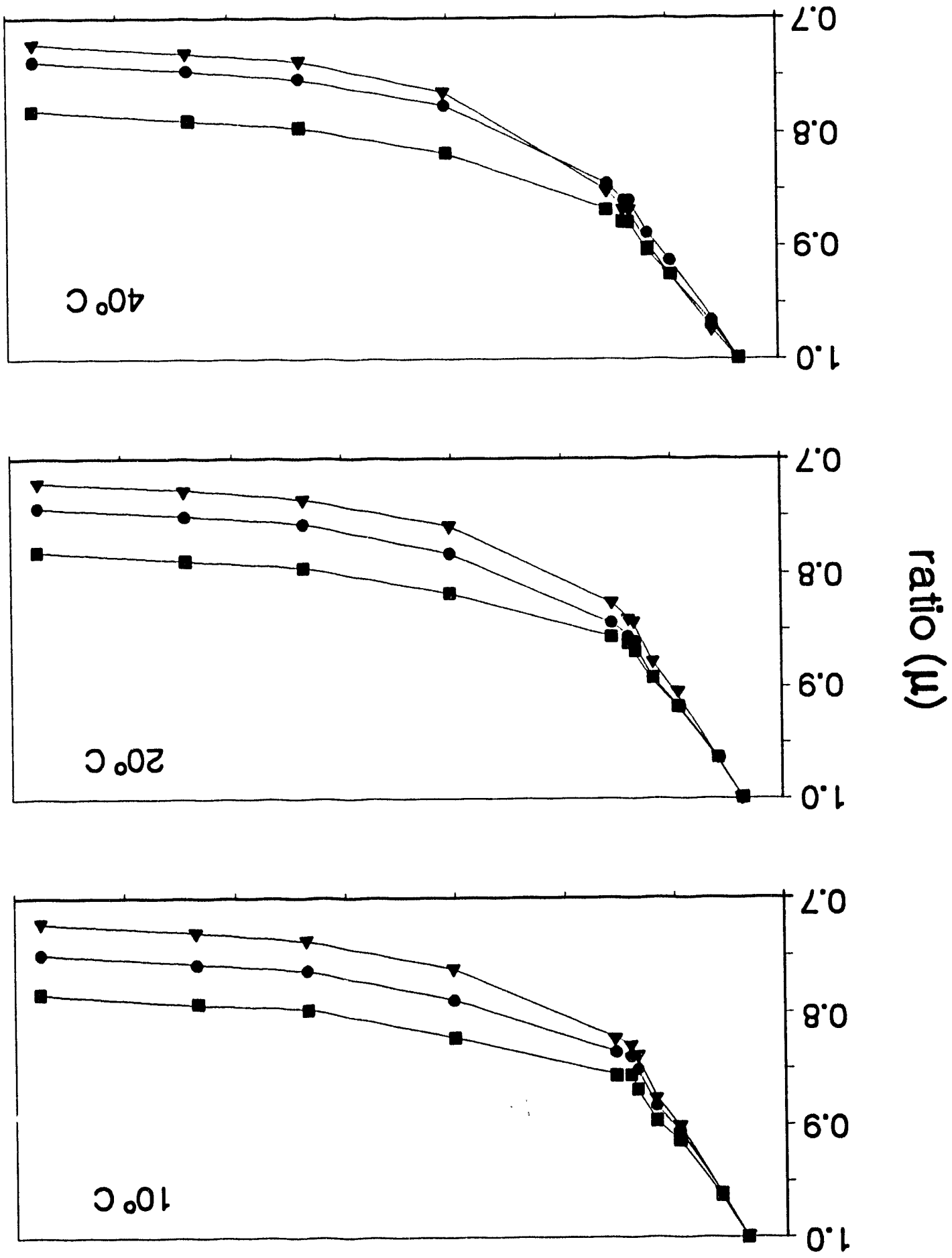
the mechanism which drives this separation. The Ogston or sieving mechanism which describes analyte through a porous medium states that the analyte can be viewed as a hard sphere and is immutable $(21,22)$. Since the porous medium is made up of a range of pore sizes, the smaller the analyte sphere, the more pores become available for the analyte to travel through, hence the 'sieving' effect. This explains the behavior of the smaller fragments. Obvi'susly, DNA is not a hard sphere but is more closely represented by a long chain. This is more pronounced for the larger ( $>250 \mathrm{bp}$ ) DNA fragments. When this happens the Ogston mechanism fails and another theory must be applied. The new mechanism will more closely resemble reptation that describes the DNA as snaking through a porous medium (22). This explains the plateau-like behavior for the larger fragments in Figures 6 and 8. When higher voltages are applied, the DNA is more stretched out parallel to the field that is applied. The plateaus therefore shift to larger values as the electric force per unit length of the molecule increases (22).

Fifth, we are able to resolve the $271 / 281$ pair of fragments under certain experimental conditions (see Figure 1-3), i.e. certain combinations of temperature and field strength. Such a separation is almost never achieved for a cellulose (14, 17) or agarose $(6,7)$ medium except if an intercalator such as ethidium bromide is used. This is in contrast to a linear polyacrylamide medium, where the native $271 / 281$ fragments are well separated $(5,11-13)$. A possible explanation is that polyacrylamide is formed with a wide distribution in pore sizes. This allows the 
small difference between the two fragments to affect separation. Cellulose solutions are generally of one viscosity rating and are not diverse enough to optimize separation in the $280 \mathrm{bp}$ range simultaneously with the larger and the smaller fragments. Fortunately, $280 \mathrm{bp}$ lies just about at the transition point between the sieving and the reptation mechanisms (Figures 1-3) for this polymer type, size and concentration. Since the applied field only affects the larger fragments, the migration of the 281 and larger fragments can be "tuned" to optimize their resolution from the 271 and smaller fragments. This then constitutes a systematic approach for enhancing the resolution of a narrow range of DNA fragments in polymer solutions.

Sixth, there are some differences in resolution between our results and those reported in the literature. High electric field strengths have been found to degrade the resolution between the larger DNA fragments in polyacrylamide gels $(5,13)$. Such is not the case in Figures 1-3, even though some of the runs are at very high fields $(700 \mathrm{~V} / \mathrm{cm})$. The degradation of resolution of the larger fragments at high fields is also not always observed in polyacrylamide gels (Figure 3 vs. Figure 8 in ref. 5). One can thus rule out field-induced DNA alignment as the cause, since alignment should be matrix independent. These results may indicate some inherent differences between cellulose versus polyacrylamide matrixes, such as the latter being less rugged at high fields.

Seventh, because of the very high fields used, the complete separation of all 
ФX174RF DNA-HaeIII fragments was accomplished in record time. The best result along these lines is for separation at $700 \mathrm{~V} / \mathrm{cm}$ and $20^{\circ} \mathrm{C}$, requiring less than 4 minutes. The number of theoretical plates averaged better than 1 million $(\sim 2.5$ million plates per meter). A direct comparison is given in Table II. Even higher plate numbers have been obtained for DNA sequencing runs $(23,24)$, but those involve run times of up to an hour. 
Table II. Separation of $\phi$ X174RF DNA-HaeIII fragments under different conditions ${ }^{a}$.

\begin{tabular}{lllcc} 
Reference & Medium & Conditions & Total time (min) & $\begin{array}{c}\text { Average plate } \\
\text { number (millions) }\end{array}$ \\
\hline This work & $0.5 \% \mathrm{MC}$ & $20^{\circ}, 700 \mathrm{~V} / \mathrm{cm}$ & 3.8 & 1.1 \\
13 & linear PA & $20^{\circ}, 400-100 \mathrm{~V} / \mathrm{cm}$ & 9.3 & 0.2 \\
5 & linear PA & $20^{\circ}, 300 \mathrm{~V} / \mathrm{cm}$ & 12 & $\mathrm{ND}$ \\
12 & linear PA & $40^{\circ}, 400 \mathrm{~V} / \mathrm{cm}$ & 14 & $\mathrm{ND}$ \\
11 & linear PA & $25^{\circ}, 250 \mathrm{~V} / \mathrm{cm}$ & 16 & 1.2 \\
5 & cross-linked PA & $20^{\circ}, 250 \mathrm{~V} / \mathrm{cm}$ & 16 & 2.0 \\
13 & linear PA & $20^{\circ}, 200 \mathrm{~V} / \mathrm{cm}$ & 27 & 0.2 \\
17 & $0.5 \%$ HPMC, EB & $25^{\circ}, 175 \mathrm{~V} / \mathrm{cm}$ & 32 & $\mathrm{ND}$ \\
14 & $0.5 \%$ HPMC, EB & $25^{\circ}, 175 \mathrm{~V} / \mathrm{cm}$ & 33 & 1.0 \\
\hline
\end{tabular}

a MC - methyl cellulose, PA - polyacrylamide, HPMC - hydroxypropylmethyl cellulose, EB - ethidium bromide, ND - not determined. 


\section{CONCLUSIONS}

Obviously, the separations are very fast and of high resolution, but of major concern in this experiment is the fact that the matrix is not an exceptionally well defined one. Although it is better than the polyacrylamide matrix, the wide range of polymer lengths quoted by the manufacturer leads to ambiguity in the separation mechanism. Although we have filtered the solutions prior to use, the biasing of the molecular weight range is still not as well defined as could be. Better defining the polymer weight range could lead to aavantages in separation of certain sizes of DNA. Grossman and Soane (14) have shown that as longer polymer lengths are used, larger DNA fragments will be preferentially separated.

In summary, we have demonstrated effective control of the separation of DNA fragments in a $0.5 \%$ methyl cellulose polymer solution. We expect this system to be a reasonable alternative to the use of linear polyacrylamide, particularly if one can further optimize the performance towards the higher mass range by suitable combinations of polymers of different specific viscosities and molecular weights (19). 


\section{ACKNOWLEDGEMENT}

The Ames Laboratory is operated for the U. S. Department of Energy by the Iowa State University under Contract No. W-7405-Eng-82. This work was supported by the Director of Energy Research, Office of Health and Environmental Research. 


\section{REFERENCES}

1. National Research Council Report of the Committee on Mapping and Sequencing the Human Genome, Board of Basic Biology, Commission on Life Sciences, National Academy Press, Washington, DC, 1988.

2. Joint U.S. Department of Energy and U.S. Department of Health and Human Services Report DOE/ER-0452P, “Understanding Our Genetic Inheritance-The U.S. Human Genome Project: The First Five Years", Washington, DC, April 1990.

3. F. M. Ausubel, R. Brent, R. E. Kingston, D. D. Moore, J. G. Seidman, J. A. Smith and K. Struhl (Editors), Short Protocols in Molecular Biology, John Wiley and Sons, New York, 1992.

4. J. Sambrook, E. F. Fritsch and T. Maniatis (Editors), Molecular Cloning: A Laboratory Manual, Cold Spring Harbor Press, Cold Spring Harbor, NY, 1989.

5. D. N. Heiger, A. S. Cohen and B. L. Karger, J. Chromatogr., 515 (1990) 33.

6. P. Bocek and A. Chrambach, Electrophoresis, 13 (1992) 31.

7. P. Bocek and A. Chrambach, Electrophoresis, 12 (1991) 1059.

8. A. S. Cohen, D. R. Najarian, A. Paulus, A. Guttman, J. A. Smith and B. L. Karger, Proc. Natl. Acad. Sci. U.S.A., 85 (1988), 9660. 
9. A. Guttman, A. S. Cohen, D. N. Heiger and B. L. Karger, Anal. Chem., 62 (1990) 137.

10. P. Bocek and A. Chrambach, Electrophoresis, 12 (1991) 620.

11. A. Guttman and N. Cooke, Anal. Chem., 63 (1991) 2038.

12. A. Guttman and N. Cooke, J. Chromatogr., 559 (1991) 285.

13. A. Guttman, B. Wanders and N. Cooke, Anal. Chem., 64 (1992) 2348.

14. H. E. Schwartz, K. Ulfelder, F. J. Sunzeri, M. P. Busch and R. G. Brownlee, J. Chromatogr., 559 (1991) 267.

15. M. Strege and A. Lagu, Anal. Chem., 63 (1991) 1233.

16. S. Nathakarnkitkool, P. J. Oefner, G. Bartsch, M. A. Chin and G. K. Bonn, Electrophoresis, 13 (1992) 18.

17. K. J. Ulfelder, H. E. Schwartz, J. M. Hall and F. J. Sunzeri, Anal. Biochem., $200(1992) 260$.

18. M. Zhu, D. L. Hansen, S. Burd and F. Gannon, J. Chromatogr., 480 (1989) 311.

19. P. D. Grossman and D. S. Soane, J. Chromatogr., 559 (1991) 257.

20. F. E. P. Mikkers, F. M. Everaerts and Th. P. E. M. Verheggen, J. Chromatogr., 169 (1979) 11.

21. A. G. Ogston, Trans. Faraday Soc., 54 (1958) 1754.

22. G. W. Slater and J. Noolandi, Biopolymers, 28 (1989) 1781.

23. H. Swerdlow, J. Z. Zhang, D. Y. Chen, H. R. Harke, R. Grey, S. Wu, N. J. 
Dovichi and C. Fuller, Anal. Chem., 63 (1991) 2835.

24. A. S. Cohen, D. R. Najarian and B. L. Karger, J. Chromatogr., 516 (1990) 49. 


\section{GENERAL SUMMARY}

In the past five years since embarking on technology development for the Human Genome Project, many improvements in existing technology and new techniques have come forward. Many new techniques and improvements in existing techniques are still needed to accomplish this lofty goal. The research presented here has shown that existing technologies can be improved by at least one order of magnitude over current instrumental parameters. This research has shown a large improvement, but if the human genome is to be finished in the fifteen years that the Human Genome Project has projected, then larger or even quantum leaps must be accomplished to achieve this goal.

Medium resolution techniques such as PFGE can take from tens of hours to days to divulge information. The need for automation and interactive control is obvious. Interactive control has been shown to be a reality. Techniques for automation have been realized in this laboratory as well (101).

Other avenues of research to achieve these quantum leaps in technology include the use of multiplexing. If an order of magnitude improvement can be accomplished with one capillary then 10,000 fold improvement is possible if 1000 capillaries are run simultaneously. These types of growth are necessary for HGP to be realized.

Capillary zone electrophoresis has proven itself to be of immeasurable value 
for the high speed and resolution separation of biomolecules such as DNA and proteins. With the use of PCR and cloning techniques, the ability to even collect fractions from $\mathrm{CE}$ and amplify these small amounts are now achievable. The Achilles heel of $\mathrm{CE}$ at this juncture is the non-reproducibility of the technique. Several factors are responsible for this problem. Temperature can now be controlled by peltier cooling. Injection can be controlled precisely with commercial automation. The one major problem that remains is that electroosmotic flow must be normalized before good reproducibility and quantitation can achieve the levels of current separation techniques. The previous literature cited have reduced the problem but more development is surely needed for CZE to come to the forefront. 


\section{LITERATURE CITED}

1. Joint U.S. Department of Energy, U.S. Office of Energy Research, and Office of Health and Environmental Research Services Report DOE/ER0544P, "Human Genome: 1991-92 Program Report", Washington, DC, June 1992.

2. National Research Council Report, "Mapping and Sequencing the Human Genomen, Board of Basic Biology, Commission on Life Sciences, National Academy Press, Washington, DC, 1988.

3. U.S. Department of Health and Human Services and U.S. Department of Energy, "Understanding Our Genetic Inheritance; The U. S. Human Genome Project: The First Five Years FY 1991-1995", DOE/ER-0452P, April 1990.

4. Lee, T. T. The Human Genome Project, Cracking the Code of Life, Plenum Press: New York, 1991.

5. Biotechnology and The Human Genome; Innovations and Impact, Woodhead, A. D., Barnhart, B. J., Eds., Basic Life Sciences Vol. 46; Plenum Press: New York, 1988.

6. U.S. Congress, Office of Technology Assessment, "Mapping Our Genes-The Genome Projects: How Big, How Fast?", OTA-BA-373, April 1988.

7. Tiselius, A., Trans. Faraday Soc., 1937, 33, 524-535. 
8. Consden, R., Gordon, A. H., Martin, A. J. P., Biochem. L., 1946, 40, 33-40.

9. Raymond, S., Weintraub, L., Science, 1959, 130, 711-713.

10. Schwartz, D. C.; Cantor, C. R. Cell, 1984, 37, 67-75.

11. Electrophoresis of Large DNA Molecules: Theory and Applications, Lai, E., Birren, B. W., Eds., Current Communications in Cell and Molecular Biology; Cold Spring Harbor Laboratory Press, New York, 1990.

12. Jorgenson, J. W., Lukacs, K. D., Anal. Chem., 1981, 53, 1298-1302.

13. Hjertan, S., Zhu, M. D., J. Chromalogr., 1985, 327, 157-164.

14. Cohen, A., Karger, B. L., J. Chromatogr., 1987, 397, ,409-417.

15. Mazzeo, J. R., Krull, I. S., BioTechniques, 1991, 10, 638-645.

16. Frenz, J., Hancock, W. S., Trends Biotechnol., 1991, 9, 243-250.

17. Issaq, H. J., Janini, G. M., Atamna, I. Z., Muschik, G. M., J. Liq. Chromatogr., 1991, 14, 817-845.

18. Karger, B. L., Cohen, A. S., Guttman, A., J. Chromatogr., 1989, 492, 585-614.

19. McCormick, R. M., Anal. Chem., 1988, 60, 2322-2328.

20. Lauer, H. H., McMangill, D., Anal. Chem., 1986, 58, 166-170.

21. Zhu, M., Rodriguez, R., Hansen D., Wehr, T., J. Chromotgr., 1990, 516, 123 131.

22. Loo, J. A., Jones, H. K., Usdeth, H. R., Smith, R. D., J. Microcolumn Sep., 1989, 1, 223-229.

23. Hjertan, S., J. Chromatogr., 1985, 347, 191-198. 
24. Gurley, L. R., London, J. E., Valdez, J. G., J. Chromatogr., 1991, 559, 431433.

25. Nielen, M. W. F., J. Chromatogr., 1992, 625, 387-391.

26. Towns, J. K., Reigner, F. E., Anal. Chem., 1992, 64, 2473-2478.

27. Gilges, M., Husmann, H., Kleemis, M. H., Motsch, S. R., Schomberg, G., J. High Resolut. Chromatogr., 1992, 15, 452-457.

28. Tsuli, K., Little, R. J., J. Chromatogr., 1992, 594, 317-324.

29. Castagnola, M., Cassiano, L., Rabino, R., Rossetti, D. V., Bassi, F. A., J. Chromatogr., 1991, 572, 51-58.

30. Bruin, G. J. M., Chang, J. P., Kuhlman, R. H., Zegers, K., Kraak, J. C., Poppe, H., J. Chromatogr., 1989, 471, 429-436.

31. Bruin, G. J. M., Huisden, R., Kraak, J. C., Poppe, H., J. Chromatogr., 1989, 480, 339-349.

32. Nashabeh, W., El Rassi, Z., J. Chromatogr., 1991, 559, 367-383.

33. Nashabeh, W., El Rassi, Z., J. High Resolut. Chromalogr., 1991, 15, 289-292.

34. Nashabeh, W., El Rassi, Z., J. Chromatogr., 1991, 536, 31-42.

35. Smith, J. T., El Rassi, Z., J. Chromatogr., 1992, 15, 573-578.

36. Swedberg, S. A., Anal. Biochem., 1990, 185, 51-56.

37. Lukacs, K. D., Diss. Abstr. Int. B, 1983, 44, 3766.

38. Moseley, M. A., Deterding, L. J., Tomer, K. B., Jorgenson, J. W., Anal. Chem., 1991, 63, 109-114. 
39. Shum, S. C. K., Johnson, S. T., Pang, H. M., Houk, R. S., Appl. Spectrosc., 1993, 47, 575-583.

40. Wu, S. L., Teshima, G., Cacia, J., Hancock, W. S., J. Chromatogr., 1990, 516, 115-122.

41. Gurley, L. R., Buchanan, J. S., London, J. E., Stavert, D. M., Lehnert, B. E., J. Chromatogr., 1991, 559, 411-429.

42. Takigiku, R., Schneider, R. E., J. Chromatogr., 1991, 559, 247, 256.

43. Cai, J., El Rassi, Z., J. Liq. Chromatogr., 1992, 15, 1179-1192.

44. Wang, T., Hartwick, R. A., J. Chromatogr., 1992, 607, 119-125.

45. Towns, J. K., Reigner, F. E., J. Chromatogr., 1990, 516, 69-78

46. Cobb, K. A., Dolnik, V., Novotny, M., Anal. Chem., 1990, 62, 2478-2483.

47. Towns, J. K., Bao, J., Reigner, F. E., J. Chromatogr., 1992, 599, 227-237.

48. Bolger, C. A., Zhu, M., Rodriguez, R., Wehr, T., J. Liq. Chromatogr., 1991, $14,895-906$.

49. Bushey, M. M., Jorgenson, J. W., J. Chromatogr., 1989, 480, 301-310.

50. Green, J. S., Jorgenson, J. W., J. Chromatogr., 1989, 478, 63-70.

51. Belder, D., Schomberg, G., J. High Resolut. Chromatogr., 1992, 115, 686-693.

52. Snopek, J., Soini, H., Novotny, M., Smolkova-Keulemansova, E., Jelinek, I., J. Chromatogr., 1991, 559, 215-222.

53. Muijselaar, W. G. H. M., De Bruijn, C. H. M. M., Everaerts, F. M., J. Chromatogr., 1992, 605, 115-123. 
54. Emmer, A., Jansson, M., Roeraade, J., J. Chromatogr., 1991, 547, 544-550.

55. Taverna, M., Baillet, A., Biou, D., Schulter, M., Werner, R., Ferrier, D., Electrophoresis, 1992, 13, 359-366.

56. Wiktorowicz, J. E., Colburn, J. C., Electrophoresis, 1990, 11, 769-773.

57. Gordon, M. J., Lee, K. J., Arias, A. A., Zare, R. N., Anal. Chem., 1991, 63, 69-72.

58. Bocek, P., Chrambach, A., Electrophoresis, 1991, 12, 620-623.

59. Bocek, P., Chrambach, A., Electrophoresis, 1991, 12, 1059-1061.

60. Bocek, P., Chrambach, A., Electrophoresis, 1992, 13, 31-34.

61. Separation Methods in Biochemistry, Morris, C. J. O. R., Morris, P., Eds., Pitman Publishing, London, 1976.

62. Guttman, A., Cohen, A. S., Heiger, D. N., Karger, B. L., Anal. Chem., 1990, $62,137-41$.

63. Zhang, J. Z., Chen, D. Y., Wu, S., Harke, H. R., Dovichi, N. J., Clin. Chem., 1991, 37, 1492-1496.

64. Guttman, A., Cooke, N., J. Chromatogr., 1991, 559, 285-294.

65. Guttman, A., Wanders, B., Cooke, N., Anal. Chem., 1992, 64, 2348-2351.

66. McGregor, D. A., Yeung, E. S., J. Chromatogr., in press.

67. Guttman, A., Cooke, N., Anal. Chem., 1991, 63, 2038-2042.

68. Ulfelder, K. J., Schwartz, H. E., Hall, J. M., Sunzeri, F. J., Anal. Biochem., 1992, 200, 260-267. 
69. Cohen, A. S., Najarian, D. R., Karger, B. L., J. Chromatogr., 1990, 516, 49. 60.

70. Paulus, A., Gassmann, E., Field, M. J., Electrophoresis, 1990, 11, 702-708.

71. Chen, J. W., Cohen, A. S., Karger, B. L., J. Chromatogr., 1991, 559, 295-305.

72. Baba, Y., Matsuura, T., Wakamoto, K., Tsuhako, M., J. Chromatogr., 1991, $558,273-284$.

73. Takigiku, R., Schneider, R. E., J. Chromalogr., 1991, 559, 247-256.

74. Pentoney, S. L., Jr., Konrad, K. D., Kaye, W., Electrophoresis, 1992, 13, $467-$ 474.

75. Tsuji, K., J. Chromatogr., 1991, 550, 823-830.

76. Gelfi, C., Alloni, A., de Besi, P., Righetti, P. G., J. Chromatogr., 1992, 608, 343-348.

77. Gelfi, C., Alloni, A., de Besi, P., Righetti, P. G., J. Chromatogr., 1992, 608, 333-341.

78. Chiari, M., Micheletti, C., Righetti, P. G., Poli, G., J. Chromatogr., 1992, 598, 287-297.

79. Gelfi, C., de Besi, P., Alloni, A., Righett, P. G., Lyubimova, V. A., J. Chromatogr., 1992, 598, 277-285.

80. Chiari, M., Giacomini, M., Micheletti, C., Righetti, P. G., J. Chromatogr., 1991, 558, 285-295.

81. Chiari, M., Ettori, C., Righetti, P. G., J. Chromatogr., 1991, 559, 119-131. 
82. Widhalm, A., Schwer, C., Blaas, D., Kenndler, E., J. Chromatogr., 1991, 549, 446-451.

83. Heiger, D. N., Cohen, A. S., Karger, B. L., J. Chromatogr., 1990, 516, 33-48.

84. Holmes, D. L., Stellwagen, N. C., Electrophoresis, 1991, 12, 612-619.

85. Oefner, P. J., Bonn, G. K., Huber, C. G., Nathakarnkitkool, S., J.

Chromatogr., 1992, 625, 331-340.

86. Lindner, H., Helliger, W., Dirschlmayer, A., Talasz, H., Wurm, M., Sarg, B., Jaquemar, M., J. Chromatogr., 1992, 608, 211-216.

87. Lindner, H., Helliger, W., Dirschmayer, A., Jaquemar, M., Puschendorf, B., Biochem. J., 1992, 283, 467-471.

88. Harrington, S. J., Varro, R., Li, T. M., J. Chromatogr., 1991, 559, 385-390.

89. Grossman, P. D., Soane, D. S., J. Chromatogr., 1991, 559, 257-266.

90. Nathakarnkitkool, S., Oefner, P. J., Bartsch, G., Chin, M. A., Bonn, G. K., Electrophoresis, 1992, 13, 18-31.

91. Strege, M., Lagu, A., Anal. Chem., 1991, 63, 1233-1236.

92. Zhu, M., Hansen, D. L., Burd, S., Gannon, F., J. Chromatogr., 1989, 480, 311-319.

93. Schwartz, H. E., Ulfelder, K., Sunzeri, F. J., Busch, M. P., Brownlee, R. G., J. Chromatogr., 1991, 267-283.

94. Cunico, R. L., Gruhn, V., Kresin, L., Nitecki, D. E., Wiktorowicz, J. E., J. Chromatogr., 1991, 559, 467-477. 
95. Demorest, D., Dubrow, R., J. Chromatogr., 1991, 559, 43-56.

96. Hayes, M. A., Ewing, A. G., Anal. Chem., 1992, 64, 512-516.

97. Blanchard, W. C., Lee, C. S., PCT Int. Appl., 1991, Chapter 22.

98. Wu, C. T., Lopes, T., Patel, B., Lee, C. S., Anal. Chem., 1992, 64, 886-891.

99. Cobb, K. A., Novotny, M., Anal. Chem., 1989, 61, 2226-2231.

100. Amankwa, L. N., Kuhr, W. G., Anal. Chem., 1992, 64, 1610-1613.

101. Koutny, L. B., Yeung, E. S., Anal. Chem., 1993, 65, 148-152. 


\section{ACKNOWLEDGEMENTS}

This work was performed at Ames Laboratory under contract No. W-7405eng-82 with the United States Department of Energy. The United States government has assigned the DOE Report number IS-T 1658 to this thesis.

Speaking of the work involved in this tome, I would like to thank many people for making this dissertation possible but unfortunately I can not thank every one I would like to, so here are a few I really would like to thank.

I thank Dr. Yeung for the patience he showed while I was maturing as an independent researcher, for the research funds, and the research that he allowed me to do. The graduate committee, Drs. Bronson, Houk, Johnson, and Small for the interest they have shown in the research I have performed by being on my committee.

Both past and present E.S.Y coworkers deserve thanks for the patience they showed me while I was either coming or going. They always were there for questions answered, equipment found, loaned, etc.. During my formative years here I owe many thanks to Lance Koutny (Tracy too), Tommy Garner, Bill Pfeffer, King Chan (I could go on and on) just to name a few. These people were always here when I needed a chuckle to lighten the 20 hour days or to break away and not have to think about research for a while.

I would like to thank my undergraduate advisor, Dr. Jon Carnahan, for his 
assistance both in the research he let me do and opportunities he offered me in summer jobs that allowed me to know I was in the field for me. I would like to mention Dr. Claude Jones for opening my eyes to analytical chemistry. The undergraduate course I took from him confirmed my love for chemistry and showed me that this was the profession for me.

While I am thinking of laboratories, I would like to thank the Ames Laboratory for the uninterrupted research funds. Residual thanks to the Tiger Team for the experience and a glimpse into what government gridlock could be. Ames Lab ES\&H, it was only a joke! (April Fool?) I have enjoyed working with all the professional people whether from lowa State or Ames Lab.

When I first came to Ames I was in culture shock. Coming from the burbs of Chicago I wasn't sure what there was to do. After I had finished the sites and sounds in Ames and Des Moines in that first month I began to worry, but the golf courses and of course the local malt beverage shops proved invaluable while I was here.

As for my friends both in and out of the chemistry department, Luther Schmidt, Rich Roberts, James Alan (Mojo) Hays, not your typical chemists, but what fun we had when we could. Michelle, for putting up with me for these last few trying months, I thank you for making my time here less of a chore and more exciting. John Morris, if it were not for you I probably would have not made it through the rigors of graduate school. I found a good friend when I verbally 
abused you many a year ago and have had a great friend since. You were that saving grace and the reason I say to anyone who asks, "It's not where you are, it's who you know". I look forward to many more years of camaraderie.

Of course my parents, Art and Elisa, deserve a great deal of thanks for all the support they have given me over the years, not just while I was here. They have been the most supportive when times were toughest and always there to listen when I needed an ear. I owe them a huge debt of gratitude that I will not be able to ever repay. 


\section{APPENDIX: SOFTWARE}

This program was written to output a square wave or other square form from the DT2827 boards equiped in several E. S. Yeung computers in the laboratory.

C This fortran program DA6.FOR will output an analog signal

C to port 0 DT2827 board.

C

C

C

C Generate a square wave dependent on the buffer sizes

C allocated in 1) NBUFSIZE (forward buffer) time width

$C$ and 2) RBUFSIZE (reverse buffer)time width

C

C Voltage outputs vary from +10 to -10 volts on the

C DT2827 board. A gain of 100 has been added.

C

C This program works on the ELECTRA 286 (BETTY) only with

C the turbo button on and the write statements removed.

C It will only pulse down to 1 millisecond. It will

C overrun below that. Possibly more buffers linked,

C declared,and filled may help this problem.

C An ATLAB error occurs.

C

C To operate this program the file must be edited for

C desired pulse widths then recompiled and linked.

C Currently to stop the program the pause is pressed

C then any key to create an overflow error.

C Or allow program to run to completion

C

SINCLUDE:'ATLDEFS.FOR'

SINCLUDE:'ATLERRS.FOR'

\section{DEFINITIONS}

INTEGER*2 RBUFSIZE

C NBUFSIZE TO BE ADJUSTED FOR FORWARD PULSE LENGTH

$C$ to be modified to produce appropriate pulse width

PARAMETER (NBUFSIZE=200)

C RBUFSIZE TO BE ADJUSTED FOR REVERSE PULSE LENGTH

$C$ to be modified to produce appropriate pulse width 
PARAMETER (RBUFSIZE $=100$ )

INTEGER*2 VALUEF

INTEGER 2 VALUER

INTEGER *2 STATUS

INTEGER *2 NUMBERF

INTEGER *2 NUMR

INTEGER *2 UNITNUMBER, RELEASEDBUFFER

REAL*4 TIMEF

REAL*4 TIME_F

REAL*4 TIMER

REAL*4 TIME_R

C INCREASE NBUFFERS SIZE TO INCREASE \# OF BUFFERS

PARAMETER (NBUFFERS $=1$ )

INTEGER *2 BUFS(NBUFSIZE,NBUFFERS)

INTEGER*2 RBUFS(RBUFSIZE,NBUFFERS)

INTEGER *2 BUFNUM(NBUFFERS,2)

INTEGER *2 RBUFNUM(NBUFFERS,2)

INTEGER *2 BLENGTH

LOGICAL DONE

CHARACTER *1 CORRECT

INTEGER*2 ZERO

REAL*4 EAV

INTEGER 4 COUNTER

REAL*4 RUN

INTEGER *4 FINTIME

REAL*4 ITIME, I2TIME, IDELTIME

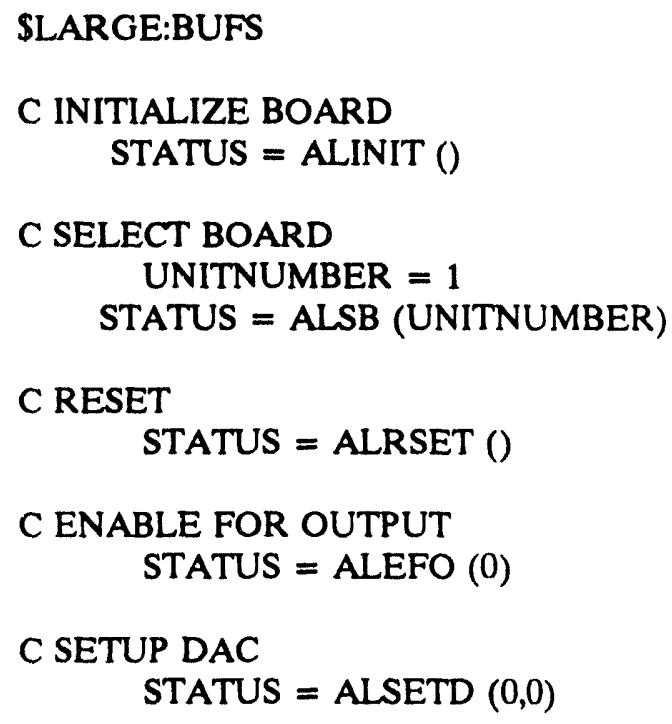




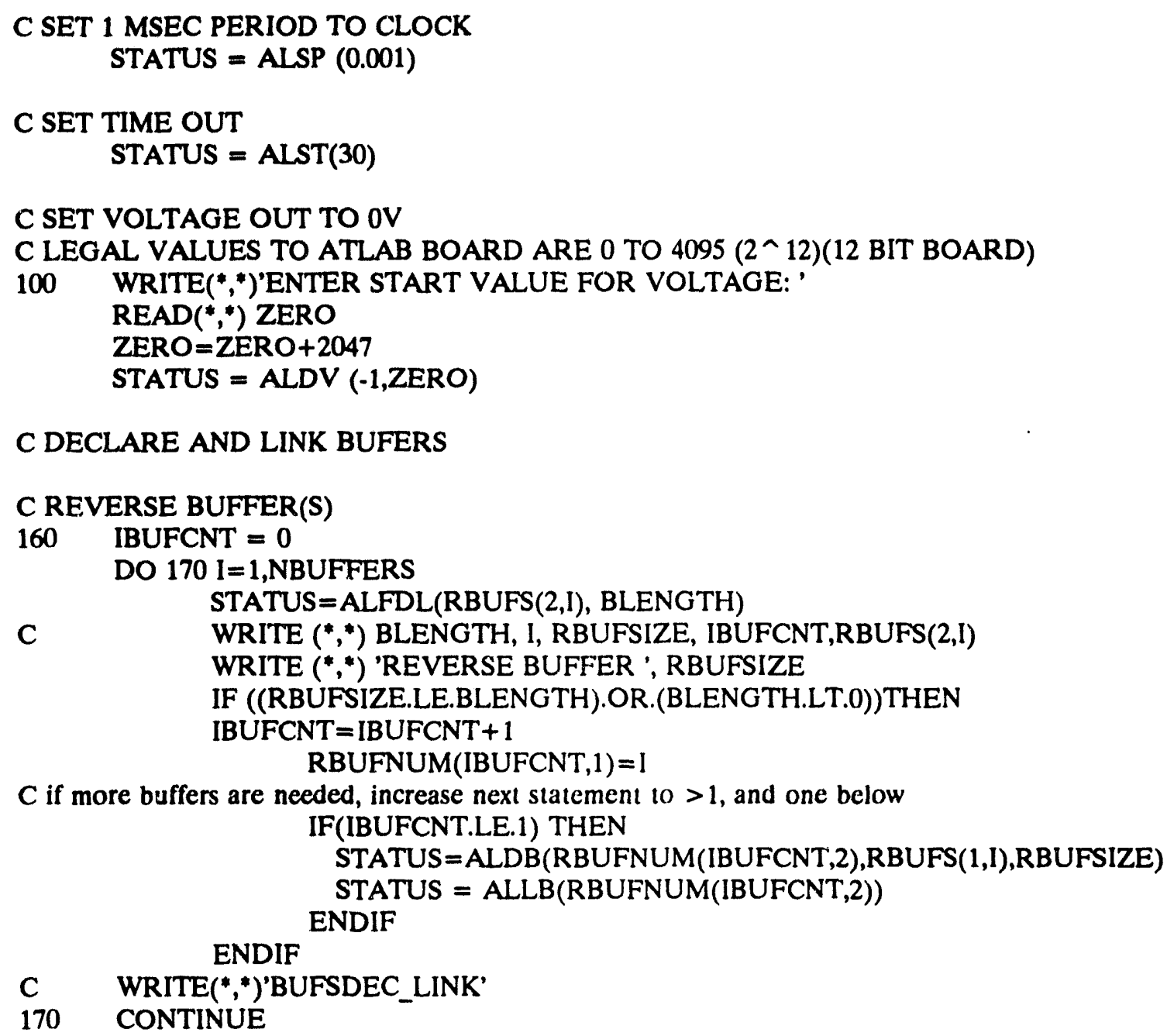

C FORWARD BUFFER(S)

175 IBUFCNT $=0$

DO $180 \mathrm{I}=1$, NBUFFERS

STATUS $=$ ALFDL (BUFS(2,1), BLENGTH)

C WRITE $\left({ }^{*}, *\right)$ BLENGTH, I, NBUFSIZE, IBUFCNT,BUFS $(2, \mathrm{I})$

WRITE $(*, *)$ 'FORWARD BUFFER ', NBUFSIZE

IF ((NBUFSIZE.LE.BLENGTH).OR.(BLENGTH.LT.0))THEN

IBUFCNT $=$ IBUFCNT +1

BUFNUM(IBUFCNT,1) $=1$

IF(IBUFCNT.LE.1) THEN

STATUS $=$ ALDB $(B U F N U M($ IBUFCNT,2),BLFS(1,I),NBUFSIZE)

STATUS $=$ ALLB $(B \cup F N U M($ IBUFCNT,2) $)$

ENDIF

ENDIF 
$\begin{array}{ll}\text { C } & \text { WRITE(**,*)'BUFSDEC_LINK' } \\ 180 & \text { CONTINUE }\end{array}$

C FORWARD VARIABLES

C CALL SUBROUTINE FORWARD

210 WRITE (",*) 'ENTER VALUES FOR FORWARD PULSE'

CALL FORW (VALUEF,TIMEF,TIME_F,NUMBERF)

IF ((VALUEF.LT.-1000) .OR. (VALUEF.GT.1000)) THEN

ENDIF GOTO 999

C REVERSE VARIABLES

WRITE $\left({ }^{*}, *\right)$ 'ENTER VALUES FOR REVERSE PULSE'

CALL FORW (VALUER,TIMER,TIME_R,NUMR)

C IF ((VALUER.LT.-1000).OR.(VALUER.GT.1000)) THEN

C GOTO 999

C ENDIF

C FILL BUFFER WITH FORWARD VALUES

C ADD BUFFERS IF REQUIRED (remove comment statement)

240 DO 250, I=1,NBUFSIZE

BUFS $(\mathrm{I}, 1)=$ NUMBERF

C $\quad \operatorname{BUFS}(\mathrm{I}, 2)=$ NUMBERF

C $\quad$ BUFS $(1,3)=$ NUMBERF

250 CONTINUE

C FILL BUFFER WITH REVERSE VALUES

C TO ADD BUFFERS (remove comment statement)

DO 260, I=1,RBUFSIZE

$\operatorname{RBUFS}(1,1)=$ NUMR

C $\quad \operatorname{RBUFS}(1,2)=$ NUMR

C $\quad \operatorname{RBUFS}(1,3)=$ NUMR

C WRITE $\left({ }^{*},{ }^{*}\right)$ I,TIMER,NUMR

260 CONTINUE

C CALCULATE AVERAGE VOLTAGE (Eav) APPLIED

C Eav $=\left(\mathrm{Er}^{*} \mathrm{Tf}+\mathrm{Er} * \mathrm{Tr}\right) /(\mathrm{T} f+\mathrm{Tr}), \mathrm{NOTE}: \mathrm{Er}$ IS NEGATIVE

C WRITE (*,*) VALUEF,TIME_F,VALUER,TIME_R

EAV $=\left(\left(V_{A L U E F}^{*} T I M E_{-} F\right)+(\right.$ VALUER $*$ TIME_R $\left.)\right) /\left(T I M E_{-}\right.$F + TIME_R $)$

$\operatorname{WRITE}\left(*^{*},\right)^{\prime}$ Eav $(\mathrm{V})=^{\dagger}, \mathrm{EAV}$ 
C ASK FOR TIME TO RUN IN MINUTES

WRITE (",*) 'Waveform duration? (min)'

READ $(*, *)$ RUN

FINTIME $=(($ RUN*60 $* 2) /($ TIME_F+TIME_R $)$

C WRITE (*,*) FINTIME

C ASK FOR CORRECTNESS OF DATA INPUT

WRITE (*,*) 'Are these values correct? [y]'

READ '(A1)', CORRECT

IF(CORRECT.EQ.'N'.OR. CORRECT.EQ.'n') GOTO 100

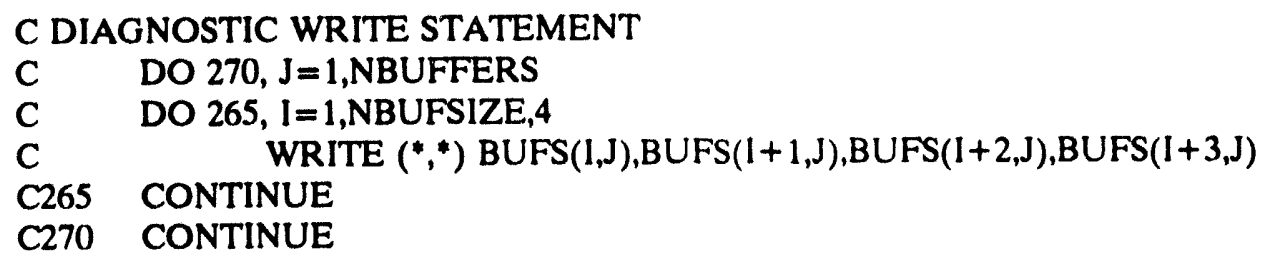

C GET START TIME FROM COMPUTER

CALL GETTIM(IHR,IMIN,ISEC,I100TH)

HR $=$ REAL (IHR)

$M I N=R E A L(I M I N)$

SEC $=$ REAL(ISEC)

R100TH $=$ REAL $(1100 \mathrm{TH})$

ITIME $=(H R * 60+M I N+(S E C / 60)+(R 1(0) T H / 6000))$

C INITIATE CONTINUOUS MODE D/A DMA TRANSFER

WRITE $\left(*,{ }^{*}\right)$ 'OUTPUT WAVEFORM...'

STATUS $=$ ALCDA ()

DONE $=$.FALSE.

300 CONTINUE

C SYNCHRONIZE USER PROCESSING OF COMPLETED BUFFERS

C WRITE $\left({ }^{*},{ }^{*}\right)$ RELEASEDBUFFER

C IF (STATUS.EQ.KNORMAL) THEN

WRITE $\left({ }^{*}, 320\right)$ RELEASEDBUFFER

C320 FORMAT (' Released buffer', 12)

C RETURN BUFFER FOR FURTHER PROCESSING

$C$ old if/then

IF (RDCNT.EQ.SAMCNT) THEN

COUNTER $=$ COUNTER +1 
C

WRITE $(*, *)$ COUNTER

IF (COUNTER.LT.FINTIME) THEN

STATUS = ALRETB (RELEASEDBUFFER)

C

WRITE(*,*)'RETBUFF

ELSE

C OR RELEASE BUFFER AND WAIT FOR COMPLETION

C BUT FIRST GET STOP TIME FROM COMPUTER

CALL GETTIM(IHR,IMIN,ISEC,IIOOTH)

$H R=$ REAL $($ IHR)

$M I N=R E A L(I M I N)$

SEC $=$ REAL (ISEC)

R1OOTH = REAL(II(X)TH)

12TIME $=(\mathrm{HR} * 60+\mathrm{MIN}+(\mathrm{SEC} / 60))+(\mathrm{R} 100 \mathrm{TH} / 6000))$

330

STATUS $=$ ALRAL (RELEASEDBUFFER)

C

WRITE(*,")'RETASLAST

STATUS = ALWFC (RELEASEDBUFFER)

C

WRITE $(*, *)$ 'WAITFCOMPL'

ENDIF

DONE $=$.TRUE.

ELSE

STATUS $=$ ALSTOP ()

C

WRITE(*,")'STOP'

ENDIF

DONE $=$.TRUE.

IF (.NOT.DONE) GOTO 300

C

C END OF PROGRAM

C

C TERMINATE PROGRAM

C DECLARE VALUE BACK TO BEGINNING, i.c., 0

999 STATUS = ALDV $(-1$, ZERO $)$

C WRITE (*,")'DECLARE VAL TO 0"

WRITE (*,")'Board Reset Normally"

C RESET BOARD

STATUS = ALRSET ()

C WRITE $(*, *)$ RESET

C TERMINATE BOARD OPERATIONS

STATUS = ALTERM ()

C WRITE $\left({ }^{*},{ }^{*}\right)$ 'TERMINATE' 
C PRINT LAPSE TIME IN MINUTES

IDELTIME $=12$ TIME-ITIME

WRITE $\left({ }^{*}, *\right)$ 'Lapsed time for this waveform (min):',IDELTIME

END

C FORWARD/REVERSE SUBPROGRAM

SUBROUTINE FORW(VALUE,TIME,TIM,NUMBER)

REAL*4 TIME, TIM

INTEGER *2 VALUE, NUMBER

100 WRITE(*,*)'ENTER Desired Pulse VOLTAGE: '

WRITE $(*, *)^{\prime}(-1000$ TO 1000 Volts, ANY OTHER \# TO EXIT): '

READ $(*, ")$ VALUE

WRITE (*,*)'ENTER Desired Pulse LENGTH (msec): '

READ (*,*) TIME

$\mathrm{TIM}=\mathrm{TIME} / 1 \mathrm{E} 3$

C REGRESSION FOR VOLTS FROM D/A OUTPUT

NUMBER $=2.0470 *($ VALUE $)+2047.2242$

110 END

C FORWARD/REVERSE SUBPROGRAM 

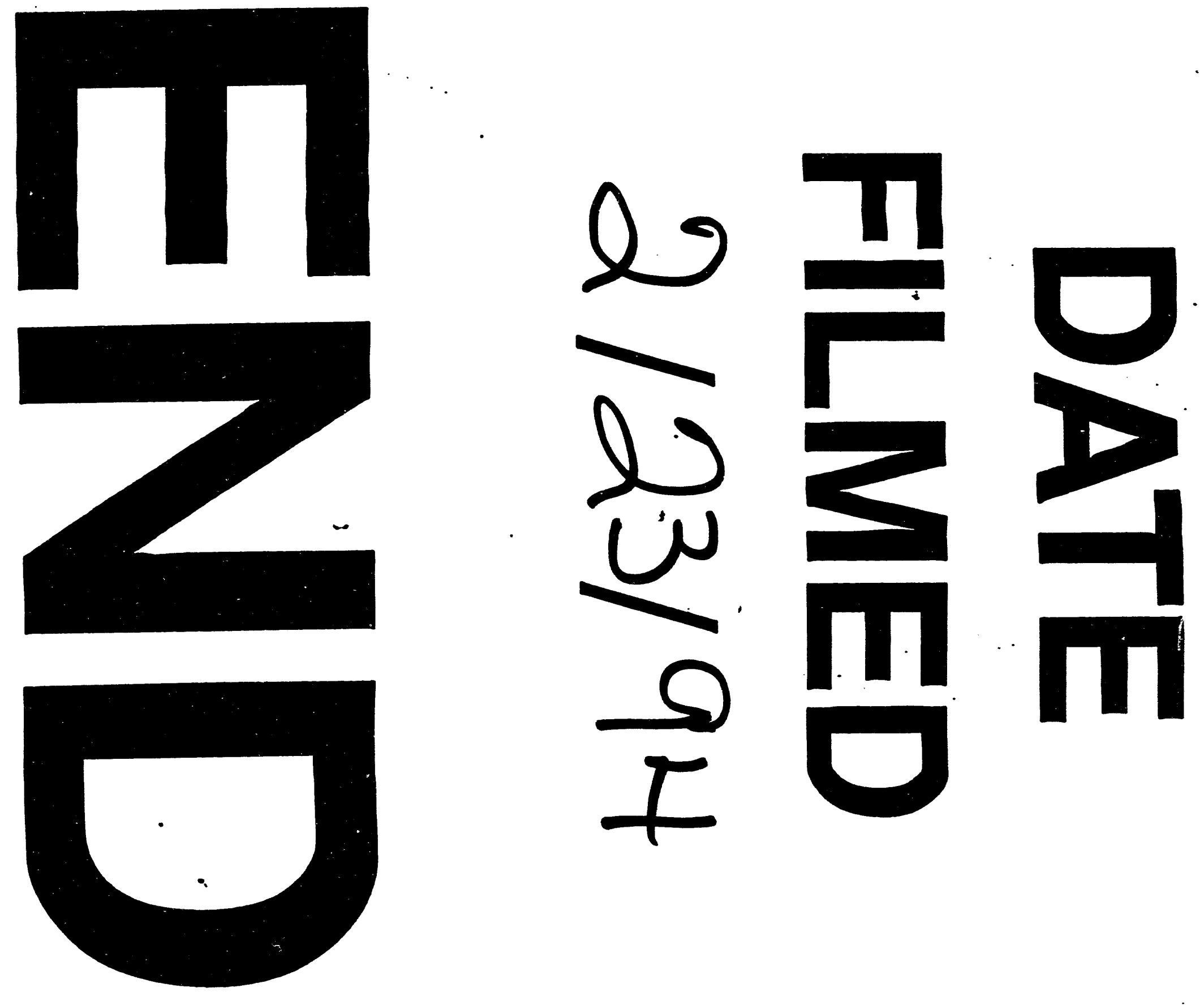
